\title{
ZEDEN, GEWOONTEN EN WETTEN VAN NAI POSPOS
}

\author{
(Gecopieerd,) \\ getranscribeerd, vertaald en gecommentarieerd \\ DOOR \\ D. W. N. DE BOER.
}

\section{INLEIDING.}

Onder Codex Oriëntalis $\mathrm{N}^{\circ} 3405$, bijnummer $767 \mathrm{~h}$, staat in de Leidsche Universiteits-Bibliotheek te boek Deel VIII van de Collectie van Bataksche Handschriften ex legato $H$. Neubronner van der Tuuk.

Volgens een zich los daarin bevindends gespecificeerde inhoudslijst - door Van der Tuuk zelf gesch ren - bevat dit Dee! „Verhalen in het Tobasch”.

Een ingeplakte voorpagina, ook van de hand van Van der Tuuk, vermeldt voorts in een korte inhoudsopgave onder „6e" (loopende van blz. 205-blz. 281 van het in totaal 300 folio's tellende manuscript) als onderwerp: „Zeden, gewoonten en wetten van „die” - (de lieden) — ,van Naie Pospos”.

Van deze aldus genoemde stof nu werd het meer adatrechtelijke gedeelte, dat de blzz. 254-281 van het manuscript beslaat, reeds vertaald door wijlen J. C. Vergouwen, die toenmaals, na een 5-jarige werkzaamheid als Hoofdambtenaar voor de bestudeering van de Bataksche Adat en het geven van advies inzake de vonnissen van de Adatrechtbanken, met verlof hier te lande vertoefde.

Aan deze vertaling werd (in 1932) onder den titel: ,Adatrechtsregelen van Nai Pospos" plaats verleend in Adatrechtbundel XXXV (Serie G $N^{\circ}$ 64, blz. 135-154), waarbij werd aangeteekend, dat de vertaling geschiedde ,naar een gedeelte der Kopie ${ }^{1}$ ) van genoemd

1) T.r. „transcriptie”.

Dl. 103. 
manuscript, in Latijnsch karakter, aanwezig in de Bibliotheek van het Bataviaasch Genootschap".

Het daaraan voorafgaande gedeelte echter, loopende van blz. 205blz. 254, bleef in hoofdzaak nog onbewerkt.

Door wijlen Vergouwen werd hiermede wel een aanvang gemaakt, door zijn te vroeg overlijden heeft hij de door hem voorgenomen algeheele transcriptie en vertaling helaas niet kunnen voltooien.

Onder de door hem aan de Adatrechtsstichting te Leiden nagelaten geschriften werd n.l. slechts aangetroffen de in 3 cahiers in potlood overgenomen Bataksche tekst van pag. 205-254, welk tekstgedeelte, behoudens enkele bladzijden en hier en daar enkele regels of woorden, ook reeds werd getranscribeerd, doch van de voorgenomen vertaling hiervan kwam niet meer dan de eerste bladzijde gereed.

Door Prof. V. E. Korn, Buitengewoon Hoogleeraar in het Adatrecht te Leiden, Secretaris van de Adatrechtstichting, werd mij nu deze nalatenschap van Vergouwen terhandgesteld, met het verzoek. den door Vergouwen aangevangen arbeid verder op mij te willen nemen; aan welk verzoek ik - ondanks? of juist met het oog op? de tijdsomstandigheden - met genoegen gevolg gegeven heb.

Hierbij meende ik mij niet slechts tot transcriptie en - voorzooveel doenlijk - woordelijke vertaling te moeten beperken, doch mede, waar mij dit mogelijk was, verklarende woorden in den tekst te moeten inlasschen, respectievelijk commentaren in noot-vorm toe te voegen, waarbij uiteraard dankbaar gebruik gemaakt werd van het „Bataksch-Nederduitsch Woordenboek” van den Verzamelaar van deze Bataksche ,verhalen” Neubronner van der Tuuk zelf.

Ten aanzien van den tekst zij medegedeeld, dat de hier gebezigde taal primitief Toba-Bataksch is, met veel Malaiismen naast zuiverMaleische woorden, doch, vooral grammaticaal, niet aan de gemeenlijk door de Toba-Bataks daaraan gestelde eischen voldoet, zoodat bij de vertaling vaak uit het verband moest worden opgemaakt, wat precies bedoeld is.

De oorzaak hiervan moet wel gezocht worden in het feit, dat de Verzamelaar van deze Handschriften, die immers handelen over de lieden van Nai Pospos, - d.i. de landstreek, die besloten ligt tusschen de Onderafdeelingen Baros, Silindoeng en Hoogvlakte van Toba, slechts in deze Westelijke randstreken van het toenmaals nog onafhankelijke en ontoegankelijke Centrale-Batakland werkzaam heeft kunnen zijn, en aldus ook zijn geestelijke auteurs van de diverse

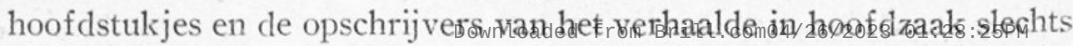


dáár heeft kınnen kiezen. Van der Tuuk zou wel een bezoek hebben gebracht bij den toenmaligen Sisingamangaradja in Bakara, een der Westelijke landschapjes van het Centrale Batakland, doch dit bezoek was maar van zèèr korten duur. (Gobée in Deel 34, Van Eerde in Deel 45 van het Tijdschr. voor Ind. T.-L.- en Volkenkunde). (Zie ook de medédeelingen hieromtrent van P. Voorhoeve op blz. 8 vlg. van zijn dissertatie: „Overzicht van de Volksverhalen der Bataks”).

De beschrijvingen geven overigens den indruk, door de diverse auteurs daarvan te zijn opgedischt volgens aanwijzingen van Verzamelaar, naar richtlijnen door dezen Taalgeleerde aangegeven; richtlijnen, zooals die o.a. ook aangevoeld worden in een gelijksoortige beschrijving van Maleische zeden en gewoonten, in „Adat RadjaRadja Melajoe", bewerkt door Prof. Dr. Ph. S. van Ronkel; en verder voor zoovele andere adatbeschrijvingen als kompas hebben gediend.

Volledig zijn de beschrijvingen niet, vele punten behoeven nog nadere uitwerking, verklaring en opheldering, die men thans nog slechts door navraag ter plaatse deelachtig zou kunnen worden, indien men in de gelegenheid zou zijn, in bij voorkeur nog Heidensche streken zijn licht hierover op te steken, zooals bijv. in een groot gedeelte van het, (schier-)eiland Samosir.

In het hier beschrevene toch maakt men kennis met een geheel van magische denkbeelden doordrenkte wereld, door Islam en Christendom hoogstens nog maar aan de peripherie beroerd.

Het meeste hiervan is dan ook in feite niet anders dan magische ritus, dat samenstel van telkens andere handelingen, van welker werking de Batak zich bepaalde effecten voorstelt. In beginsel tot in het oneindige variabel, zijn deze handelingen nochtans op een vaste, van leermeester op leerling steeds even nauwkeurig overgedragen wijze verbonden aan de verschijnselen, waarvoor zij in werking worden gesteld. Met de voorwerpen, waarmede ze worden verricht, en de specifieke woorden, door welke ze worden begeleid, zijn zij de uitsluitende vorm, waarin de beoogde krachten en werkingen kunnen worden opgeroepen; de naleving ervan is voorwaarde voor de totstandkoming der werking, die men aan het ceremonieel toeschrijft, en die men alleen door preciese naleving van alle bijzonderheden verwachten mag; kleine modaliteiten kunnende verdragen, maar altijd moetende beantwoorden aan de voorstellingen, die de primitieve geest zich van de verschijnselen om zich heen gevormd heeft. 
Bij de vertaling kan dan ook meermalen gewezen worden op de magische kracht van het gesproken woord, en de in verband daarmede voor elk geval speciaal gekozen woordspelingen, waarmede de symbolische handeling gepaard gaat. De dwingende kracht van de gegeven regelen uit zich tenslotte in het woord „oehoem”, waarmede elk hoofdstuk aanvangt; en als de vertaling van dit woord diverse omschrijvingen toelaat, en soms den zachteren klank geeft van : ,hetgeen te doen staat", dan moet men dit in verband met het bovengezegde nochtans zóó opvatten, dat „oehoem” voor den Batak wijst op een bindenden vorm van het beschreven ritueel.

Het woord „mangoehoem” (Mal. menghoekoem) beteekent immers „,berechten”,en het actiefverbaalsubstantief „pangoehoem” (,Toean Pangoehoem” is nog altijd het „epitheton ornans” van den Bestuursambtenaar in de Bataklanden) = ,rechter”, óók en vóóral in de beteekenis van: „straffer”.

Wat nu nog de indeeling van de hier behandelde stof in hoofdstukken aangaat, diene het volgende:

Zooals in het begin van deze inleiding reeds werd vermeld, vindt men van de hand van den Verzamelaar zelf in Deel VIII twee inhoudsopgaven: een summiere en een gespecificeerde.

Deze inhoudsopgaven komen echter nict met elkaar overeen:

De summicre n.l. deelt de geheele stof in 7 nummers in, t.w.: 1e Soetan Malien Deèman ${ }^{1}$ ) (blz. 1); 2e Moela nie bodat diebahen na lan nannón (blz. 101); 3e Radja Nadiengien (blz. 151); 4e Tonggotonggo (blz. 181); 5e Sie Tadjom Bolak (blz. 189); 6e Zeden, gewoonten en wetten van die van Naie Pospos (blz. 205); 7e Sietapie boenga boroe (blz. 281). (Hiervan zijn de met 1e, 2e, 3e, 5e en 7e genummerden „Verhalen”, nummer 4 een opteekening van gebedsformulieren voor het aanroepen van geesten).

In de gespecificeorde opgave daarentegen blijven wel de nummers 1e tot en met $5 \mathrm{e}$ die nummering behouden, wordt echter nummer 6 onderverdeeld, waarbij, instede van die onderverdeeling met letters, of op andere wijze, aan te duiden, een dóórnummering plaats vindt. Zulks wordt althans gedaan tot en met blz. 259; (nummer 45), waarna verdere nummering achterwege blijft, zoodat het in de korte

1) Deze „romance” is ook in het Maleisch, Minangkabausch en Atjehsch een van de meest geliefde Hikajats (vgl. „Over Mal. literatuur” van Dr. C. Hooykaas, blz. 50). 
inhoudsopgave als nummer 7 gerangschikte onderwerp mede geen afzonderlijk nummer meer heeft.

Een tweede moeielijkheid baarde mij de indeeling van het hierbehandelde onderwerp, waar mij n.l. verder bleek, dat in evengenoemde gespecificeerde inhoudsopgave twee - zoo te noemen: „,bindoe” 's ${ }^{1}$ ) ontbreken, t.w. : tusschen de 9e en de 10e de „bindoe”'s die resp. handelen over: „Oehoem ni halak na marharoan anak barang boroe”, en „Oehoem ni halak na mangoli”, terwijl in de dóórnummering 2 cijfers, n.1. 32 en 33 , gemist worden.

Het leek mij nu maar, conform Vergouwen's plan, het beste, zulks, om althans voor het in de summiere inhoudsopgave ad 6e genoemde Onderwerp een afgerond geheel te bereiken, in deze aan te sluiten op Vergouwen's 26e Hoofdstuk, en de hier behandelde stof een nieuwe en meteen cigen nummering te geven, beginnende dus met: „1e Hoofdstuk”, correspondeerende met Van der Tuuk's 6e „bindoe”.

Dit moest hierbij wel extra vermeld worden om verdere verwarring en misvatting te voorkomen.

De inhoudsopgave luidt derhalve aldus:

\begin{tabular}{|c|c|c|c|c|}
\hline $\begin{array}{l}\text { Gespecific. } \\
\text { inhoudsopg. } \\
\text { v.d. Tuuk }\end{array}$ & $\begin{array}{l}\text { Transcr. en } \\
\text { vertaling }\end{array}$ & $\begin{array}{l}\text { Phonetische tekst van } \\
\text { v. d. Tuuk's inhoudsopgave }\end{array}$ & $\begin{array}{l}\text { Pag. v. h. } \\
\text { Handschr. }\end{array}$ & $\begin{array}{l}\text { Vert.: } \\
\text { zie blz.: }\end{array}$ \\
\hline 6e bindoe & 1e Hfdst. & $\begin{array}{l}\text { Oehoem nie halak na toe- } \\
\text { boean anakna barang bo- } \\
\text { roena }\end{array}$ & 205 & 384 \\
\hline $7 \mathrm{e}$ & $2 \mathrm{e} \quad$, & $\begin{array}{l}\text { Oehoem nie halak na mar- } \\
\text { balieanbaliean }\end{array}$ & 207 & 386 \\
\hline $8 \mathrm{e}$ & $3 \mathrm{e}$ & $\begin{array}{l}\text { Oehoem nie na manggoar- } \\
\text { goar na mètmèt }\end{array}$ & 209 & 387 \\
\hline $9 \mathrm{e}$ & 4e ., , & $\begin{array}{l}\text { Oehoem nie halak na padao- } \\
\text { gieal }\end{array}$ & 209 & 388 \\
\hline & $5 \mathrm{e}$ & $\begin{array}{l}\text { Oehoem nie halak na mar- } \\
\text { haroan anak barang boroe }\end{array}$ & 210 & 389 \\
\hline & $6 \mathrm{e}$ & $\begin{array}{l}\text { Oehoem nie halak na mang- } \\
\text { olie }\end{array}$ & 212 & 390 \\
\hline $10 \mathrm{e}$ & $7 \mathrm{e}$ & $\begin{array}{l}\text { Oehoem nie halak na mal- } \\
\text { lottiek }\end{array}$ & 217 & 397 \\
\hline 1le & $8 \mathrm{e}$ & $\begin{array}{l}\text { Oehoem nie halak na mor- } \\
\text { dang }\end{array}$ & 220 & 400 \\
\hline
\end{tabular}

1) „,bindoe” is het Toba Bataksche woord voor „hoofdstuk” of ,afdeeling”. In de Bataksche tekst zijn de diverse hoofdstukken inderdaad door een bindoefiguur (lijn-teekening) aangegeven. 


\begin{tabular}{|c|c|c|c|c|c|c|}
\hline \multicolumn{2}{|c|}{$\begin{array}{l}\text { Gespecific. } \\
\text { inhoudsopg. } \\
\text { v. d. Tuuk } \\
\end{array}$} & \multicolumn{2}{|c|}{$\begin{array}{l}\text { Transcr. en } \\
\text { vertaling }\end{array}$} & $\begin{array}{l}\text { Phonetische tekst van } \\
\text { v. d. Tuuk's inhoudsopgave }\end{array}$ & \multirow{2}{*}{$\begin{array}{l}\begin{array}{l}\text { Pag. v. h. } \\
\text { Handschr. }\end{array} \\
223\end{array}$} & \multirow{2}{*}{$\begin{array}{r}\text { Vert.: } \\
\text { zie blz. } \\
402\end{array}$} \\
\hline $12 \mathrm{e}$ & .. & $9 e$ & , & $\begin{array}{l}\text { Oehoem nie halak na sieap- } \\
\text { pahaèk }\end{array}$ & & \\
\hline $13 \mathrm{e}$ & , & $10 \mathrm{e}$ & , & $\begin{array}{l}\text { Oehoem nie halak na ma- } \\
\text { ngaleon ramot ramot. }\end{array}$ & 225 & 404 \\
\hline $14 \mathrm{e}$ & , & $11 \mathrm{e}$ & , & $\begin{array}{l}\text { Oehoem nie halak na ma- } \\
\text { ngalehon oepa mangandang }\end{array}$ & 226 & 405 \\
\hline $15 \mathrm{e}$ & ,. & $12 \mathrm{e}$ & ", & $\begin{array}{l}\text { Oehoem nie halak na pasar- } \\
\text { hon gora }\end{array}$ & 227 & 406 \\
\hline $16 \mathrm{e}$ & , & $13 \mathrm{e}$ & , & $\begin{array}{l}\text { Oehoem nie halak na pa- } \\
\text { djongdjong datu dohot } \\
\text { pandee musu }\end{array}$ & 228 & 407 \\
\hline $17 \mathrm{e}$ & .. & $14 \mathrm{e}$ & " & $\begin{array}{l}\text { Oehoem nie halak na pa- } \\
\text { djongdjong pattangan }\end{array}$ & 228 & 407 \\
\hline $18 \mathrm{e}$ & , & $15 \mathrm{e}$ & , & $\begin{array}{l}\text { Oehoem nie na mangoppo } \\
\text { pattangan }\end{array}$ & 232 & 411 \\
\hline $19 \mathrm{e}$ & , & $16 \mathrm{e}$ & , & $\begin{array}{l}\text { Oehoem ni halak na tahie } \\
\text { porang }\end{array}$ & 233 & 411 \\
\hline $20 \mathrm{e}$ & , & $17 \mathrm{e}$ & , & $\begin{array}{l}\text { Oehoem nie halak na mar- } \\
\text { haroan binununa di hamu- } \\
\text { suon }\end{array}$ & 234 & 413 \\
\hline $21 \mathrm{e}$ & ," & $18 \mathrm{e}$ & , & $\begin{array}{l}\text { Oehoem nie halak na mam- } \\
\text { bahen sopo gindjang ba- } \\
\text { rang bagas na bolon }\end{array}$ & 235 & 415 \\
\hline $22 \mathrm{e}$ & , & $19 \mathrm{e}$ & , & Oehoem nie na mangasee & 238 & 417 \\
\hline $23 \mathrm{e}$ & " & $20 \mathrm{e}$ & , & $\begin{array}{l}\text { Oehoem nie na padjong- } \\
\text { djong langgatan }\end{array}$ & 242 & 420 \\
\hline $24 \mathrm{e}$ & ," & $21 \mathrm{e}$ & , & $\begin{array}{l}\text { Oehoem nie na martondi } \\
\text { emee }\end{array}$ & 244 & 423 \\
\hline $25 \mathrm{e}$ & ,. & $22 \mathrm{e}$ & , & $\begin{array}{l}\text { Oehoem nie na pardalan par- } \\
\text { sili }\end{array}$ & 246 & 425 \\
\hline $26 \mathrm{e}$ & , & $23 \mathrm{e}$ & ", & $\begin{array}{l}\text { Oehoem nie na pardalan si- } \\
\text { paimbar }\end{array}$ & 247 & 427 \\
\hline $\begin{array}{l}27 \mathrm{e} \\
28 \mathrm{e}\end{array}$ & ," & $\begin{array}{l}24 \mathrm{e} \\
25 \mathrm{e}\end{array}$ & ," & $\begin{array}{l}\text { Oehoem nie na paoelie pagar } \\
\mathrm{Na} \text { paoelie mombang }\end{array}$ & $\begin{array}{l}249 \\
253\end{array}$ & $\begin{array}{l}428 \\
433\end{array}$ \\
\hline
\end{tabular}

Volledigheidshalve zij ten aanzien van Vergouwen's vertaling nog medegedeeld, dat een vergelijking van zijn in Adatrechtbundel XXXV gegeven indeeling der door hem bewerkte stof (blz. 254 -blz. 281) met evengenoemde gespecificeerde opgave van Verzamelaar zelf mij deed zien, dat Vergouwen vanaf nummer ,30e" zich niet aan de rangschikking van Van der Tuuk gehouden heeft. 
Deze inleiding moge ik beëindigen met het inroeper van clementie voor den stijl van de vertaling, die geen vlotte en vloeiende is, gelijk bij een vrije omwerking van de stof had kunnen zijn verkregen, aangezien, zooals boven al opgemerkt, de primitieve Bataksche tekst zooveel mogelijk op den voet gevolgd is.

\section{NASCHRIFT.}

Door Prof. Van Ronkel werd n.a.v. deze publicatie de wensch geuit, ook den naam bekend te stellen van den Batakschen schrijver van het hier bewerkte Deel van de Manuscripten-collectie, daarbij verwijzende naar een artikel van Pleyte in Deel 47 (blz. 469) van het Tijdschr. v. Ind. T.L.V.K., waaruit nu in dit verband het volgende geciteerd moge worden:

„Gewoonlijk geven de schrijvers der stukken hun namen niet op; ,zij volstaan met te vermelden op welk landschap hun opgaven ,,betrekking hebben, en vragen »Si Pan dor Toek « daarbij een ,enkele maal het stuk toch goed te bewaren en den inhoud ervan ,niet te vergeten.

„Een uitzondering op dezen regel maakt evenwel zekere Goeroe „Tian Dangan uit Nai Pospos, opsteller van een hoogst belangrijke ,,ethnographische beschrijving van zijn land en tal van andere stukken, ,waaronder ook een tonggo-tonggo, aanroepingsformulier, in casu ,om de Pane, naga-achtige slangen, die in het uitspansel verblijf „,houden, op te roepen, teneinde hare tusschenkomst bijv. in krijgs,aangelegenheden te vragen".

Inderdaad vinden wij hierin een duidelijke aanwijzing van ,zekere „Goeroe Tian Dangan” (tenrechte: „Goeroe Tinandang” = ,de veel ,bezochte Leermeester”) als verantwoordelijk voor gedeelten op Nai Pospos betrekking hebbende.

En dit stemt overeen met het voorkomen van dien naam - Goeroe Tinandang - op de voorpagina van een der voorafgaande Deelen van de Bataksche manuscriptenverzameling, waar die naam als handteekening prijkt naast dien van andere medewerkers, terwijl Deel VIII in het geheel geen naam vermeldt, zoodat ook dit laatstgenoemde Deel geacht kan worden te behooren tot het door de eerdergenoemde medewerkers, w.o. dan Goeroe Tinandang, te boek gestelde. 


\section{ZEDEN, GEWOONTEN EN WETTEN VAN NAI POSPOS}

(p. 205-281)

\section{le HOOFDSTUK (6e "Bindoe").}

p. 205 Ia ma oehoem ni halak na toeboe anakna barang boroena. Ia doeng mahoemansoep djolmana $\mathrm{i}$ naeng di api, asa dihirehon ma amak di telaga bahen pangondingi, atik adong halak na mamoloes di alaman, oenang diida boroeboroe na mardakdanak $i$, doeng ni diborothon ma holoetoe pardoaldoalan bahen sitataingan ni na mardakdanak i. Doeng ni didjooe ma boroeboroe na malo mandampol; doeng ro dibagas ni na mandjooe $i$, asa disoerdoengkon ma handoengan toe djinooena $i$, doengni marnapoeran ma $\mathrm{i}$; ba, na doeng soen marnapoeran, asa disoengkoen ma soehoet i: ,,noenga dilehon hamoe ahoe marnapoeran, aha ma nidokmoena di ahoe?” botima ninna. „Olo ba, oenang hoelehon pe napoeranki dipangan ho, sahit ni djolmangkon ma na hoeandoshon di ho, barang haroan pe $\mathrm{i}$, ba, na naing tolhas, asa tandap hoeboto”, botima ninna soehoet i. „Olo, ba, amang, molo ima hape niandoshonmoe toe ahoe, djadi ma toetoe, asa marbinege antong begoe ni sihaso pardjolo dohot begoe ni goeroengkoe moengka ni hasibasoonsa di sintong soenggoe pinodahonna di ahoe", botima ninna. Djadi dipoentar ma boeloeng gadong toe saoan, dibahen dahanon doea hali pitoem pisik, dibahen ma hoenik pitoe ngiris, dibahen aek sabale, doengi asa didampol ma boetoeha ni na marposoposo $\mathrm{i}$. Doengni didongkon ma datoena mambahen saloesoe. Doeng toeboe na di bortian $i$, noenga sahat dohot anggi ni na toeboe $i$, asa didongkon ma ama ni na toeboe i mangarit boeloe bahen sambiloe; doeng soen dipaoeli sambiloe $i$, asa didongkon ma na metmet manaroehon toe bagas, doengni dilehon na metmet $\mathrm{i}$ ma toe sibaso $\mathrm{i}$; doengni

p. 206 dipangido sibaso i ma gadong dohot tali, doengni disoepak ma gindjang ni poesok i sian bonana toloe djari gindjangna, doeng ni diholting ma poesok $i$ di na sinoepakna $i$, doengni ditiop ma gadong $i$, diodothon ma toe sipoesok $i$, doengni diseat ma dohot sambiloe $i$. Doeng soen diseat, dibahen ma toe bogasan parindahanan na imbaroe, 
doengni didongkon ma na mananom toe tombara; ditantan ma poesok i sian hosa ni roema, doengni didjalo na mananom i ma poesok i; doengni ditanom ma toetoe; soen ditanom, marboeri ma na mananom i. Doengni dididi sibaso i ma boroeboroe na mardakdannak i, doeng soen dididi, hoendoel ma ibana di api inon toe lamboeng tataring. Doengni diabing na marbadjoe ma posoposo i, doengni dilalo ma toetoe lalo posoposo: „Na ale begoe, dohot ho ale babiat, dohot ho ale porhas, sandok hamoena nasa siboenoe djolma! boeat hamoe ma siboersok on! molo so diboeat hamoe nannon, matoea andigan indadong be di hamoena on!" botima ninna na mangalalo $\mathrm{i}$; doengni dilehon ma toe inana $i$, doengi ditoendoenhon ma posoposona $i$. Doengni didongkon ma naposo boroeboroe mangalompa; soen masak indahan i, didongkon ma mangan saloehoetna boroeboroe na mandjagai ibana i. Doeng soen mangan laho be ma halak midjoer. Doengni laho ma ama ni posoposo i masisaganon, diboeat ma hajoe simartoelan dohot alngit bahen saganon; na tata do i diboeat indadong djadi anggo na masak bahen pansisoedoean ni djolmana i. Doeng sampe doea borngin doeng toeboe, dipahoendoel ma datoena, p. 207 diboeat ma sada manoek na hatioeran na gorakgorahan, sada na oembalga ; ia na metmet i, sampoer pandidion" ma goarni i, masitilihon ni datoe, disi ma diboto barang na saoer mangoloe na toeboe $i$, barang na so saoer mangoloe; ia manoek na balga i ,bangoen-bangoen” ma goarni. Doengni didjooe ma dohot sibasona i mangan toe bagasna $i$; doengni dilehon ma na margoar ni manoek $i$, toe sibaso sihombang ma sada toesi; ia toe datoe sada haehae, sada pamoengkoeri, ima djambar ni datoe. Doeng soen nasida mangan, mangkatai ma nasida; soen mangkatai, laho ma midjoer datoena i dohot sibasona i. Doeng ni molo naadong hoelahoelana, ro ma i mangoepaoepa dohot marboan oelos parompa, doeng ni mamboeat djoehoet ma ibana panganan ni hoelahoelana i, diporbaga ma riar sada bahen piso ni hoelahoelana i, doengni laho ma i moelak. Doeng ni molo adong do ianangkonna, ro ma i mangoepaoepa, diboan ma riar sada bahen piso ni hoelahoelana i, molo toeng dibahen ianangkonna songoni, molo toeboe boroena moese, indadong tarpabolihonsa be $\mathrm{i}$ toe halak na poelik, anggo inda djolo disoengkoen ianangkonna $\mathrm{i}$; ingkon na so tarolisa pe, asa djadi $\mathrm{i}$ pabolihononna toe halak. Molo toeng dipabolihon boroena i, inda djolo disoengkoen ianangkonna i, sipalangkoephonboroe ma goarni; marmoesoe ma ibana dohot ianangkonna $i$. Ba, ima oehoem ni pardakdanak di djolma on. 


\section{2e HOOFDSTUK (7e ,Bindoe”).}

$$
\text { (p. 207). }
$$

Ia oehoem ni na marbalianbalian.

Asa didongkon ma datoe mandjoedjoer ari; doeng djoempa ari na denggan, disi ma halak na mardakdanak i marbalian-balian. Asa

p. 208 diengge ma dahanon sagantang, doengni didoeda ma i bahen nitak; doengni dibahen ma dibogasan parindahanan na imbaroe; doengni dipabongkot ma parindahanan toe bogasan angkadangan; doengni asa didongkon ma halak mangarit boeloe bahen piso, ima partanda ni na pinarbalianhon $i$, dibahen na diboto halak pamoloes lahilahi; hape molo boroeboroe do na pinarbalianhon, sondoek ma dibahen partandana. Doengni asa disoengkoen sinondoekna i ma datoe i, barang didia ninna begoe monggop. Molo di tapian begoe monggop, moelak ditongandalan ma na marbalian $i$; molo di dalan begoe monggop, moelak di harbangan ma na marbalian i; molo di harbangan ma na marbalian $i$, asa dibahen ma nitak $i$ toloempohoel diatas boeloeng, dibahen napoeran samboeloeng, sanggoel toloen ranting; ganoep sirpang ma dipeakkon nitak $\mathrm{i}$; hape molo na sahat ditongandalan ma nasida, di poegoe ni dalan i ma dipeakkon nitak $\mathrm{i}$; hape molo na sahat ro di tapian, di djoeloe ni tapian ma dipeakkon nitak i, dohot partanda i. Doeng moelak sian balian moelak ma toe hoeta, asa dilehon ma nitak na tinadingkonna di parindahanan $\mathrm{i}$ djolo toe dakdanak si-oeli-goar, doeng pe $\mathrm{i}$ asa diganoepi na metmet ni hoeta $i$ nasa na ro toe alaman $i$; doeng ganoep diparlehon nitak $i$, asa laho ma toe bagas na marbalian i. Doengni asa didimpoe ma indahan toe pinggan, dipeakkon ma dengke saoer doea toeatas indahan $i$; doengni dioepahon ma i toe na metmet i. Doengni asa mangan ma nasida. $\mathrm{Ba}$, ima oehoem ni halak na marbalianbalian.

\section{3e HOOFDSTUK (8e „Bindoe”).}

Ia ma oehoem ni na manggoargoar na metmet.

Molo nadong bahenon ni soehoet, balga ma, diboeat djoehoet manggoargoar anakna barang boroena; ia doeng ma diparmasak djoehoet i asa dipahoendoel ma datoena i dohot dakdanak na so haboeboehan. 
Doengni dibahen soehoet i ma dahanon sasoloep toebogasan parindahanan loging na imbaroe; dibahen ma napoeran pinormoensoeng ni sahiri, dohot soelandak toloe, toe dahanon i ma i dipagohon: doengni dibahen ma pardaoepaan di ngarngar; disorpi ma oelos ragidoep, dipeakkon ma toedjolo ni datoe $\mathrm{i}$; hoendoel ma na sa haboeboehan $\mathrm{i}$ toe siamoen ni datoe $\mathrm{i}$; doengi didok soehoet $\mathrm{i}$ ma goar ni dakdanakna $i$, doeng ni ro ma datoe $i$; didjompoet ma dahanon $\mathrm{i}$, dipeakkon ma toe tangan ni na metmet $i$, doengni dibilang ma dahanon i. Molo noenga singko, goar nidok ni soehoet i ma dibahen goar ni dakdanak i; ia na ,,singko" dahanon, molo gonap bilangan ni dahanon masiopatopat sahoendoelan; ima na ,singko”; molo na ,singko di „,hoendoelanna”, molo toloe hoendoelan, barang opat, barang lima, barang pitoe, barang sia, na ,singko di hoendoelan” na ma goarna. Ia doeng soen ditilik singkosingko $i$, asa didjompoet datoe $\mathrm{i}$ ma dahanon $\mathrm{i}$ toe oeloe ni na metmet $\mathrm{i}$ dohot toe oeloe ni inana $\mathrm{i}$ dohot toe oeloe ni amana i. Doengni tole ma nasida mangan saloehoetna isi ni hoeta $i$, nasa na olo. Doeng soen mangan, asa marhata ma soehoet $i$, disoengkoen ma datoena $i$ dohot sibasona $i$ asa dipaboa horashoras. Ima oehoem ni halak na mambahen goar ni na metmet.

\section{4e HOOFDSTUK (9e „Bindoe”).}

Ia oehoem ni halak na padaogial ni na metmet.

Molo nadong bahenon ni soehoet, mamboeat babi ma i, hape molo soada bahenonna tombal manoek pe diboeat dohot dengke; doengni diarahon ma toelang ni na rorobot, mamboeat oboek ni dakdanakna p. $210 \mathrm{i}$, diboan ma amak toe alaman, dipahembang ma amak $i$; doengni marhobasma nampoenasa anak i, diboan ma anakna i toe alaman i, hoendoel ma nasida, diabing ma anakna i. Doengni marhobas ma hoelahoelana i, ditiop ma djonap doea, doengni diarit ma boeloe bahen tondoeng parepare, songon hiashias ma dibahen boeloe i. Doengni ditiop datoe ma i boeloe, dipadompak ma dompak poerba; doengni marsoembia ma datoe i: ,Ale ompoeng tondoeng parepare, dompak ,poerba ma hami na mamboeat oboek ni na metmet on; ima, diba,hen na ma horas madingin! poeloe ma ho, tondoeng parepare! hape, „molo so djadi dompak i, lia ma ho, tondoeng pare!" botima ninna 
datoena $\mathrm{i}$; doengni dilotakkon ma toe sitoemoedoena pitoehali; doengni dipaloea ma boeloe $\mathrm{i}$, doengni dibèreng ma toetoe; molo toengkap boeloe i, ima na ,poeloe" goarna. Dompak poerba ma hoendoel nampoenasa anak $\mathrm{i}$ dohot anakna $\mathrm{i}$, doengni diboeat ma oboek ni na metmet $i$; doengni di lehon ma dengke, ditiop na metmet $i$, doengni diganoepi ma na metmet ni hoeta i nasa na ro toe alaman $i$, ganoep ma i diparlehon dengke i. Doeng soen diboeat oboekna i, asa diboan ma toe bagas, doengni mangan ma nasida. Doengni dipiohon ma radja ni hoeta i dohot namora dohot sintoea hoeta. Doeng soen nasida mangan, mangkatai ma nasida; doeng soen mangkatai, laho be ma nasida midjoer. Doengni sintap toloen sogot sai digoensir ma $\mathrm{i}$ oboek ni na metmet i. Ima oehoem ni halak na padao gial ni na metmet.

\section{5e HOOFDSTUK.}

Ia oehoem ni halak na marharoan anak barang boroe.

Molo nadong bahenon ni soehoet na balga ma, diboeat haroan nasi dohot mangkoeling gondang ma dibahen. Ia na pogos do soehoet, 211 na metmet ma diboeat. Doengni dipormasak ma djoehoet inon dohot indahan; soen masak indahan $i$ dohot djoehoet $i$, asa dibahen ma indahan sampohoel toe boeloeng motoeng, diboeat ma dohot sondisondi ni djoehoet inon, dibahen ma toeak toe tandoek, diirisi ma pege toe boeloeng motoeng. Doengni marhobas ma datoe mangkatahon i; molo di pintoe begoe monggop, oeloe ni tangga ma disoelangi; molo di soehisoehi begoe monggop, tiang na di soehisoehi i ma disoelangi, toesi ma diborothon sondi-sondi ni djoehoet na di boeloeng motoeng i; doeng pe soen i dipahani, asa djadi halak mangan. Doeng soen nasida mangan asa mangkatai ma nasida. Doengi asa masidok poedjipoedjian ma na torop, nasa na oembotosa. Doeng sampe toloe didok poedjipoedjianna, asa marolopolop ma nasida saloehoetna. Doengni dilehon soehoet $\mathrm{i}$ ma toeak sasaoan, dilehon djoehoet sadjambaran. Ima oehoem ni na marpoedjipoedjian. Doeng soen halak na torop sidok poedjipoedjianna, laho be ma halak midjoer. Ia molo nadong hoelahoelana ro, dohot ianangkonna, marsogotna pe i dipamoeli; doeng torang ari, diboeat ma djoehoet sada panganon ni hoelahoelana $\mathrm{i}$ dohot ianangkonna $\mathrm{i}$; doengni asa dilehon ma riar sada toe hoelahoelana, ,singkatnipiso” ma i, molo laho mangoli 
hoelahoelana i, sitoempahanna ma i. Molo toe ianangkonna i, oelos ma silehononna. Hape molo soada olo mandjalo ianangkonna $i$, molo „oelos na so ra boeroek" dipangido, mandok: boroe, olionna ma i, molo na toho rohani hoelahoelana i mangalehon boroe toe ianangkonna $i$, mangalehon ma ianangkonna i binsang sada ima pangodo ni boroena i. Ima oehoem ni halak na marharoan anakna.

\section{6e HOOFDSTUK.}

Ia ma oehoem ni halak na mangoli.

p. 212 Molo boroe ni sipanarbangi dioli, djolo didongkon ma pangaririt toe hoeta ni halak. Molo adong ma siolionna i ninna pangaririt $i$, asa laho ma nasida toe hoeta ni parboroe i, diboan ma babi paronomhoepang i, ima ,tamboeltamboel” goarna, ima bona ni porhoelaon; dilehon ma pansamotan doea binsang patoedjolo ni djambar ni soehoet, dibahen ma padan barang na piga borngin haroro ni pangoli $i$ laho mamboeat hata saoet. Ia doeng djoempa padan i, ro ma nasida, diboan ma babi partoloeriaran, dilehon ma i dipangan parboroe $i$; doengni dilehon ma pansamotan sitonga, doengni dibahen ma padan haroro ni sialapari. Doeng djoempa padan binahennasida i, ro ma paranak, disoeroe ma pangariritna $i$ laho mangalap ari ; doengni diboeat paranak i ma manoek sada, soen diparmasak dohot indahan, dibahen ma di hadjoet boanon ni sinoeroena $i$, dilehon ma hepeng sahoepang „,djoedjoerari”, dilehon hepeng oealoe oeang, i ma „boeha parha„laan”. Doengni laho ma sialapari. Doeng ro di hoeta ni parboroe i, ditaroehon ma toe bagas ni parboroe i manoek na binoannasida $i$; doengni dipangan parboroe i ma manoek inon; doengni dipiohon ma sialapari i mansipanganon. Doeng soen mangan laho ma nasida modom. Torangniarina diboeat parboroe i ma sada manoek panganon ni sialapari i; doeng soen masak sipanganon, didjooe ma na ro $i$, didjooe ma dohot datoe na di hoeta $\mathrm{i}$; doengni mangan ma nasida. Doeng soen mangan marhata ma nasida; dilehon sialapari i ma hepeng $\mathrm{i}$ : ,botima i hamoe parboroe! ia on ma sisahoepang djoedjoerari ma on, ba òn sioealoeoeang, boehaparhalaan ma on! ba djoe„,djoer hamoe ma ari, barang sipiga borngin nari haroronami!' botima didok na ro i. Doeng ni (di)djalo parboroe i ma hepeng i, delehon p. 213 ma toe datoe $i$ opat oeang boehaparhalaan $i$; doengni dirior ma 
parhalaanna $\mathrm{i}$; doengni dipaboa ma toe soehoet $\mathrm{i}$ barang na piga borngin nari ari na denggan, dipaboa ma i. Doengni dibahen parboroe i ma poedoenpoedoen, dilehon ma toe sialapari i. Doengni mangkatai ma nasida, ro ma parboroe $i$, didok ma toe sialapari i: ..Botima $i$, amang! hamoe na pande $i$ ! ba, ia hata na pinandeanmoe ,,ingot hamoe ma i!" botima didok parboroe i. Doeng(ni) soen nasida na mangkatai, borhat ma nasida laho moelak toe hoeta nasida. Doeng nasida ro di hoeta, asa dipaoelak ma hadjoet $i$ toe soehoet $i$. Doeng masak sipanganon, dipiohon paranak i ma sialapari i mansipanganon. Soen mangan nasida, dilehon ma poedoenpoedoen $i$ toe paranak $i$. Doeng soen nasida mangkatai, midjoer ma nasida. Doeng djoempa padan i, ba, marhobasi ma nasida, diboeat ma manoek sada bahen ingkaoe ni indahan dibogasan ampang; hape molo na diboenoe di hoetana $i$ do pardjoehoetna $i$, dibogasan balandja ma deba dibahen djoehoet $i$, deba dilandjai; doengni dibahen ma tabotabo ni oengkapan bahen langkop ni balandja i. Doengni laho ma nasida, didjolo ma ina ni pangoli $i$, dipoedini inana $i$ sihoenti ampang; dipoedi ni sihoenti ampang $i$ bao pangoli $i$. Ro ma parboroe $i$, dibahen ma tangkingan ni boroena i diroeah tonga. Doeng ro dihoeta pangoli i, didongkon parboroe i ma boroena i toe bagas ni ianangkonna. Doengni laho ma bao pangoli i toe bagas ni parboroe i, dohot inana $i$ dohot sihoenti-ampang i. Doengni hoendoel ma pangoli i toe lamboeng tangkingan nasida $i$, disangkothon ma oelosna toe tangkingannasida i, disolothon ma pisona toe tangkingan i. Doengni dilehon mangan pangoli $\mathrm{i}$; doeng soen mangan ibana, asa djadi midjoer toe toroe. Doengni marhobasi ma soeroean ni parboroe i mangalompa. Doeng p. 214 soen masak indahan dohot djoehoet $i$, asa mangan ma djolo nasida soehoet parboroe $\mathrm{i}$ saloehoet. Doeng soen nasida 'mangan, midjoer be ma nasida, tole ma marpio di pangisi ni hoeta dohot marpio paroendjoek i. Doeng ro na pinio i saloehoet, asa mangan ma nasida; soen mangan, marhata ma nasida, tole ma nasida marpande. Mangido doegoel-doegoel ma naposo ni hoeta $i$, dipasah ma tangga ni bagas $\mathrm{i}$; doengni dilehon ma doegoel ni djoehoet $\mathrm{i}$, dohot hepeng setali; doeng didjalo naposo $\mathrm{i}$, so ma nasida, indadong be djadi oroehanna na marhata i. Doeng soen nasida marpande, dilehon ma djolo raoetni-pansamotan; doeng soen dilehon raoet-ni-mas $i$, asa midjoer ma halak. Doeng ni dibahen ma indahan toe pinggan, dibahen ma dengkesaoer doea toeatas indahan i. Doengni didjooe parboroe i ma boroena $i$; doengni ro ma na panangkokkon $i$, diboan ma boroe nioli $i$; di djolo ma na marboan, di poedi boroe nioli i. Doeng ro di bagas i. 
hoendoel ma $\mathrm{i}$ toe lamboeng ni inana; doengni dipadonok bao pangoli i ma hoendoel toe lamboeng ni boroe nioli i; doengni dilehon ma parboerian, dihandit ma panganan, dipeakkon ma toe djolo ni na mangoli i; doengni hoendoel ma panghombari di talaga; doengni djongdjong ma pangabis, doengni di pangido na mangabis i ma piso pangabis toe ama ni pangoli $i$, doengni mangabis ma $i$; ba, na soen diabishon, marboeri ma pangoli i dohot boroe nioli i dohot panghombarina $i$, doengni didjompoet ma indahan hasampoeran $i$ toloe hali be nasida; doengni dihandit soeroean ni inana $i$ ma panganan $i$, doengni laho be ma halak midjoer. Doengni dibahen ma hadjangan, doengni bongkot ma toe bogasan hadjangan i boroe nioli i dohot bao pangoli $\mathrm{i}$ dohot panghombari i; doengni dibahen ma indahan toe pinggan dohot dengke, ima ,indahan loengloengan” goarna; doengni mangan ma nasida dibogasan hadjangan $\mathrm{i}$; doengni didongkon ina ni boroe nioli i ma panghombari i manaroehon indahan toe inantasida. Doeng soen mangan helana $i$ dohot boroena $i$, dilehon ma napoeran niatoep. 215 pan sampoeloedoea, diatas lapiklapik ni parindahanan na imbaroe ma dibahen; doeng soen marnapoeran, modom ma nasida; di tongatonganasida ma dibahen panghombarina i. Doeng sampe tahoeak manoek sahali, midjoer ma toe toroe bao pangoli i, didoedoek diolmana i ma hadjanganna i. Doeng ni impas ma torang ari, diboeat parboroe i ma silana panganon ni paroendjoek i; doeng soen inasal., dipio ma paroendjoek $\mathrm{i}$ dohot isi ni hoeta $\mathrm{i}$; doeng soen mangan, marhata ma nasida. Doenğni dilehon ma pansamotan. Deengni ro ma soehoet parboroe i, dipangido ma ,ina ni mas" dohot ,tandoek „ni mas”; ia ,ina ni mas” na oembalga ma i; molo ,tandoek ni mas” sionomriar argana, sabinsang do i laho pangoli, si-doea-binsang argana padoealomboe do i bahen pangoli; ima titik ni tandoek ni mas. Doengni dilehon ma djambar ni paramaan doea binsang pasia piso; alai molo sampe nasa $\mathrm{i}$ djambar ni paramaan, oembarbar goendoer na ma i; hape molo padoea-lomboe do djambarna papitoe piso, inda dong oembarbar goendoerna dape i. Doengni dilehon ma djambar ni amangoeda sabinsang; molo sampe doea binsang, oembarbar goendoer na ma $\mathrm{i}$; hape anggo sabinsang do djambarna, so do ibana. Dos do godang ni djambar ni dohot amangtoea. Doengni dilehon ma djambar ni parsinaboel doea riar; molo sampe sabinsang djambarna, djooeonna ma hela $\mathrm{i}$ dohot boroena $\mathrm{i}$ toe bagasna. Doengni dilehon ma djambar ni radja doea riar. Doengni dilehon ma oepapariban sariar; molo sampe doea riar djambarna, mangalehon oegasan ma i toe horoe nioli i, didjooe ma i toe ohagasta 
toelang doea binsang pasia piso; molo sampe nasa i djambarna, diontang ma i toe bagasna $\mathrm{i}$; anggo padoea lomboe do djambarna papitoe piso, so do ibana. Doengni dilehon ma oepa oedoeng tonga riar toe sibahenhata ma i. Doengni dilehon sada riar toe pande

p. 216 mangarinsan, toe dongan ni parboroe ma i. Doengni dilehon ma nioendjoek na torop tonga riar isi ni hoeta masibagi $i$; doengni dilehon ma oepa panghombari satali riar; dilehon oepa panangkokkon sataligodang. Doeng soen digarar oetang i, dipangido paroendjoek i ma oelos tibalan roedjiroedji toe parboroe; dilehon ma $\mathrm{i}$; doengni dipangido ma „oelos hoekkoep ni ampang” dohot „oelos tanda hela” dohot „oelos sampe toea”. Ia doeng soen dilehon parboroe oelos i, asa disorpi ma oelos tibalan roedji i; doengni diboeat ma baion, digotapi ma i; doengni diroedji ma pansamotan i; dipampeakkon ma toe oelos i roedji-roedji i. Doeng soen diroedji mas, diroedji ma oelos, riar sada ma dibahen arga ni oelos. Doeng soen diroedji, dioelangkon ma mangkatai; doengni dipatoebegehon ma toe na torop godang ni mas, na oenang loepa halak, atik beha mate boroe soada martinading anak; asa bandje godang ni mas paboaonna; dipatoebegehon ma toe na torop godang ni oelos ni parboroe, asa oenang loepa di oelos djinalona. Doeng soen nasida na marhata $i$; moelak ma paroendjoek $i$, tinggal ma bao pangoli i. Doeng ro di hoetana ama ni pangoli $i$, dipaoeli ma sioelak ni djoehoet binoeatna $i$; soen dipaoeli, dibahen ma indahan toe pinggan, dibahen ma dohot djoehoet $i$, doengni dipahembang ma lage toe pangoembari, doengni ditibalhon djoehoet $\mathrm{i}$ dohot indahan i toe pangoembari i; dibahen ma dohot parboerian; dibahen ma dohot pola. Doeng loehoet ro di pangoembari $\mathrm{i}$, asa dihatahon ma $\mathrm{i}$ toe begoe ni ompoena, toe begoe ni amana, toe begoe ni inana nasa tingting; nasa parsoemangotanna ditonggo ma disi. Doeng soen dihatahon, dipaima satarnapoeran. Doeng ni dihehei ma sian pangoembari; soen dihehei, dibahen ma napoeran pitoe p. 217 soehoe toe lapiklapik ni parindahanan na imbaroe, doengni diampehon ma i toe pangoembari i. Doengni dipangan nasida ma tibal-tibalnasida i. Soen dipangan nasida, dihehei ma $i$ napoeran $i$, dipangan nasida ma dohot i. Doengni djoempa ma ari na oeli, paoelakoene ma anakna i dohot paroemaenna i. Ro ma parboroe i, diboeat ma sada manoek bahen ingkaoe ni indahan boanon ni boroena $\mathrm{i}$; molo nadong bahenon ni parboroe i, marboan oelos ,sitomoetomoeon” ma dibahen boroena i di simatoeana boroeboroe i. Doeng ro di hoeta ni simatoeana i, laho ma toe bagas nasida i; di djolo ma lahilahi i. Doeng ro di bagas, dilehon ma indahan na binoanna $\mathrm{i}$; doeng ni diatoepi boroe nioli $\mathrm{i}$ 
ma napoeranna; doengni dilehon ma toe simatoeana boroeboroe $\mathrm{i}$ oelos na binoanna $i$, dohot napoeran niatoepanna i ganoep ma diparlehon nasa tondongna i. Doengni laho ma nasida moese paoelakoene toe hoeta ni simatoeana, ia boanonna, babi ma diboeat bahen ingkajoe ni indahan. Doeng pe $\mathrm{i}$ asa moelak moese toesi inana $\mathrm{i}$ dohot djolmana i. I ma oehoem ni halak na mangoli. Hape molo ,poedoen „manaek” ninna goarna, hata saoet diboeat, las i ma hasampoeranna. Hape molo mangoli ama ni boroe $\mathrm{i}$ barang ibotona, sigararon ni helana i ma djoehoet sadanari. Ima oehoem ni poedoen manaek. Molo boroe ni toelangna do niolina, molo doeng mamboeat djoehoet na oembalga, i ma ,panangkoti simata”, ,pandok goar”, pe i do i; doeng diboeat djoehoet $i$, marhata ma nasida, doengni didok ma goar ni boroeboroe, didok ma goar ni anak pangoli i. Ima roehoet ni halak mangoli.

\section{7e HOOFDSTUK (10e „Bindoe”).}

Ia oehoem ni halak na marlontik.

Molo marsogotna marlontik, masibadja ma arian i. Tole marsogot p. 218 i marhobasi ma soehoet i mangalompa indahan dohot ingkajoe. Doeng soen masak, marpio ma soehoet $i$, dipiohon ma pandena $i$ dohot panggaroeti; molo boroeboroe nilontikna $i$, sianak ni namboroe na ma panggaroeti; hape molo anakna do nilontikna, donganna do panggaroeti. Doeng ni mangan ma nasida. Anggo pande i dohot na nilontik i indadong djadi boetong i mangan; molo maboetongkoe, taroeba habiaran. Ia doeng soen mangan, marnapoeran be ma nasida. Soen marnapoeran, diboan soeroean ni soehoet i ma amak toe sopo, diboan ma dohot lage dohot halangoeloe; doengni diboan ma soboeon sanali godangna; diboeat ma dohot boeloeng ni lanting. Doeng ro di sopo parhohasna $i$, borhat ma silontihon $i$, dohot pande $i$, dohot soehoet $i$, dohot tondongna, dohot panggaroeti, diboan ma garoet dohot aek di saoan; dibahen dahanon sandjompoet toe bogasan saoan $i$; doengni dipahembang ma lage $i$, modom ma silontihon $i$; doengni hoendoel ma pande $i$ diatas oeloe ni na modom $i$; doengni dilehon ma toengkol toe silontihon i. Doeng(ni) diharat toengkol i, digigi ma ngingina i. Doeng digigi, marhobas ma boroeboroe i saloehoetna, dihaliangi ma na modom i, dipahembangma oelos, toe abarana ma

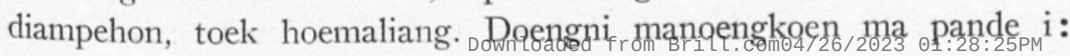

D1. 103. 
„Botima i, hamoena soehoet! ia na beha bahenon ompak ni ngingi ,ni dakdanakmoena on? ia na boeangon ompak ni ngingi anakmon? ,,asa binoto hape molo na djoroton? asa hoeboto!' botima ninna pande i: „Olo ba, amang! boeang hamoe do ompak ni ngingi dak,,danakki!” Djadi diboeang ma ompak ni ngingi i. Doeng soen diboeang, ditoeloethon ma ompak i; molo toe oeloe ni tot ni silontihon laho, barang toe ambihoel ni patna, barang toe soehisoehi ni tanganna. ima na tarboehoe ma goarni; molo toe bitisna, barang salpoe patna, barang di haehaena, ima na tarrear ma goarni; molo toe boetoehana

p. 219 laho dohot toe parateateanna, na oeli ma i; molo toe andorana laho, ima „ramboesan andora”; molo toe roengkoengna laho, na oeli ma i; ima sangkotan horoenghoroeng goarna; molo toe bibirna laho. ima na mardaoep; molo toe dilana laho, barang toe tolonanna, na roa ma $i$, na diotsop poesat ma goarni; molo toe igoengna laho. simanihoes ma goarni, panangkonangko ma i; molo toe matana laho, na roa ma i, simarandoeng ma goarni; molo toe bohina laho, ramboesanbohi ma goarni; na roa ma i! molo toe tangan ni datoena $i$ laho, na oeli ma i! Alai sitoboeson ni soehoet ma i: Ia godang ni toboesna tonga riar. Hape molo toe ampoean ni inana laho, na oeli ma i; molo toe ampoean ni hoelahoelana laho, na oeli ma i, alai sitoboesonna ma i: ia godang ni partoboesna djoehoet sada, hepeng sariar ganti ni piso sada. Ia toe ampoean ni ianangkonna laho, na oeli ma i, alai sitoboesonna ma $\mathrm{i}$ : ia godang ni partoboesna oelos sada, djoehoet sada, ima toboes ni. Doeng soen diompak, didoedoek ma oelos i; doengni dilontihi ngingina na saloehoet. Soen dilontik ngingina $i$, diboan ma badja na doeng tinoetoeng sian bagas, diboan ma dohot asom dohot sira dohot hoenik dohot hapoer; doengni dioelakkon ma moese dihaliangi dihembangi ma oelos $\mathrm{i}$; doengni didaishon ma djolo hoenik $i$, dohot hapoer mahiang $i$; doeng soen $i$, didaishon ma asom i dohot sira $i$, las dibondoet ma i; doengni didaishon ma badja $i$; martoeloetan ma pande i molo mabaor toe toroe ngingina $i$; na roa ma i. Molo hontot do badja i, na oeli ma i. Doeng soen didaishon badja $i$, laho ma toe bagas, doengni diboenoe ma manoek sada; dirior ma gorakgorahan ni manoek $i$, doeng soen dirior, dipaoeli ma roengkoeng ni manoek i. Soen dipaoeli dilehon ma dipangan na nilontik i. Doeng pe soen dipangan i, asa djadi laho toe balian; anggo inda dong dipangan, inda dong djadi haroear toe

p. 220 balian. Doengni marhobasi ma mangalompa indahan dohot ingkajoe dohot manoek i. Molo na adong bahenon ni soehoet, mamboeat babi ma ibana. Hape molo soada, bahenonna tombal dengke ma dibahen 
ingkajoe ni halak. Doeng soen masak saloehoetna, morpio ma soeroean ni soehoet $\mathrm{i}$ di pangisi ni hoeta $i$. Doeng ro, mangan ma nasida saloehoet: ia manoek parlontik i di pande i ma sitonga, di soehoet $i$ sitonga. Doeng soen mangan, marnapoeran be ma nasida. Doengni mangkatai ma nasida. Doeng soen disaoethon sipanganon i, asa disoengkon ma pandena i; molo oeli, parhahoean ma dipangido, marhahoe ma datoe $i$; ia godang ni parhahoean sariar. Hape molo na roa, parsili ma dipangido; ia godang ni parsili; molo na sopar idaidaon, tonga riar ma dipangido; hape molo soada sopar gorakgorahan, sahoepang ma dipangido. Ia toboes ni halangoeloe saparmasan eme.

Ima oehoem ni parlontihon.

\section{Se HOOFDSTUK (11e „Bindoe”).}

Ia ma oehoem ni halak na mordang.

Dibahen na dong tolhas taon di pangordangon, ia titik ni tolhastaon, asa marroenggoe ma djolo nasida sahoeta i sibodarina; doeng soen marroenggoe, torang ni arina marsitingting ma pangisi ni hoeta $i$, masiboan rabina sahalak, doengni dipasae halak ma dalan tapian i, dohot tapian i. Doeng soen dipasae nasida, moeli ma nasida toe roema, doengni mangan be ma nasida, doeng soen mangan, margoegoe ma parripe, sasoloep be saripe, indadong djadi mangkoroes, ingkon sai manoeksoehi do asa djadi; ia goegoe ni na mora doea soloep. Doengni ditaroehon ma toe bagas ni radja $i$; doeng ro di bagasna $i$, asa didokkon ma diengge naposo boroeboroe dahanon goegoean $\mathrm{i}$ doea soloep bahen sitompion dohot nitak; doengni didokkon ma deba naposona i masiboeloeng, mansalong deba, masiordang deba. Doeng ni didoeda ma dahanon nienggena $\mathrm{i}$; doeng soen didoeria, 221 asa dipaoeli ma bahen sitompion sahoendoelan, nitak sapinggan: doengni mangalompa, ima naposo boroeboroe mangalompa i, ingkajoe mo naposo lahilahi deba, paoeli babi deba; soen masak saloehoet na sipanganon $i$, marhobas ma nasida, nasa na ro ringgasna, laho ma nasida toe tapian. Didongkon ma na sohaboeboehan lahilahi doea halak marabit boroeboroe, sahalak marhoenti nitak, sahalak marhoenti sitompion; doengni didongkon ma na deba marboan amak dohot lage, sahalak marboan toeak di tandoek dohot sira pege, ia. 
santisanti, dohot pira ni manoek. Doengni laho ma toe tapian. Doeng ro di tapian, dipahembang ma amak $i$ dohot lage $i$; doengni dipeakkon ma sitompion $i$, dohot nitak $i$, dohot santisanti $i$, dohot toeak na di tandoek i, dohot sapa pege $i$; doengni martonggo ma datoe ni hoeta i. Doeng soen martonggo, asa dibahen hajoe toe tondjolan ni aek i, „pandang" ma goarni: molo denggan roha ni sombaon mandjalo peleanna $i$, magodang ma $i$ aek $i$, sipat ma pandang binahenna $i$; hape molo so denggan roha ni somboan $i$, soeroet ma balga ni aek i, maroempak ma pandang binahennasida i. Doeng soen dibahen pandang i, laho ma nasida moeli. Doeng ro di hoeta, marpoengoe ma nasida na sahoeta $i$ toe bagas ni soehoet $i$; doengni dipangampehon ma toe pangoembari sitompion $i$ dohot nitak $i$, satingting na binoanna sian tapian $\mathrm{i}$; doengni ditibali ma djoehoet babi i toe sapa; doengni dibahen ma indahan toe pinggan; doengni dibahen ma tanggotanggo dongan ni indahan $\mathrm{i}$; dibahen ma ateaete sasaoan, na pinadar sasaoan, daromata sasaoan; doengni dipangampehon ma p. 222 toe pangoembari i djoehoet i, dohot indahan i. Doeng saloehoet ro di pangoembari i, asa dihatahon ma toe na martoea sombaon, dohot toe simangot ni ompoena, doeng soen dihatahon, mangan ma nasida saloehoet, soen mangan dihehei ma tibatibal $i$; doeng ni dibagihon ma ganoep ripe saloehoetna dohot sitompion i, dohot nitak i. Doeng ni borhat ma soeroean ni radja i laho marhara di hoeta i. Doeng soen na marhara $i$, dibilang ma hinarana $i$ : molo onom pangordang saloehoet, onom soehat ma dilompa, hape molo pitoe pangordang, pitoe soehat ma dilompa. Doeng soen dibilang, marhobas ma lahilahi mangalompa inkajoe, marhobas boroeboroe mangalompa indahan. Doeng soen masak saloehoetna, mangan ma pande inkajoe $i$, mangan ma dohot silompaindahan i. Doeng soen nasida mangan, mangan ma isi ni bagas i. Doengni dipambahen ma deba toe parindahanan. Doengni didongkon soehoet $\mathrm{i}$ ma dipantaroehon pangalompa $\mathrm{i}$ toe pangisi ni hoeta i ganoep ripe saparindahanan be. Doeng soen dipantaroehon, dipadimpos ma indahan i. Doeng torang ari laho ma nasida toe tordangan i, doeng ro di haoema i, dipampeakkon ma indahan $i$ dohot ingkajoe i. Doengni dibagihon soehoet i ma boni toe pangeme: masitatadjomi ordangan ma pangordang, masipaoeli sesana ma panesa, doengni tole ma nasida mordang. Doeng adong sitonga diordang, mansohot ma nasida djolo, mangan ma nasida, sapoengoean ma boroeboroe mangan, sapoengoean lahilahi. Doengni marhobas ma pande ingkajoe i marbagi ingkajoe dengke i; anggo ingkajoe godang digomahi ma i toe panganan; doengni dibilang ma na godang, barang 
223 na sadia torop ni djolma na oembalga, nasa i ma torop ni djambar. Doeng soen didjambari, asa diparlehon ma toe na mangan i. Doeng ganoep saloehoet, dibilang ma na niambilhon; soen dibilang, asa diparlehon ma tohapni. Doeng ganoep maroeli na hinara $\mathrm{i}$ dohot na niambilhon i, asa dilehon ma djambar ni soehoet. Doeng soen dilehon, mangan ma pande ingkajoe. Doeng soen na torop mangan, dibahen soehoet ma napoeran di lapiklapik, dibahen ma dohot pinang dohot gambir dohot hapoer dohot timbaho, doengni dilehon ma toe lahilahi sada, toe boroeboroe sada, doengni dibagi nasida ma i, ganoep djolma ma dibahen. Doengni maridi (i) ma nasida djolo, soen maridi, tole ma nasida mordang. Doeng soen diordang nasida haoema $i$, mangan ma nasida, ia ro ma soehoet $i$, dipangido ma parindahanan ni na niambilhon i, diganoepi ma i dibahen indahan. Doeng soen halak na mangan $i$, disoengkoen nasida ma godang ni boni ni soehoet $i$; ro ma soehoet i, dipaboa ma toetoe. Doengni marsaesae ma soehoet i: „Ba! „,sae oelaonta, ale amang, hamoe lahilahi! dohot hamoe boroeboroe! „ba! laho be ma hita moeli!” botima didok soehoet i. „Olo ma toetoe!” botima didok na hinarana i, doeng ni laho be ma halak sian haoema i. Molo noeng $(\mathrm{g})$ a songoni didok soehoet, atik adong pe halak barang na mahoea, indadong soehoet $\mathrm{i}$ be soesa disi; ba, molo soada marsaesae soehoet $i$, molo toeng adong halak marsahit moelak sian ordangonna $i$, soehoet ma sidongkon datoe paoeli daon; hape molo toeng mate halak moelak sian ordangonna $i$, soehoet $i$ ma sibahen sapoetna dohot batangna. Ba, i ma oehoem ni pangordangon.

\section{9e HOOFDSTUK (12e „Bindoe”).}

Ia oehoem ni halak na siampakaek moela ni parmoesoeon.

Asa didongkon ma datoena mandjoedjoer ari. Doeng djoempa ari na oeli, asa marhobas ma nasida na sahoeta $i$, marsitolong dohot masitabartabar dohot masihodongnibagotnametmet dohot masibomban dohot masimaremare dohot masiidjoeknabegoeon. Doeng soen diboeat nasida, asa diboan ma toe hoeta, doeng ro di hoeta, asa disoerat ma tolongtolong i saloehoetna, doeng ni dirigai ma maremare i. Hape molo na maralohon halak, dohot ma isangsisang na masoeak ma dibahen dohot andaloe aosaos; hape molo na marsaharoenggoean do halak marmoesoe, indadong djadi bahenon andaloe aosaos; ia paoelihon andaloe $i$, asa didongkon ma na malo manggana. Doeng soen 
digana, asa diatas oeloe ni ganagana $\mathrm{i}$ ma diborothon isangisang $\mathrm{i}$. Doeng soen dipaoeli, asa didongkon soehoet i ma djolmana barang boroena mangengge dahanon sasoloep; doeng mengge, asa didoeda ma i. Doeng ni dibahen ma sitompion sahoendoelan, nitak sapinggan. Doeng soen masak sitompion $i$, asa dipamborothon ma maremare $i$ toe tolongtolong $\mathrm{i}$, doengni dipahembang ma amak di tonga ni alaman $\mathrm{i}$; doeng ni dialap ma toe bagas sitompion $\mathrm{i}$ dohot nitak $\mathrm{i}$ dohot santisanti, diboan ma toe alaman $\mathrm{i}$; doeng ni dipeakkon ma toe djolo ni datoe $\mathrm{i}$; doeng ni djongdjong ma datoe $\mathrm{i}$, ditiop ma sitompion $\mathrm{i}$, di hambirangna ma dibahen, di siamoenna santisanti na di saoan i; doengni dihatahon ma i toe boraspati ni tano, toe martoea sombaon, toe boroe saniang-naga, toe debata na toloe. Doeng soen i dihatahon dipeakkon ma i. Doeng ni dihatahon ma moese nitak i toe simangot ni ompoe ni soehoet $i$, dohot toe simangot ni goeroena na doeng mate, toe badia ni goeroena na mangoloe. Doeng soen dihatahon, asa ditaroehon ma toe bagas sitompion $\mathrm{i}$ dohot nitak i dohot santi-santi i. Doeng ni didongkon ma sahalak mamaloe gordang, doengni borhat p. 225 ma nasida, didjolo ma soehoet; diboan ma tolongtolong i nasa sialo-moesoe, ganoep sada be. Doengni dipaloe partonga ma bodil sahali, ima ,bodil panindi” goarna. Doengni diboan datoe ma i andaloe aos-aos $i$, di poedi sahali ma ibana, Doeng sampe toloe ngombas marlodjong dao nasida sian hoeta $i$, asa dipampagohon nasida ma tolongtolongna $i$, pardoeroe dibahen andaloe $i$; doeng ni martangiang soehoet i. Doeng ni tole ma nasida mamodili doea hali be asa moeli ma nasida toe hoeta, mamodil ma nasida toloe hali laho toe hoeta. Ia doeng ro di hoeta, marpoengoe ma nasida di alaman i. Doengni ro ma djolma ni soehoet $i$, disanti ma paranganna $i$ saloehoet, dohot datoena i, dohot sinondoekna i. Doengni ditangkoep ma sada manoek hatioeran na gorakgorahan, diseat ma manoek $i$, doengni digantoeng datoe i ma manoek i; disi ma diboto barang na monang nasida; doeng soen ditilik, ditoetoengi ma manoek $i$, doengni dilapa ma toetoe, ditilik ma toe bogasan; soen ditilik diparmasak ma manoek inon. Soen masak, asa dipangido ma indahan toe bagas ni soehoet i, doeng ni dibahen ma toe pinggan na metmet, doengni diboan na mangalap i ma toe alaman i, doeng ni ditibali ma djoehoet manoek $\mathrm{i}$ toe indahan $\mathrm{i}$, doeng ni dihatahon datoe $\mathrm{i}$ ma toe tondi ni nasida sahoeta i. Doeng soen dihatahon, asa dibagi ma djoehoet manoek $i$ dohot indahan i, diganoepi ma saloehoetna ripe ni hoeta $i$, Doeng ni laho be ma halak toe bagasna. Asa ima oehoem ni parsampakaehon moela ni parmoesoeon. 


\section{0e HOOFDSTUK (13e „Bindoe”).}

Ia oehoem ni halak na mangaiehon ramotramot, soehoet toe na torop.

Ia balga ni djoehoet ramotramot partongadoeariaran, dahanon sasibalamboeng. Doengni diboeat ma babi i; doengni diparmasak ma 226 djoehoet i. Doeng soen masak, asa dipapoengoe ma saloehoet pangisi ni hoeta i, nasa lahilahi. Doengni didongkon soehoet i ma djolmana barang boroena mangalompa dahanon na sasibalamboeng $i$, doengni dipangido ma indahan sapinggan; doengni ditibali ma tanggotanggo ni babi $\mathrm{i}$ toe indahan $\mathrm{i}$; doengni dihatahon datoe ma $\mathrm{i}$ toe boraspati ni tano dohot toe namartoea-sombaon dohot toe boroesaniangnaga dohot toe boroenamora dohot toe ari na toloepoeloe dohot toe debata na toloe dohot toe parsimangotan ni nasida sahoeta $i$, Doeng soen dihatahon, asa dibagihon ma djoehoet $\mathrm{i}$ dohot indahan $\mathrm{i}$; doeng ganoep saloehoet nasida, asa diparboan be ma toe bagasna; doeng ni masioepahon di ibana ma nasida na sahoeta i. Doeng soen dipangan be di bagasna, asa marpio ma soehoet $i$, dipio ma saloehoetna, nasa sialomoesoe. Doengni mangan ma nasida, soen mangan asa marhata ma nasida. Doeng soen marhata, laho be ma halak midjoer. Asa i ma oehoem ni na mangalehon ramotramot. Molo noeng $(\mathrm{g})$ a dilehon soehoet $\mathrm{i}$, asa mangaramot ma halak. Ia na soada raboekna dohot anakbodilna, asa ditoehor ma; ia na soada bodilna, asa diindjam; ia molo so mangaramot halak, toeng mate pe halak dibahen moesoe, indadong mangido aboel be tinading ni na mate $\mathrm{i}$ toe soehoet $\mathrm{i}$; toeng tarsonggot pe ibana dibahen moesoe, indadong soehoet be sioepaoepa na tarsonggot i. Asa ima oehoem ni hamoesoeon.

\section{1e HOOFDSTUK (14e „Bindoe”).}

Ia oehoem ni halak na mangalehon oepa mangandang, soehoet toe isi ni hoeta.

227 Nasa balga ni ramotramot $i$ do balga ni oepa mangandang, dahanonna pe nasai do; asa dibagihon do i saloehoetna toe isi ni hoeta $\mathrm{i}$. Anggo dahanon i dibagas ni soehoet i do i dilompa, Ia soen masak, asa dipiohon ma pangisi ni hoeta i saloehoetna nasa na olo. Doengni mangan ma nasida. Soen mangan asa marhata ma nasida, soen marhata midjoer be ma halak toe toroe. Ima oehoem ni halak na 
mamboeat oepa mangandang. Molo noenga diboeat soehoet $i$, na hoerang togoe handang dipatogoe ma $i$, na hoerang togoe randjona dipatogoe ma i; molo so dipatogoe halak handangna, toeng bongkot moesoe barang babiat, toeng diboeat babi ni halak, diboenoe moesoe anak ni halak, sidohonon ma i toe nampoena handang $\mathrm{i}$.

Ima oehoem ni.

\section{2e HOOFDSTUK (15e „Bindoe”).}

Ia oehoem ni na pasarhon gora toe donganna sahoeta.

Molo na djoemoedjoer oetang do na pasarhon i, parbaribaan ma djoehoet, sada ampang dahanon, dilehon soehoet ma $\mathrm{i}$ toe isi ni hoeta i, hape noio singir do tinoenggoena, partongadoea-riaran ma djoehoet diboeat pasarhon gora, saparmasan dahanonna. Molo noengga dilehon soehoet $i$, rap soehoet ma saloehoetna pangisi ni hoeta $i$, barang ro pe pangoeloe, sai digoegoei ma panganon ni; sandok: barang aha diboeat di gora $i$, sai digoegoei ma i; hape molo na soada gararna, disoerathon oetangna; radja ni hoeta djolo mangoeboeng; doeng soen gora, disi pe dibahoni oetangna. Ia soen ma gora, molo mandjalo dangdang na sada; hira djambar ni paroetang i ma dipadaboe toe oetangna. Hape molo mardangdang do nasida, djoemolo ma dangdang i digarari, asa oetang goegoean i. Asa ima oehoem ni halak na pasarhon gora toe donganna hoeta.

\section{3e HOOFDSTUK (16e „Bindoe”).}

Ia oehoem ni halak na padjongdjong datoe dohot pande moesoe dohot parhara moesoe dohot partahi moesoe.

Asa diboeat soehoet i ma sada babi parriari; doeng soen masak, asa dipiohon ma datoe $\mathrm{i}$ dohot pande $\mathrm{i}$ dohot partahi $\mathrm{i}$ dohot parhara $i$; doeng ni mangan ma nasida; soen mangan asa marhata ma nasida; soen marhata, asa dilehon soehoet i ma boelangboelang na bontar, dilehon ma oelos ni datoe sada na bontar, dilehon hepeng sariar bahen pasinapoeranna; ia datoe hoeta, sabinsang ma diparbaga soehoet di datoe $\mathrm{i}$; hape molo datoe nialap, doea binsang ma diparbaga soehoet di datoe i. Doengni asa diadjari datoe i ma naposona i. Ia 
oelaon ni pandè moesoe: molo tole nasida marhata na sanga marpande, ibana ma pandepande; i ma oelaon ni; ia oelaon ni partahi moesoe: molo nadong halak ro toe hoeta $i$, barang pangoeloe ro, barang oelaon nasida di hoeta $i$, tole mamboeat manoek, barang babi, barang biang, i ma mamboeat; ia tole mangido dahanon goegoean, i ma mangido; asa ima oelaon ni partahi moesoe $i$; ia oelaon ni parhara moesoe: ia tole nasida marroenggoe, barang martahi badjo, barang aha pe oelaonnasida i, i ma mandjooe halak laho marroenggoe: i ma oelaon ni parhara moesoe.

\section{4e HOOFDSTUK (17e „Bindoe”).}

Ia oehoem ni na padjongdjong pantangan.

Asa marroenggoe ma djolo nasida na sahoeta $i$; doeng ni tole marsogotna i; molo noengga djoempa ari na oeli, asa laho ma nasida masiparhajoe dohot masimaremare; asa dipagohon ma sada sopo, soen sada ari do $\mathrm{i}$ dibahen, indadong djadi $\mathrm{i}$ doea ari paoelion ni p. 229 halak. Ia doeng soen dipaoeli sopo, asa dihaliangkon ma maremare i di pantangan i; doengni dipampe ma gordang toe bogasan pantangan $\mathrm{i}$ dohot tataganing dohot ogoeng; doengni dibahen ma ragaraga, dilamboeng ni oeroer ma $\mathrm{i}$ dibahen, digantoeng ma sada mombang na metmet diatas ni pat ni gordang i, doengni dibahen ma mombangpoea na balga dilamboeng pangoembari ni pantangan i. Doengni diboeat ma manoek na pangompo ni pantangan $i$, digantoeng ma i manoek i. Doengni didongkon ma mangalompa soehoet i dohot mandoeda nitak, doengni dilompa ma indahan na hoenik. Doeng masak saloehoetna, asa ditaroei ma toe pantangan i saloehoetna amboe-amboean $i$; doengni ditibali ma manoek i toeatas indahan $\mathrm{i}$; doengni dibahen ma pat ni manoek $\mathrm{i}$ dohot indahan sampohoel dohot dengke saotik dohot tali pasa; doeng ni dibahen ma toe mombang na metmet i sitompion na so tarhaol begoe. Doeng ni dibahen ma sitompion na hinoenihon sahoendoelan, na so hinoenihon sahoendoelan, ganoep ma i martimpa be dohot margaboer-gaboer, dohot marpinarboetoehamboeloe dohot marpoeroerpoeroer dohot djoeroerdjoeroer dohot djaloedjaloe dohot pinasa na metmet dohot soehat dohot pisang dohot toboe dohot dajoeng na pandang; doengni ditibali ma toe mombang na doea $\mathrm{i}$; dibahen ma sanggoel na rara dohot sanggoel na bontar dohot harehare dohot mangemange. Doeng ni 
dibahen ma sitompion sahoendoelan toe pangoembari ni pantangan i; doengni diampehon ma dohot indahan nioebatan i toe pangoembari i; doeng ni dipaoeli ma pangoerason; soen dipaoeli, diampehon ma toe pangoembari i. Doengni dipangido ma toe djolma ni soehoet i parimbahoan na oembalga dohot salapa na metmet, dohot hadam p. 230 golanggolang, doeng ni dibahen ma napoeran dohot gambir dohot pinang dohot timbaho dohot hapoer; doengni diampehon ma toe pangoembari i. Doengni asa diradja ma andoeri bahen partondoengan; doengni marhobas ma datoe $i$, dihatahon ma i toe boraspati ni tano, toe namartoeasombaon, dohot toe boroe saniangnaga, dohot toe boroe na mora, dohot toe ari na toloe poeloe, dohot toe boelan na sampoeloedoea, dohot toe debata na toloe, dohot toe simangot ni goeroena na doeng mate, toe badia ni goeroena na mangoloe. Doeng soen dihatahon, mangan ma ibana; soen mangan, asa didongkon ma parhara moesoe i mandjooe pargonsi. Doeng ro djinooena i, dipaloe ma gondang i. Doeng ni marhobas ma datoe i, ditiop ma oelos ragidoep, djongdjong ma ibana diherbang ma oelos ragidoep $i$, ima balokbalok goarna, oenang ro tondi ni nasida sahoeta i mandoelo pantangan i. Doengni asa didjooe ma goar ni radja ni moesoena i: ,Mari ma ho, partondion ni radja sianoe! manontor ma ,ho di pakpak ni gordang sipamoetoeng on! disi do panganonmoena ,diondjapindjap i, disi do indahan sampohoel, dohot dengke, dohot ,pat ni manoek! disi ma tali-pasa bahen mangihoti ho! tadingkon „ma djolmami dohot dakdanakmi dohot bagasmi dohot sopomi dohot ,hoetami!" botima didok datoe i. Doeng ni sai diganoepi ma didjooe goar ni moesoena i, nasa na diboto. Doeng soen didjooedjooe tondi ni moesoe na i, mansohot ma nasida na margondang i, doeng ni modom be ma nasida. Doeng torang ari, diboeat soehoet i ma babi parriari, doeng soen masak, dipiohon ma datoe $i$ dohot namorana $i$ saloehoetna isi ni hoeta i. Doeng ni mangan ma nasida; soen mangan asa morhata ma nasida. Doeng ni mangkoeling ma datoena i: „Botima, amang: hita na sada hoeta on masiadjar dakdanak ma ,hita on, oenang toeng laho toe pantangan i; molo toeng laho, toe p. 231 ,simaroetang ma i bahenon; ia godang ni oetangna manoek lahi ,bini, dahanon sasoehat, oelos na bontar sangkolak; ima oetang ni. „Hape molo halak roear laho toe pantangan i, sisoroon ma i, doeng ,pe nühotan asa bineangkon; hape molo nadong donganna manopot, ,hinata ma oetangna, ia godang ni oetangna sada babi parriari, ,sadjoeal dahanonna, dipasahat dohot gondang ma i; ima godang „ni oetangnasida i. Ba, ia hita on, oenang marbada, dohot djolmana 
,pe, dohot halak pe! Molo toeng marbada ibana, maroetang do i ,sada manoek rombadan, sasoehat dahanonna; ima godang ni „,oetangna. Ia na marpangir di pamispisan, barang na mangongkal tano ,pe ibana, barang na mamoerai, toe moesoe diboerahon; molo na „metmet songon $i$, indahan na oebaton dohot pira ni manoek sada; ,molo na magodang, sada manoek djagar pangase, dahanon doea so„loep, ima oetang ni. Ia na masisaratan dialaman, barang mortoedjoe,toedjoe, barang na djanggedjangge oboekna di alaman, maroetang ,ma i nitak sapinggan, sitompion sahoendoelan, santisanti sasoloep, „dohot pira ni manoek doea; ima oetangna. Ia na sanga hona tangan „djolmana, barang tiris moedar dibahen, balga ma oetangni.

,Ia godang ni oetangna: sada babi na bolon, sasibalamboeng daha.non, dihalang gordang, dirambing ogoeng di alaman, dibahen siton,pion; i ma oetang ni. Ia na masiihotan halak inda djolo disoengkoen „,sintoea, maroetang ma na mangihoti bahenon. Ia godang ni oetangna ,,sada babi parriari, sadjoeal dahanonna, dibahen pangoerason, dioeras „ma na niihotna $i$, dilehon ma dipangan djoehoet binoeatna $i$; alai „molo noenga songoni dibahen, barang sadia pe oetang i, sai gararp. 232 „onna ma saloehoetna, indadong mardebadeba be i gararonna”. botima didok datoena i. Ro ma soehoet $i$; dinihohon ma di isi ni hoeta i: „Botima i, amang, hita on! dibege (hamoe) hata ni goeroe „,i!" botima ninna soehoet $i$. Doeng soen nasida na marhata i, laho be ma nasida midjoer, doeng ni laho ma datoena $i$ toe pantangan; sintap pitoe borngin sai margondang di pantangan i, sai didjooedjooe tondi ni moesoe i. Ima oehoem ni halak na padjongdjong pantangan.

\section{5e HOOFDSTUK (18e „Bindoe”).}

Ia oehoem ni na mangompo pantangan.

Diboeat manoek lahi bini hira pelean ni goeroe, diboeat manoek sada na hatioeran na gorak-gorahan hira panilihanna; diboeat babi sada hira panganon ni datoe dohot sintoea dohot naposo ni datoe i. Doeng ni diboeat ma boeloe sangharair, diborothon ma oelos na rara bahen mandera, doengni dipagohon ma didjolo ni pantangan $i$. Doeng ni masiharoear mas na ma isi ni hoeta i saloehoetna i, digohi ma toe pinggan. Doengni didongkon ma djolma ni soehoet i mangengge dahanon bahen nitak, doeng ni didoeda ma toetoe, doeng ni 
dibahen ma sitompion sahoendoelan, dibahen nitak sapinggan, dibahen poeroerpoeroer toloe, djoeroerdjoeroer toloe, djaloedjaloe toloe, gaboergaboer toloe, timpa doea, pinarboetoehamboeloe doea. Ia doeng masak, ditibali ma toe pinggan, doengni ditaroehon ma toe toroe; ro naposo ni datoe $i$, didjalo ma toetoe, diboan ma toe pantangan $i$. Doengni dipaloe ma gondang di pantangan $i$; doengni manontor ma datoe $i$, ditortor ma sitompion $i$; doeng soen $i$ ditortorhon, dipeakkon ma $\mathrm{i}$, ditortorhon ma moese nitak $\mathrm{i}$; doeng ni mansohot ma datoe $\mathrm{i}$,

p. 233 doengni mansohot ma nasida na margondang i. Doeng ni mangan ma nasida na sahoeta $\mathrm{i}$, doengni laho be ma halak toe bagasna. Ima oehoem ni halak na mangompo pantangan.

\section{6e HOOFDSTUK (19e „Bindoe”).}

Ia oehoem ni halak na tahi porang,

asa marroenggoe ma djolo nasida na sahoeta $i$, simanogot do $i$; doengni asa disoengkoeni datoe $\mathrm{i}$ ma paranganna i barang piga na olo; doeng soen disoengkoen, nasa na olo didongkon ma marmangmang nipina. Doengni torang ni arina disoengkoeni ma paranganna i, doengni masipaboa nipi na ma nasida saloehoet; nasa na denggan nipina, dipopar ma $i$, nasa na so gabean nipina indadong $i$ dipopa Doeng soen disoengkoeni, asa martondoeng ma nasida dohot marmanoek gantoeng. Doeng mandjorot manoek-gantoeng-na i dohot tondoengna $i$, didongkon datoe $i$ ma mamboeat patoeng soehoet $i$; doengni diboeat ma babi, di sopo do i diparmasak; didongkon ma djolmana i mangalompa indahan toe bagas. Doeng soen masak djoehoet inon dohot indahan $i$, disondoehi ma toe parboebean, doengni diboan ma toe sopo; doengni dipahaliang paranganna i ma di sopo i, sama hoendoel ma nasida saloehoetna, doengni disoelangkon soehoet i ma djoehoet babi i toe paranganna i; doeng ganoep disoelangi saloehoetna, mangan ma nasida; doeng soen nasida mangan, midjoer ma nasida sian sopo i toe alaman; doeng ni masialap paliasna ma nasida toe bagasna saloehoet; doengni marpoengoe ma nasida di alaman i; Doengni dipistik datoe i ma paranganna i saloehoet dohot pangoerason; doengni marsoerak ma nasida, soen nasida na marsoerak i, borhat ma nasida; Doeng ro dibalian-dipaloe ma bodil panindi sahali, doengni laho ma nasida toe ladang ni moesoena $\mathrm{i}$. 
Doengni modom ma nasida. Doeng martahi torang ari, dipadonok nasida ma toe harbangan ni moesoena i; dirior ma pangaropan nasida, molo adong do na taloep diida, disi ma nasida mangarop hape molo soada na taloep diida, dipaoeba toe na poelik. Doeng roear moesoena $i$, dibingkasi ma toetoe, masibodilan ma nasida. Molo na mamoe :se nasida, disi tolap na masibodilan i, sai mamaris ma nasida sahat ro di hoeta nasida i. Hape anggo horas be do nasida, disi tolap nasida na masibodilan i, mamodil nasida sahali be mandapothon hoeta nasida, sahali be sahat ro di hoeta. Didjompoet djolma ni soehoet i ma dahanon toe oeloe ni paranganna $i$, doengni mangan be nasida toe bagasna i, molo na so mamoenoe. Hape molo na mamoenoe, di balikhandang dape nasida, noengga dirambing ogoeng, dihalang gordang di alaman, noengga disingkang babi, bahen pegepege. Sahat ro di hoeta parbadjo $i$, manontori ma nasida saloehoetna, dohot datoena $i$, dohot soehoet $i$, saloehoetna isi ni hoeta $i$, nasa na olo. Doengni dipasohot ma na margondang i; diboenoe ma babi i, diparmasak ma, dilompa ma dohot indahan. Doeng soen masak djoehoet inon dohot indahan i, mangan ma nasida saloehoetna; ia soen mangan, asa marhata ma nasida; Soen mangkatai, asa midjoer be nasida. Ima oehoem ni halak na marbadjo.

\section{7e HOOFDSTUK (20e „Bindoe”).}

Ia oehoem ni halak na marharoan binoenoena dihamoesoeon.

Molo nadong bahenon ni soehoet, hoematop ma diparharaon; hape molo na mandjalahi dape soehoet, loemeleng ma dibahen; ia doeng adong dapotsa, asa dihoeroeng ma djolo pangisi ni hoeta i saloehoet i: ,saloehoetna ale amang! hita na sada hoeta on! oenang djolo laho „,toe haoemana barang toedia pe; oenang djolo laho! naeng itapar„,haroan na itaboenoe $\mathrm{i}$, nanggo anak ni manoek itaboeat haroanna! ,,asa poengoe hita dihoeta on!” botima didok soehoet i. ,Olo ba, ,soehoetnami!” botima ninna natorop. Doengni marhobasi ma nasida, dialap ma hajoe saroemarnaek bahen borotan, diboeat ma dohot sanggar dohot boeloeng ni borta dohot boeloeng ni baringin dohot boeloeng ni andoedoer. Doeng diboeat nasida saloehoet, diboan ma toe hoeta, doengni dipagohon ma di alaman hajoe i, doengni ditapol

p. 235 ma sanggoel ni borotan i di tampahanna, doengni didongkon soehoet i ma djolmana i mangengge dahanon bahen sitompion; doeng mengge, didoeda ma $i$, doengni dibahen ma sitompion sahoendoelan; soen 
masak, ditibali ma toe pinggan, doengni diboan ma toe alaman i; Doengni dirambing ma ogoeng, dihalang gordang di alaman $i$; doengni manontor ma soehoet $\mathrm{i}$ dohot radjana $\mathrm{i}$ molo namora soehoet barang parripe; doengni manontor ma djolma ni soehoet $\mathrm{i}$; doeng mansohot nasida manontor, asa manontor ma paranganna i saloehoet; dihaliangi nasida ma babi na haroanna di borotan $\mathrm{i}$; doeng ganoep saloehoet manontor isi ni hoeta $i$, nasa na olo, asa mansohot ma nasida djolo; ditaroe $\mathrm{i}$ ma toe bagas ni soehoet $\mathrm{i}$ ogoeng $\mathrm{i}$ dohot tataganing $\mathrm{i}$. Doengni diboenoe ma babi i, dilompa i ma toe bagas, dilompa i dohot indahan; soen masak djoehoet inon dohot indahan i dohot ingkajoe godang, dipambahen ma panganan; doengni dibagi pande djoehoet i ma djoehoet inon; dipartoloe ma tanggo-tanggo ni djoehoet $\mathrm{i}$; dibahen ma sada di soehoet, sada di na torop dohot di radja dohot di namora; dibahen sada diparbadjo i saloehoetna nasida nampoenasa $i$; anggo niadopan, di soehoet do i. Doeng ni marpio ma soeroean ni soehoet $i$, dipio ma saloehoet pangisi ni hoeta i saloehoetna; doeng ro di bagas ni soehoet $i$ saloehoetna pinio $i$, mangan ma nasida; doengni dibagihon soehoet $\mathrm{i}$ ma deba djambarna $\mathrm{i}$; doengni dipadalan ma na margoar; dilehon ma na marngingi dohot panaoran toe radja $i$; doengni dilehon ma parsanggoelan toe namora; doengni dilehon ma deba na margoar $i$ toe donganna. Doeng soen dipadalan na margoar i, soen ma nasida mangan; doengni marnapoeran ma nasida; doengni marhata ma nasida; doeng soen marhata, midjoer be ma nasida. Ima oehoem ni halak na marharoan binoenoena di hamoesoeon.

18e HOOFDSTUK (21e „Bindoe”).

Ia oehoem ni halak na mambahen sopo gindjang barang bagas na bolon.

Anggo pande di hoeta do pandena, doea riar do abit ni pande, hape molo pande nialap, opat riar abitna. Doengni ia tole ma laho martaba hajoe toe ramba, mamboeat djoehoet ma soehoet $i$, panganon ni pande i. Doengni laho ma nasida toe ramba, ditaba ma hajoe i; doengkonsa dipaoeli nasida parhajoe $\mathrm{i}$ saloehoet, tole ma mamboan toe hoeta; ia na so piga djolma di hoeta $i$, marhara ma soehoet $i$ toe hoeta na poelik; doeng ro hinarana $i$, diboeat ma sada babi panganon ni na hinarana $\mathrm{i}$; doeng ni laho ma nasida na sahoeta $\mathrm{i}$ 
saloehoetna dohot na hinara $i$, ditaroe nasida ma parhajoe $i$ toe hoeta. Ia soen ma ditaroe nasida, diboeat soehoet $\mathrm{i}$ ma babi pardoeariaran bahen panganon ni sialap parhajoe i. Doengni sampe toloe borngin doeng ro dihoeta parhajoena $i$, diboeat ma babi na bolon bahen haroan ni parhajoena i. Doeng djoempa ari na oeli, didongkon pande i ma djolma ni soehoet i mangengge dahanon bahen sitompion. Doeng soen dipaoeli, ditibali ma toe pinggan; doengni ditaroehon ma toe toroe. Doengni dipahembang ma amak di parbagasan i; doengni dipeakkon ma nitak $\mathrm{i}$ dohot sitompion $\mathrm{i}$; doengni dihatahon ma toe boraspati ni tano, toe na martoea sombaon, toe Boroe Saniangnaga, toe Boroe na Mora, toe Debata na toloe. Doeng soen dihatahon, asa disoelangi ma parhajoe $i$; doeng ni dilehon ma toe soehoet $i$; doengni diganoepi ma saloehoetna marhobas i. Doengni dipagohon ma tiang ni bagas i, doengni dipasonggop ma parhajoe olat ni na lolo toe toroe; doengni diboeat ma sada babi bahen ingkajoe ni halak; doeng soen masak, mangan ma nasida. Soen ma nasida mangan, dipaoeli nasida ma olat ni na lolo toe gindjang; soen ma diparait bagas i, soen dioeroeri, soen dibahen dohot lais; doengni bot ma ari mansohot ma nasida djolo. Doengni mangan ma nasida. Doeng torang ari p. 237 ditaroep ma bagas i. Doengni diboeat soehoet i ma babi sada bahen panganon nasitaroep bagas i. Doeng ni soen ma dipaoeli bagas $i$, doengni dipaoeli ma tataring, dibahen ma sanggesangge dohot bangoenbangoen ganoep soehisoehi ni tataring i. Doeng ni didjoedjoer ma ari; doeng djoempa ari na oeli, diboeat ma sada babi na bolon; doengni bongkot ma soehoet $i$ toe bagasna $i$; doengni dipio ma na sahoeta $i$ mangan toe bagas $i$; soen mangan, marhata ma nasida, masidok poedjipoedjianna ma halak na pinio $i$, nasa na oembotosa. Hape molo adong bahenonna soehoet, diompo ma bagasna i, ditonggo ma nasida na saharoenggoean, margondang ma ibana pitoe ari pitoe borngin; ia siarian, di bonggarbonggar ni bagas i ma margondang, di alaman ma halak manontor; ia siborngin, dibogasan bagas ma halak manontor dohot margondang; doeng sampe i sipitoe borngin $i$, asa mansohot ma nasida na margondang $i$, doengni diboeat soehoet i ma horbo sada pamoeli radjana, ro dohot pamoeli ianangkonna, dohot pamoeli hoelahoelana; Doeng soen diparmasak djoehoet $\mathrm{i}$, asa mangan ma nasida; doeng ni asa dilehon ma toeak sataboetaboe toe radja tinonggona $\mathrm{i}$, dilehon sataboetaboe toe hoelahoelana, sataboetaboe toe ianakkonna dilehon. Doengni soen ma nasida mangan, doengni dihandit ma pinggan panganan i; doengni disoerdoekkon ma handoengan toe na piniona $i$, djadi marnapoeran $i$ ma nasida 
saloehoet; doeng soen, dipaoelak ma handoengan i; doengni marhata ma nasida, soen marhata toe natorop, disaoethon ma toe hoelahoelana $\mathrm{i}$ dohot ianakkonna. Doeng ni dilehon ma hepeng sariar be hoelahoelana i singkat ni piso; dilehon ma toe ianakkonna i oelos sada be; doengni dilehon inakkonna i ma riar sada be nasida toe hoelahoelana i. Doengni laho be ma halak moelak toe hoetana. Ima oehoem ni halak na mambahen bagas barang sopo, molo di halak na gabe; ianggo na pogos do halak, indadong songoni dibahen.

\section{9e HOOFDSTUK (22e „Bindoe”).}

p. 238

Ia oehoem ni halak na mangase.

Asa marroenggoe ma djolo nasida na sahoeta i; ba, ia pinaroenggoena: ,Soede ma hita na sahoeta on mardengke masibahen nia„,nangna dohot polongna dohot dengke-saoerna!' botima didok radja i. „Olo ma toetoe!” botima didok parripena i dohot namorana $\mathrm{i}$. Doengni mardengke ma saloehoet nasida na sahoeta $i$, masibahen nianangna ma nasida dohot polongna dohot dengkesaoerna. Doengni djoempa ma ari na oeli, marhobas ma nasida, laho ma nasida mamboeat amboeamboean toe balian; ditaba ma boeloe, disoepak ma gindjang ni boeloe i sipat djolma, doengni dipasomboe ma disi ranting ni boeloe i dohot boeloengna, doengni diboeat ma horsik dohot idjoek, doengni ditimpoesi ma horsik i toe idjoek $\mathrm{i}$, doengni dipanggantoengkon ma horsik na tinimpoesna i toe boeloe $\mathrm{i}$; doengni didongkon ma djolma ni radja i mangengge dahanan bahen nitak, dilompa ma dohot indahan, doengni didoeda ma na nienggena $i$, dibahen ma sitompion doea hoendoelan, sahoendoelan ma i dibahen na metmet, sahoendoelan na balga; doengni dibahen ma nitak goergoer sapinggan, tinaroe ni manoek sada toesi, doengni dilompa ma sitompion i, doengni disondoehi ma indahan $\mathrm{i}$ toe parboebean, doengni diboeat ma hoenik dohot boeloeng motoeng, doengni dihoenihi ma sitonga indahan $i$, sitonga indahan indang dihoenihi, doengni disapoeti ma toe boeloeng motoeng $i$, dibahen ma soengsoeng doea, tomos doea, poholan doea, djinodjoran doea; Doeng soen dipaoeli nasida saloehoet amboeamboean $i$, asa mamake be ma nasida na sahoeta $i$, nasa nadong bahenonna; doengni diparoear ma ogoeng sian bagas ni radja i, diboan

p. 239 toe alaman $i$, doengni diboan ma sian sopo gordang dohot tataganing toe alaman i, diboeat ma dohot saroene; doengni dipambahen ma 
indahan $\mathrm{i}$ dohot sitompion $\mathrm{i}$ dohot nitak $\mathrm{i}$, doengni ditangkoep ma manoek, na bontar sada, na rara sada, margondang ma nasida di tonga ni alaman $\mathrm{i}$, sai ditortorhon datoe ma manoek na doea $\mathrm{i}$. Doengni laho nasida toe tapian, sai didatdati nasida ma margondangdalan; Doeng sahat ro di tapian i, asa dipagohon ma boeloe i, doengni ditibali ma amboeamboean $i$ di lamboeng ni boeloe $i$, doengni hoendoel ma datoe $i$, doengni dipeakkon ma pagar di sihambirangna, dibahen dorma di siamoenna; doengni sai didatdati nasida ma(na) margondang $i$, doengni martonggo ma datoe $i$, ditonggo ma saloehoetna sombaon, nasa na diboto goar, ditonggo ma Boroe Saniangnaga dohot Boraspati ni tano dohot Debata na toloe; saloehoetna sigonggom portibi doemanggor on ditonggo, soen martonggo datoe $i$, asa manontor ma ibana; doeng adong toloe hali ditortorhon, ditortorhon ma sitompion $\mathrm{i}$; doengni asa mardoengdang ma ibana, asa didjooe ma goeroena moengka ni pangaseon: „Asa mari ma hamoe badia „,ili goeroengkoe Datoe Rangga ni Adji dohnt goeroengkoe Datoe „,Sorsor di Bale dohot Datoe Rindang di Baho! sian hamoe, goeroe,nami, moengka ni pangaseon! soemoen ro di ahoe on, asa tindjak ,tondjol hamoe mangadjari mamodai di ahoe on! asa dison do sitom,pion na godang dohot nitak sigoergoer on dohot pira ni ambaloengan ,,dohot indahan na djagar dohot dengke saoer dohot polong ,,dohot na nianang, dison do soengsoeng dohot tomos dohot „,hinopolan, dison do toeak tangkasan dohot pege niirisan dohot p. 240 ,manoek lahi bini, dison do hape mombang na djagar on pelean „di hamoe ma i, goeroenami, asa ima hape parsantabian di hamoe, ,paboa na hoepadjodjong hariara sampoer mamora on, ai on ma hape ,na toeboe sadarion, na magodang sadarion, na marpoesoek sadarion, „,na marranting sadarion, na mardangka sadarion, na marpaboee „,sadarion, na toeboe di Poelo Morsa on, asa on ma hape partoem,poean ni pidong ramboe marsada!" botima ninna datoe i. Doeng ni mansohot ma ibana na manontor. Doengni manontor ma saloehoetna nasida na sahoeta $i$, ganoep ma nasida manontorhon manoek $i$ dohot sitompion i dohot nitak i. Doeng ganoep nasida manontorhon, mansohot ma nasida. Doengni diseat ma manoek na doea $i$, doeng ni ditoetoengi ma toetoe, doeng pe i asa dilapa, dirior gorakgorahan i; doengni diparmasak ma toetoe; soen masak, asa ditibali ma toe pinggan, doengni dihatahon ma toe na tinonggona i, Doeng soen dihatahon, mangan ma nasida, dipapangani nasida ma dengke $\mathrm{i}$ dohot djoehoet manoek $i$; doeng soen dipangan nasida, marhata ma nasida; doeng soen marhata $i$, moeli ma nasida toe hoeta, sai margondang-

DI. 103. 
dalan ma nasida laho toe hoeta. Doeng ro di hoeta, diboan ma toe bagas ni radja ni hoeta i ogoeng i dohot tataganing i. Doengni marhobas ma naposo boroeboroe mangalompa indahan, marhobas ma naposo lahilahi mangalompa ingkajoe; soen masak sipanganon saloehoet, marpio ma soeroean ni radja $\mathrm{i}$; doengni dipioi ma pangisi ni hoeta $i$ saloehoet. Doeng ro piniona $i$, mangan ma nasida; soen p. 241 mangan, dipaoeli soeroesoeroean lahilahi ma panganan $i$; doengni disoerdoengkon djolma ni radja $\mathrm{i}$ ma handoengan toe na piniona $\mathrm{i}$, djadi marnapoeran ma nasida saloehoetna, doengni dipaloelak ma handoengan i. Doengni tole ma nasida margondang, manontor ma nasida nasa na ro ringgasna, diparimpas ma na margondang i sahat torang ari Doengni diboeat radja i ma sada babi na bolon, diborothon ma di alaman, doengni dipaidjoer ma hohas i saloehoetna toe alaman, doengni dipaidjoer ma gordang sian sopo, dihalang ma ditonga ni alaman, dirambing ma dohot ogoeng, doengni diboan ma sitompion sian bagas dohot santisanti; doengni margondang ma nasida, doengni manontor ma radja $\mathrm{i}$, ditortorhon ma santisanti $\mathrm{i}$, doeng soen $\mathrm{i}$ ditortorhon, ditortorhon ma sitompion $\mathrm{i}$; doengni dihaliangi ma pitoe hali babi inon, doengni mansohot ma ibana; Doengni manontor ma namorana i dohot parripena $i$, ganoep ma nasida na manontor i manontorhon santisanti i dohot sitompon $i$; doengni mansohot ma nasida lahilahi manontor, doengni marhobas ma boroeboroe manontor, ganoep ma nasida manontorhon santisanti $i$ dohot sitompion $i$; doengni mansohot ma nasida, manontor ma datoe $\mathrm{i}$; doeng toloe hali ditortorhon ma santisanti $i$, doeng soen $i$, ditortorhon ma sitompion $i$; Doeng ni dipangido ma toenggal panaloean dohot hobahoba, doengni marhobahoba ma ibana, dipagohon ma toenggal panaloean i di lamboeng ni babi $i$, doeng ni didongkon ma disoehoei pargonsi i pitoe hali gondang ni sitompion i. Doeng soen disoehoei dipeakkon ma sitompion i; doengni didongkon ma dibahen pargonsi i gondang hadjembar, ima gondang ni Boroe Sibaso Bolon; doengni manontor ma ibana, ditiop ma toenggal panaloean i, dihaliangi ma babi inon. Doeng ni dipasohot djolo na manontor $i$, doengni dipangido ma gondang ni

p. 242 Datoe Panoesoer, ditortorhon ma toetoe; doengni mansohot ma ibana na manontor i. Doeng ni didoedoek ma hobas i, ditaroehon ma ogoeng toe bagas, ditaroehon ma tataganing dohot gordang toe sopo; doengni diboenoe ma babi inon; doengni dilompa i ma toe bagas ni radja $i$, dilompa ma dohot indahan; doeng soen masak saloehoetna indahan dohot djoehoet $i$, marpio ma naposo ni radja $i$; doeng ro saloehoetna piniona $i$, mangan ma nasida; soen mangan, 
marnapoeran be ma nasida; doengni marhata ma nasida, soen marhata, midjoer be ma nasida sian bagas $i$; soen ma oelaon nasida $i$. Asa ima oehoem ni halak na mangase.

\section{0e HOOFDSTUK (23e „Bindoe”).}

Ia oehoem ni halak na padjongdjong langgatan, barang di sahit ni halak dioelpoek datoe, barang di gora pe, boti do:

Asa dipahoendoel soehoet ma datoena; Doeng ni didjoedjoer ma ari. Doeng djoempa ari na oeli, didjooe soehoet $\mathrm{i}$ ma datoena $\mathrm{i}$ mansipanganon, diarahon datoe i ma naposona doea halak, doengni laho ma nasida na mangan i. Soen mangan, borhat ma datoe $i$ dohot naposona $\mathrm{i}$ laho paoelihon langgatan $\mathrm{i}$; dibahen soehoet $\mathrm{i}$ ma santisanti di parindahanan, doengni didongkon datoe i ma ditompi naposona $i$ santisanti $i$, oelos ragidoep ma dibahen partompina, doengni laho ma nasida toe loboe parsombaonan; disi ma dipaoeli langgatan i. Dipamboeat naposona i ma anak ni hajoe, dilaklahi ma hajoe i; doengni didongkon ma na sahalak masimaremare dohot masisanggar dohot masiboeloengniandoedoer, dohot masiboeloengniborta dohot masiboeloengnibaringin. Doeng ro na mangalap i, dibahen nasida ma langgatan $i$, doeng soen digoelanggoelangi, ása diborothon ma maremare i, dihaliangkon. Doengni dipagohon ma hajoe sada di hoedoek ni langgatan i, toesi ma diborothon oedjoeng ni maremare $i$, doengni diborothon ma boeloeng ni andoedoer $i$, dohot boeloeng ni borta $i$, dohot sanggar $i$, dohot boeloeng ni baringin $i$, ganoep tiang ni langgatan i. Doeng soen dipaoeli langgatan i, dibahen ma boeloe songon sangkak ni pangobohi, doea dibahen, dipagohon ma $\mathrm{i}$ toe pintoe ni langgatan i, sada di siambirang, sada di siamoen; ia na di siambirang i sian tano ma dibahen, ia na di siamoen i sian aek ma dibahen; ditimpoes ma aek di boeloeng langge, disangkothon ma toe sangkak i. Doengni diboeat ma anak ni hajoe na sabotohon balgana, dibangki ma i bahen balatoek. Doeng soen dibangki, dipagohon ma i toe pintoe ). 243 ni langgatan $i$; soehar do $\mathrm{i}$ dipagohon, oedjoengna dibahen dompak toroe, bonana dompak gindjang. Doengni dihatahon datoe i ma santisanti i toe Boraspati ni tano, toe $\mathrm{Na}$ Martoea Sombaon, toe Boroe Saniangnaga, toe Debata na toloe. Doeng soen dihatahon, 
disanti ma langgatan i, ima panggongkon di begoe i, asa diipai langgatan $\mathrm{i}$ saborngin $\mathrm{i}$ oenang disegahon barang aha. Doengni laho ma nasida moeli. Doengni didongkon ma soehoet i mangengge dahanon; djadi diengge ma doea soloep. Doengni dibahen ma sitompion toloe hoendoelan, sahoendoelan na so tarhaol begoe, doea hoendoelan na oembalga; dibahen ma donganna sahoendoelan poeroerpoeroer, toloe djoeroerdjoeroer, toloe djaloedjaloe, toloe pohoelpohoel, toloe gaboergaboer, toloe pinarboetoehamboeloe. Doeng soen dipaoeli, dilompa ma i. Doengni dibahen ma nitak sapinggan. Doengni dibahen ma napoeran tinangkean opat ranting, na doea i pinarbahoelbahoel, doea pinarmoensoengnisahiri. Doeng soen masak nilompana i, dipapoerpoer ma toe sapa, doeng ni dibahen ma toe bogasan ampang saloehoetna amboeamboean $i$, dibahen ma dohot sanggoel na rara, dohot sanggoel na bontar, dohot pege saoer dohot mangemange. Doengni dilompa ma indahan; soen masak dibahen ma soengsoeng doea, tomos doea, poholan doea. Doengni didjooe ma datoe i dohot naposona i mangan, Doeng soen mangan, midjoer ma nasida toe toroe. Doeng torang ari, diarahon soehoet i ma pargonsi dohot parhobas, dilehon mangan ma i, rappon datoe i. Doengni dipaoeli soeroean ni soehoet i dengke na nianang dohot polong boanon toe balian; doeng ni ditangkoep ma manoek doea, sada na bontar, saboengan ma $i$, sada na birong, boroeboroe ma i. Doeng ni dipahe ma sada boroeboroe na marbadjoe, marabit na imbaroe ma i, dohot marmas, dohot marsimata godang, Doengni dipaloe ma ogoeng sada dohot odap dohot saroene dohot hasarhasar; doengni borhat ma nasida. Sahat ro di langgatan i, asa ditibali ma amboeamboean $i$ toe langgatan i, ditadingkon ma sitompion $\mathrm{i}$ sahoendoelan, bahen parsantabian ma $\mathrm{i}$; di amak ma dipeakkon, doeng ditibali di pinggan; doeng soen ditibali, asa hoendoel ma datoe $i$, ditiop ma manoek na doea $i$, doeng ni martonggo ma ibana, sai dipaloe pargonsi i ma gondang $i$; doeng ni sai didatdati datoe i ma na martonggo i. Soen ma ibana na marp. 244 tonggo i, dipasohot ma djolo, dohot na margondang i. Doeng ni diseat ma manoek i; Soen dirior manoek i, doengni diparmasak ma manoek i; soen diparmasak, ditibali ma toe pinggan. Doeng ni dioelakkon pargonsi i ma dipaloe gondang $i$, Doeng ni dihatahon datoe i ma manoek $\mathrm{i}$; soen dihatahon, dibagi ma $\mathrm{i}$; dilehon ma djambar ni pargonsi, dilehon ma dohot djambar ni naposona $i$, dilehon ma djambar ni soehoet. Doeng soen nasida mangan, laho ma nasida moeli, sai margondang ma nasida sahat ro di hoeta. Doeng ro di hoeta, laho ma nasida toe bagas, margondang ma nasida, doengni 
manontor ma soehoet i saloehoetna. Soen nasida manontor, dipasohot ma djolo na margondang $i$, doeng ni marhobas ma naposo boroeboroe mangalompa indahan. Ro ma soehoet i, diboeat ma babi parriari, didongkon ma dipaoeli soeroesoeroean lahililahi. Doeng soen masak indahan $\mathrm{i}$ dohot djoehoet inon, doeng ni marpio ma soeroean ni soehoet $i$; Doeng ro piniona i, mangan ma nasida; soen mangan, dioelangkon nasida ma na margondang i. Doeng ni manontor ma naposo ni datoe $i$, doengni manontor ma pargonsi, doengni manontor ma soeroean boroeboroe, doengni manontor ma soehoet $i$, doengni manontor ma datoe i. Doeng toloe ngombas, dilehon soehoet i ma sitompion di datoe $\mathrm{i}$; doengni dihatahon ma toe simangot ni goeroena na doeng mate, toe tondi ni goeroena na mangoloe; doeng soen ditortorhon, mansohot ma ibana. Doeng ni soen ma gondang $\mathrm{i}$, doengni midjoer be ma halak, diboan ma tataganing $\mathrm{i}$ toe sopo. Doeng torang ari, diboeat soehoet $\mathrm{i}$ ma manoek sada panganon ni datoe $i$; doeng masak, asa dipiohon ma datoe $i$; doeng ni mangan ma nasida. Soen mangan, disoerdoengkon ma handoengan toe datoena i. Doengni disaoethon ma datoena i; disoengkoen ma horashoras dingindingin. Doeng ni soen ma nasida mangkatai, asa midjoer ma datoena i, djadi soen ma oelaon nasida i. Asa ima oehoem ni halak na padjongdjong langgatan.

\section{1e HOOFDSTUK (24e „Bindoe”).}

Ia oehoem ni halak na martondi-eme di haoemana asa gabe nioelana.

Moesim ordangon pe i dibahen, djadi do, soen ordangon pe i dibahen, barang soen baboan, djadi do. Doengni asa disoengkoen ma datoe, doengni didjoedjoer ma ari. Doengni laho ma soeroean ni soehoet i mardengke. Doeng ro sian pardengkean i, dipaoeli ma 245 deba bahen nanianang, dibahen polong deba, na hiboel bahen dengke saoer. Doeng djoempa ari na djinoedjoerna $i$, asa marhobasi ma soehoet $i$, didongkon ma boroeboroe masisanggoel dohot masiboeloengmotoeng; doengni didongkon deba mangengge dahanon; doengni didongkon ma lahilahi masiborotan. Doengni didoeda boroeboroe i ma na nienggena $i$, dibahen ma deba nitak, deba sitompion. Songon ragam ni na padjongdjong langgatan do ragam ni na martondi eme. 
Doeng ni torang ni arina marhobas ma naposo ni soehoet $\mathrm{i}$ mangalompa indahan; doeng masak, didongkon soehoet i ma naposona $i$ marpio; djadi dipio ma saloehoet pangisi hoeta i. Doeng ro na pinio $i$, asa mangan ma nasida. Soen mangan asa marhata ma nasida. Soen mangkatai, asa didongkon soehoet i ma naposona i maningkang babi, djadi disingkang babi na bolon. Doengni marhobas ma nasida, laho ma toe haoemana i. Doeng ro di haoema, dipagohon ma borotan i, toesi ma diborothon babi i. Doengni dipatibal ma amboeamboean i saloehoetna. Doeng ni martonggo ma datoe $i$; soen martonggo, asa diboenoe ma babi inon, doeng ni diparmasak ma djoehoet inon, masak ma dohot indahan, doengni mangan ma nasida. Soen mangan, disoerdoengkon djolma ni soehoet i ma handoengan; doengni marnapoeran ma nasida saloehoet; soen marnapoeran, asa marhata ma nasida. Doeng soen nasida na marhata $i$, dipaboa datoe $i$ ma roboe ni hapandeanna i: ,Botima i amang, hamoena soehoet i! bege hamoena „hatangkon! ba, ia roboe ni hapandeankon: pitoe borngin on na so ,,djadi degeonna halak toe haoema on di balik ni hamoe soehoet $i$; „ba, molo toeng didege halak toeson dibogasan sipitoe borngin on, „barang sadia hasoedaanmoe soehoetnami, nasai ma gararonna; hape „,molo na poelik hoeta manompas roboe, ingkon marhasahatan di ,gondang do panoelana bahenonna”, botima ninna datoe i. Doeng ni dipatoebegehon soehoet i ma toe isi ni hoeta i : „Botima i, amang! „hita na di haoema on, atik adong na so dohot dakdanakna, dipaboa „, be bodari roboe nidok ni datoe i: ,Soehoetnami! bege hata ni roboe

p. 246 ,hapandeankon!” botima ninna. On pe, amang! sitoean na torop! ,,bege hamoe ma roboe nidok ni goeroe i!" botima ninna soehoet $\mathrm{i}$. „Olo ma toetoe!" botima didok na torop i. Doeng soen nasida na marhata i, moeli ma nasida toe hoeta, soen ma oelaonna i. Asa ima oehoem ni halak na martondi eme.

\section{2e HOOFDSTUK (25e „Bindoe”).}

Ia oehoem ni halak na padalan parsili, barang di sahit, barang di saem sitasita.

Molo tombal oensim i do dihatahon, indadong marsitompion, tombal santisanti ma dihatahon parsantabianna. Doeng ditaroehon toe balian parsili i, tombal pira ni manoek ma diboeat bahen oepaoepana, i ma parsili rompar-rompar goarna. Hape molo na sopar nipi ni 
halak, barang gorakgorahan na sopar, asa diboeat ma gaol na balga dohot maremare dohot boeloeng ni bagot na matoras bahen mombang. Doengni digana ma pisang $i$, dipaoeli ma mombang $i$, dirigai maremare $i$; didongkon soehoet $i$ ma na mamboeat anak ni andoelpak toe balian. Doeng ni didongkon ma djolmana i mangengge dahanon sagantang; doeng soen diengge dohot didoeda, asa dibahen ma sitompion na oembalga sahoendoelan, na so tarhaol begoe sahoendoelan, na so tarhaol begoe sahoendoelan. Doeng soen masak, asa didjooe ma datoena $\mathrm{i}$; diboan ma parsili i toe bagas, dohot maremare i, dohot mombang i, dohot hajoe andoelpak i. Doeng loehoet ro di bagas amboeamboean $i$, asa dihishis naposo ni datoe $i$ ma te ni hoedon, doengni dihoebangi ma parsili $\mathrm{i}$; doengni dibahen ma sitompion na metmet $\mathrm{i}$ toe mombang $\mathrm{i}$, ditibali ma toe pinggan sitompion na oembalga $i$; doeng ni diirisi ma pege toe boeloeng motoeng, dibahen ma toeak toe tandoek. Doeng ni dipangido ma rere sian soehoet $i$, disapoet ma parsili $i$; doengni ditapolhon ma maremare $i$ toe andora ni parsili i; doeng ni ditapolhon moese oesoengoesoeng i toe andora ni parsili i. Doeng ni dipangido datoe i ma santisanti toe soehoet $i$, djadi dibahen ma di parindahanan; doengni martonggo ma datoe $i$. Soen ibana martonggo, disoelangi ma parsili i, digotil ma saotik sagoesagoe $i$ dohot timpa $i$, dibahen ma toe baba ni parsili $i$, doengni didjompoet ma pege $i$, dibahen toe baba ni parsili i; doengni ditiris-

p. 247 hon ma toeak na di tandoek i. Doeng soen disoelangi, asa djongdjong ma datoe $\mathrm{i}$, ditoedjoengkon ma hain bontar toe oeloena, doengni ditoendjang ma papan toloe hali, marmioel ibana toloe hali, doengni diendei ma parsili i, disisikki; ,oeloebalang” ma goar ni parsili i didok datoe i. Doeng soen diendei, asa mamoersik ma nasida soehoet i; doeng soen mamoersik, ditaroehon naposo ni datoe i ma toe balian, di poedi ni siboan-parsili i ma datoe i. Doeng dipeakkon parsili i, doeng ni didjooehon ma doea hali, doengni laho ma nasida moeli. Sahat ro dibagas, asa didjompoet ma dahanon toe oeloe ni soehoet $i$. Doeng ni hoenđoel ma datoe $\mathrm{i}$; doeng ni diboeat soehoet i ma manoek na hatioeran na gorakgorahan, doeng ni dilehon ma toe datoe $i$ dohot napoeran na hombang sangatoepan. Doengni dimangmang datoe $i$ ma manoek inon. Soen dimangmang, asa diseat ma manoek i, doengni ditoetoengi ma toetoe; soen ditoetoengi, asa dilapa ma manoek i; doengni ditilik ma gorakgorahan $\mathrm{i}$; soen $\mathrm{i}$ ditilik, disintak ma boetoeha ni manoek $i$; doeng soen disintak boetoehana i, diparmasak ma djoehoet manoek inon dohot boetoeha $i$; soen masak djoehoet $i$, masak dohot indahan, asa didimpoe ma indahan $\mathrm{i}$ toe pinggan, 
doengni ditibali ma toesi djoehoet manoek inon. Doeng ni dibahen sadanari panganan hira di datoe. Doengni marpoengoe ma nasida soehoet i saloehoetna. Doengni dioepahon datoe i ma toe partondion ni nasida soehoet $i$ saloehoetna. Soen dioepahon, mangan ma nasida, mangan ma datoe i dohot naposona i. Doengni dilehon soehoet i ma oepa datoe „na margoar” ni manoek i: sada haehaena, sada pamoengkoeri, sada sihombang. Doeng soen nasida na mangan i, asa marnapoeran be ma nasida. Soen marnapoeran, asa disoengkoen soehoet $i$ ma horashoras dingindingin; doengni dipaboa datoe i ma toetoe. Soen ma nasida na marhata $i$, midjoer ma datoena $i$ dohot naposo ni datoe i, soen ma oelaon i. Asa i ma oehoem ni halak na padalan parsili.

\section{3e HOOFDSTUK (26e „Bindoe”).}

Ia oehoem ni halak na padalan sipaimbar, barang manoek na soemopsop tinaroena niimbarna, barang biang marsage di bagasna niimbarna, barang oelok marsahe niimbarna, barang ilik marompaompa, barang goerampang marompaompa, barang siapor, barang djolma marsahe niimbarna. Doeng ni asa disoengkoen ma datoe, barang andigan ari na denggan; doeng dipaboa datoe $i$, asa marp. 248 dengke ma soehoet $i$, doeng ni dibahen ma deba nanianang, deba bahen polong. Doeng ni djoempa ma ari na djinoedjoer ni datoena i; asa dipio ma i mangan; diarahon datoe i ma naposona doea halak; doeng ni laho ma nasida na mangan i. Soen mangan, marhata ma nasida; disoengkoen soehoet i ma, barang aha amboeamboeanna; doengni dipaboa datoe i ma saloehoet. Doeng ni laho ma naposona i mamoeloeng, dipaboa ma saloehoet sipoeloengon ni naposona $i$. Doeng ni dipangido ma hadjoet sian soehoet $i$, doengni laho ma nasida toe balian, diboeat nasida ma boeloeng ni tabartabar, pitoe boehoe na pitoe boeloeng ni sibalikangin, pitoe boehoe na pitoe boeloeng ni andoelpak; pitoe boehoe na pitoe boeloeng ni sisangkil; pitoe boehoe na pitoe boeloeng ni sipilit; pitoe boehoe na pitoe boeloeng ni sipalis; pitoe boehoe na pitoe boeloeng ni siroengkas; pitoe boehoe na pitoe boeloeng ni sibabolhas, pitoe boehoe na pitoe boeloeng ni langge; sihoek doea; boeloeng ni siling doea; boeloeng ni bira doea; siarang doea. Doeng dapot saloehoet dipoeloeng nasida, diboan ma toe bagas ni soehoet i. Doeng ni didongkon datoe i ma mangengge dahanon soehoet i. Doeng ni diengge ma toloe bale. 
Doeng ni didoeda ma toetoe. Doeng soen didoeda, asa didjooe ma datoe i. Doeng ni dipaoeli ma djolo sitompion sahoendoelan. Doeng ni asa dipangido ma sian naposona $\mathrm{i}$ boeloeng ni bira $\mathrm{i}$ dohot boeloeng ni siling doea $i$, doeng ni dipaoeli ma nitak i. Molo djolma niimbarna, pinardjolma dibahen nitak $i$; molo biang do niimbarna, songon biang ma dibahen; molo manoek do niimbarna, songon biang ma dibahen; molo manoek do niimbarna, songon manoek ma dibahen; molo oelok do niimbarna, songon oelok ma dibahen; molo ilik do niimbarna, songon ilik ma dibahen; molo goerampang do niimbarna, songon goerampang ma dibahen; molo siapor do niimbarna, songon siapor ma dibahen. Doeng soen dipaoeli, asa dipangido ma andoeri na boeroek sada, toesi ma dipapoengoe poeloengpoeloengan i. Doeng ni ditibali ma sitompion i toe pinggan; dibahen ma toe saoan na nianang dohot polong $\mathrm{i}$, alai poelik be do dibahen ingananna. Doeng ni dipangido ma santisanti toe soehoet $i$; djadi dibahen ma toe parindahanan. Doeng ni ditangkoep soehoet i ma sada manoek saboengan na hatioeran gorakgorahan, doeng ni dilehon ma toe datoe i, doeng ni asa martonggo ma ibana; soen martonggo, p. 249 asa disoelangi naposona i ma poeloengpoeloengan i saloehoetna; doeng ni asa martompitompi ma datoe $i$, ditiop ma manoek $i$, doeng ni martabas ma ibana; soen ditabasi, asa mamoersik ma nasida soehoet i saloehoetna; doeng soen mamoersik, ditaroehon naposo nidatoe i ma toe djolo ni harbangan. Doeng ni moelak nasida toe hoeta. Doeng ni diseat ma manoek $\mathrm{i}$; doeng soen diseat dohot ditoetoengi, asa dilapa ma toetoe; doeng ni dirior ma gorakgorahan i; doeng soen dirior, diparmasak ma manoek inon; doeng soen masak djoehoet i dohot indahan, asa didimpoe ma toe pinggan; doeng ni ditibali manoek $\mathrm{i}$ toe indahan $\mathrm{i}$, doeng ni didimpoe ma sadanari panganan hira panganan ni datoe, Doeng ni marpoengoe ma nasida soehoet $i$ saloehoet, doeng ni dioepahon ma manoek i toe partondion nasida. Doeng soen dioepahon datoe $i$, mangan ma nasida, mangan ma datoe $\mathrm{i}$ dohot naposona i. Doeng ni dilehon soehoet i ma djambar ni datoe. Doeng ni soen ma nasida mangan i, marnapoeran be ma nasida. Doeng ni soen ma nasida mangan i, marnapoeran be ma nasida. Doeng ni marhata ma nasida, disoengkoen ma horashoras dingin-dingin toe datoena i. Doeng ni soen ma nasida na marhata i, midjoer ma datoe i dohot naposona i; djadi soen ma oelaonna i. Asa i ma oehoem ni halak na padalan sipaimbar. 


\section{4e HOOFDSTUK (27e „Bindoe”).}

Ia oehoem ni halak na paoeli pagar.

Ia pagar sahoeta, soede ma na sahoeta i margoegoe dahanon dohot manoek; doeng ni mardengke ma nasida na sahoeta i. Doeng ni djoempa ma ari na oeli, asa masitaroehon dahanonna ma pangisi ni hoeta $i$ toe bagas ni radja i. Doeng ni dilompa naposo ni radja i ma dahanon $\mathrm{i}$, dilompa naposona lahilahi ma ingkajoe godang dohot dengke. Doeng soen masak sipanganon, asa marpio ma naposo ni $\operatorname{radja} i$, dipiohon ma pangisi ni hoeta $i$ saloehoet. Doeng ro na piniona $i$, mangan ma nasida. Soen mangan, diengge naposo ni radja i ma dahanon; doeng ni dibahen ma sitompion sahoendoelan; doeng ni dilompa ma toetoe; soen masak, dibahen ma toe hadangan; dohot santisanti, dohot toeak ditandoek, dohot pege, dohot miak, dohot badja dohot bonang. Doeng ni dipahe ma datoena pamoeloeng na so haboeboehan, dibahen ma i martompitompi ragidoep, marabit simarindjam, marhohos soeranti, marpiso djonap,

p. 250 martoengkot toenggal-panaloean. Ia datoe i martoengkot hoedjoerhinandjar ma i. Doeng ni borhat ma nasida na mamoeloeng i; deba masiboeloe, deba masimaremare, deba masiidjoek; ia sanggesangge dohot bangoenbangoen, di pasigadong ma ditonahon. Doeng ni di siharoear do nasida, pintor sai didatdati nasida do mamboeat poeloengpoeloengan i. Doeng soede diboeat nasida poeloengpoeloengan nasa na dapotsa, laho ma nasida toe bona ni pisang sitabar; doeng ni dipagohon ma toenggalpanaloean di siamoeanna, hoedjoer-hinandjar di siambirang; doeng ni ditibali ma sitompion i, dohot toeak $i$, dohot pege $i$, dohot santisanti $i$ dohot pardoepaan, doeng ni dihatahon ma $i$. Soen dihatahon, asa diasap ma bona ni pisang $i$; soen diasap, asa dililithon ma bonang $i$ toe bona ni pisang i. Doeng ni dilompas ma langkat ni pisang i doea djari bidangna, maropatsoehi ma dibahen, doengni didjoengkit ma dohot oedjoeng ni djonap $\mathrm{i}$. Doeng madaboe toe oelos $i$, asa ditilik ma i: molo pintor ,poeloe”, na oeli ma i; hape molo ,lia”, dipadoeahali ma didjoengkit; dipasaor ma pangompahanna i toe santisanti i. Doeng ni dioengkap ma lambak ni pisang $i$; disoepak ma bidangna opatopat djari, disoepak gindjangna poelapogoe; dihoroti ma doea hali pitoe toropna. $\mathrm{Na}$ doeng soen i, moeli ma nasida toe hoeta. Sahat ro di hoeta, ditaroehon ma poeloengpoeloengan binoanna i toe bagas ni radja i. Doengni disoerati nasida ma boeloe $i$, doea be sabagas, sada didjolo ni roema, sada dibagasan bagas. Doeng ni dipambahen ma songon sangkak 
oedjoeng ni pargagaran i. Doeng ni bot ma ari; dipiohon soehoet $\mathrm{i}$ ma datoe i dohot pamoeloeng i saloehoetna, mangan ma nasida. Soen mangan, asa diradja nasida ma poeloengpoeloengan $i$, dibahen ma radjaradjaan na ,toempak sala" dohot bindoe-matoga dohot pinarpoejoean. Doeng soen diradja, dipabongot ma toe bogasan ampang. Doeng ni ditangkoep ma manoek sada na hadenggananna manoekgantoeng, saboengan ma i; ditangkoep manoek mira sipamoetoeng, doeng ni diboeri ma pat ni manoek $\mathrm{i}$ dohot toektoekna, dipainoem ma i; doeng ni diihoti ma patna hambirang; doeng ni dipahembang ma amak di paraparasoban; doeng ni diampehon ma toesi poeloengpoeloengan $\mathrm{i}$; doeng ni diborothon ma manoek $\mathrm{i}$ toe lamboeng ni ampang i; dipagohon ma hoedjoer i di siambirang, dipagohon toenggal-panaloean di siamoen; doeng ni dipeakkon piso djonap $\mathrm{i}$; doeng ni ditibalhon ma di lamboeng ampang i sitompion, dohot santisanti, dohot toeak di tandoek, dohot pege niirisan, dohot polong, dohot nanianang. Doeng ni diparsomahon ma i toe Boraspati ni tano, toe Onggoeng ni hoeta, toe na martoea sombaon, toe Boroe Saniangnaga, toe Boroe na Mora, toe ari na toloepoeloe, toe boelan na sampoeloedoea, toe badia ni goeroena na mangoloe, toe simangot ni goeroena na doeng mate, toe Debata na toloe. Doeng soen diparsomahon, asa disoelangi ma poeloengpoeloengan i, dohot piso i, dohot toenggalpanaloean i, dohot hoedjoer i. Doeng soen disoelangi, asa didaik ma sitompion $\mathrm{i}$ dohot santisanti $\mathrm{i}$, doeng ni midjoer be ma nasida toe toroe, modom be ma nasida. Doeng torang ari, asa dipahembang ma amak ditonga ni alaman; doeng ni dipaidjoer ma sian bagas poeloengpoeloengan $i$ dohot toenggal-panaloean $i$, saloehoet nasa amboeamboean $\mathrm{i}$ diparboan toe toroe; doeng ni diradja ma andoeri; doeng scen i diradja, dibahen ma pardaoepaan; doeng ni diasap ma djo!o lageloging. Soen i didaoepa, diasap ma andoeri parhalebatan i; doeng ni diasap me oente tondoeng $i$ dohot raoet tongontongon $i$, Soen diasap, dipahembang ma lage $\mathrm{i}$, doeng ni dipeakkon ma andoeri $\mathrm{i}$ toe atas ni lage i, doeng ni dipeakkon ma oente $\mathrm{i}$ toe atas ni andoeri, rap ma $\mathrm{i}$ dohot raoet $\mathrm{i}$; doeng ni dihaloengkoephon ma hain bontar toe oente $\mathrm{i}$; doeng ni ditabasi ma toetoe; soen ditabasi, asa dioengkap ma hain na bontar $i$; doeng ni dibagihon ma oente $i$; dilehon ma djolo toe radja $\mathrm{i}$ doea: sada $\mathrm{i}$ oente ni lahilahi, sada oente ni boroeboroe, doeng ni dilehon toe namora doea; doeng ni diganoepi ma saloehoet pangisi ni hoeta $i$, sai doea be ma saripe: sada oente ni lahilahi, sada oente ni boroeboroe; doeng ni dilehon ma toe radja i oente ni hoeta; doeng ni dilehon ma toe naposona $\mathrm{i}$ oentena dohot 
oente ni datoe; dilehon ma oente ni pamoeloeng; ditadingkon ma

p. 252 sada di parindahanan i, hira oente ni pagar ma i. Doeng ni tole ma radja $i$, disahadathon ma toe tondi ni nasida lahilahi oente nasida $\mathrm{i}$, doeng ni dilehon ma toe datoe i. Doeng ni dihorot ma diatas ni andoeri i; doeng soen dihorot, molo nadong oelpoehan, dipaboa ma toe radja i. Doeng ni dilehon ma oente ni boroeboroe ni nasida saripe. Doeng ni dihorot datoe i ma; soen dihorot, dipaboa oelpoehanna. Doeng ni masiparlehon oentena ma nasida na soehoet i. Doeng soen i asa dihorot ma oente ni hoeta. Doeng ni soen, asa ditiop datoe i ma djonap i, Doeng ni dipeakkon ma sangkalan, doeng ni ditallik ma oente ni pagar i; disi ma diboto, barang na margogo pagarna i, barang na so margogo; molo rap ,poeloe” do tampoekna dohot parboengaanna, na oeli ma i, ,,simargogo" ma goarni; hape tampoekna pe „poeloe”, parboengaanna ,lia”, na oeli do i, ,oente „toeboe” ma goarni ; molo „lia” saloehoetna, hoemoerang do gogo ni pagar i; molo „poeloe” parboengaanna, „lia” tampoekna, na roa ma i, ima na „rangkaproengkap” ma goarni. Doeng soen nasida martondoeng, asa diseat ma manoek i. Doeng ni digantoeng datoe i ma toetoe; doeng mate, asa dirior ma pat ni manoek i, dohot omboeloena, dohot habongna; doeng soen dirior, ditoetoengi ma toetoe; soen ditoetoengi, dohot dilapa, asa dirior datoe i ma gorakgorahan i; soen dirior, diparmasak ma manoek i. Doengni digatgat ma poeloengan i saloehoet; doengni sai marsoeroeng ma nasida saloehoet. Soen ma digatgat nasida, masak ma manoek i; doengni dipangido naposo ma indahan toe bagas, doengni ditibali ma manoek $\mathrm{i}$ toe indahan i; doengni dihatahon ma i toe na tinonggona i. Doengni asa dialap ma nanggar toe bagas. Doengni disoelangi ma poepoek ni pagar i dohot hoedjoer i dohot toenggalpanaloean $\mathrm{i}$ dohot piso $\mathrm{i}$ dohot hoedjoer $\mathrm{i}$ dohot toenggalpanaloean $\mathrm{i}$ dohot piso $\mathrm{i}$ dohot nanggar. Doengni martabas ma datoe $i$, ditiop naposona $i$ ma nanggar $i$, sai dipasakpasak ma i, marsoeroeng ma nasida saloehoet. Soen martabas datoe $i$, mansohot ma dohot na marsoeroeng $i$; masipambahen toe p. 253 parpagaranna ma nasida sahoeta $i$; doengni dipagohon ma didjolo ni bagasna parpagaran na goemindjang, ia na djoempok di bagas ma i; doengni digantoengkon ma maremare di harbangan $i$, dohot boeloeng ni hatoenggal, dohot boeloeng ni silindjoeang, dohot sipilit, dohot sisangkil. Doeng soen songgop be di bagasna, asa marpio ma naposo ni radja i mangan, doengni mangan ma nasida saloehoetna. Soen mangan, asa disoerdoengkon ma handoengan toe na pinio $i$, toe datoe sada. Doengni marhata ma nasida, disaoethon radja i ma 
datoe i. Doeng soen saoet na sipanganon, disoengkoen radja i ma horashoras. Doengni masisoengkoen di ibana ma pangisi ni hoeta i saloehoetna. Doeng soen dipaboa datoe i angka pandohan ni oentena, dipaboa ma roboe ni pagar: ,sintap toloe borngin on na so djadi „marbada; molo toeng marbada dibogasan ni sitoloeborngin on, ,maroetang sada manoek mira, doea soloep dahanon; ba, ima oetang„na! Sintap sadarion na so djadi mangongkal tano! ba, ima roboe ,ni pagarta i di hita hoeta on! Ia toe halak roear, na soada marton,doeng toe hoeta on, na so djadi do i masoek; molo toeng masoek „ibana inda soemoengkoen roboe, inda dong na martingki oetangna, „gogonta do martoenggoe!" botima didok datoe i. Doengni soen ma nasida na marhata $i$, midjoer be ma nasida; Sintáp toloe borngin sai tabasan ni datoe ma pagar i. Asa ima oehoem ni halak na paoeli pagar sahoeta: ianggo pagar sabagas, tombal na sabagas $i$ do sihasoesahon i.

\section{5e HOOFDSTUK (28e „Bindoe”).}

Ia oehoem ni halak na paoeli mombang-tolak.

Asa mardengke ma djolo nasida na sahoeta i. Doeng adong be dengke soelasoelana, asa masiboeat mombangna ma sahoeta i, ganoep ripe masiengge dahanonna. Doeng soen be dipaoeli mombang i, asa diboeat ma boeloe bahen sangkak. Doeng botari, asa masitibali mombangna ma nasida. Doengni asa didongkon ma naposo dohot na metmet mangarop toe balian, doeng ni haroear ma nasida sian hoeta,

p. 254 diparboan be ma mombang i; borhat ma dohot siboanbodil doea halak. Doeng ro di balian, dibaririthon ma, dipagohon mombang i; doengni masihatahon di (i)bana ma nasida saloehoetna. Doeng soen dihatahon, dipaloe ma bodil na doea i, Doengni hehe ma na mangarop $i$, dipamboeat ma pangisi ni mombang $i$, doengni dilele ma na mamboeat $\mathrm{i}$; doengni laho ma marlodjongi nasida mangaloeahon binoeatna $i$; doengni moeli ma toe hoeta nasida na mangalele $i$; oempoedi ma na mangarop $i$, mamangani binoeatna $i$; ai so djadi i boanonna toe hoeta. Doeng soen dipangan nasida, moeli nasida toe hoeta. Doengni modom be ma nasida. Ima oehoem ni halak na paoeli mombang tolak. 


\title{
ZEDEN, GEWOONTEN EN WETTEN VAN NAI POSPOS
}

\author{
(p. 205-254).
}

\section{1e HOOFDSTUK (6e „Bindoe”).}

p. 205 Hetgeen te doen staat aan iemand aan wien een zoon of een dochter geboren wordt.

Als zijn vrouw in weeën is gekomen, en naar het vuur verlangt (waarvoor zij zich neerzetten zal), dan moet er voor de middenruimte der woning een mat gespannen worden als afschutting, opdat, als er mogelijk menschen op het dorpsplein voorbijgaan, zij de barende vrouw niet zullen kunnen zien. Verder moet er op de middenplank van den vloer bast van den toropboom uitgespreid worden, opdat deze dienen kan tot ligplaats voor de barende vrouw. En tenslotte wordt de vrouw geroepen die deskundig is in het masseeren (de vroedvrouw). Als deze in het huis van hem die haar riep is aangekomen, wordt het betelzakje aan haar toegereikt, en neemt zij betel tot zich, waarna ze zich tot den heer des huizes wendt met de vraag: „Gij hebt mij thans de betel aangeboden, wat „hebt gij mij nu te zeggen?” (zoo zegt ze). „Wel”, aldus de heer des huizes, ,al hadde ik u niet van mijn betel gegeven, ik zou u ,omtrent de ziekte van mijn vrouw hier willen raadplegen, en u ,,vragen of het te verwachten is, dat zij spoedig bevallen zal, opdat ,,ik het met juistheid wete!" (Hierop zegt de vroedvrouw :) „Juist, „mijnheer, als dat het geval is, waarover gij mij wilt raadplegen, ,welaan, laten we dan ons vertrouwen stellen in de geesten van de ,,vroedvrouwen vàn voorheen en in den geest van mijn leermeesteres ,die mij in de wetenschap der verloskunde is voorgegaan, en van hen ,hooren of zij (die kunde) deugdelijk en juist aan mij heeft overgebracht”. Vervolgens drukt ze oebi-bladeren op een bord uit, doet daar tweemaal zeven korrels rijst bij, zoomede zeven stukjes kurkuma, benevens een maat water, en daarna wrijft ze de buik van de barende in. Aan den wichelaar geeft ze voorts opdracht, om een middel ter verlichting van de verlossing te maken. Als het kind ter wereld gekomen is, en ook de nageboorte heeft plaats gehad, laat 
de vader van de jonggeborene uit bamboe een mesje snijden, en als dit mesje (vervaardigd) is, het door een meisje in de woning brengen, waarop genoemd meisje het aan de vroedvrouw aanreikt; deze vraagt nu nog om een aardknol (oebi) en een touwtje, meet dan een stuk van den navelstreng af tot een lengte van drie vinger (-dikte) van af den navel, bindt den navelstreng dáár, tot waar ze dien afgemeten heeft, af, neemt de oebi op, legt die onder den navelstreng, en snijdt deze dan met het bamboemesje door. Het afgesneden stuk doet zij voorts in een nieuwe rijstzak, en laat die onder het (op palen staande) huis begraven; den (zak met den) navelstreng laat ze daartoe uit het kleine raampje in den achterwand van het huis neer, waar het door den persoon die het begraven zal, in ontvangst genomen wordt, en op deugdelijke wijze begraven, (zoodat varkens en honden er niet bij kunnen komen). Nadat hij zich van zijn taak gekweten heeft, wascht hij zich. Vervolgens baadt de vroedvrouw de kraamvrouw, en gaat deze na het bad bij het vuur zitten, terzijde van de kook-plaats. Een ouder meisje neemt nu de jonggeborene op, en solt ermede zooals men het pasgeboren kinderen doet, daarbij uitroepende: „Kom, jullie kwade geesten, en jullie ,tijgers, en jij bliksem, kortom, jullie allen, die menschen doodt! ,neemt dezen kleuter maar weg! wanneer jullie hem nu niet dadelijk „,weghaalt, dan krijgen jullie hem nooit of te nimmer meer!"; daarop geeft ze het kind aan de moeder, die het dan bij het vuur warmt (zelve met den rug naar het vuur zittende, zooals kraamvrouwen doen). Vervolgens gelast zij een vrouwelijke bediende te koken; als de rijst gaar is, noodigt zij alle vrouwen, die haar oppasten, uit, ie eten. Is het eten afgeloopen, dan gaan de menschen weg. En nu gaat de vader van de jonggeborene houtblokken halen (zooals men voor een vrouw in het kraambed gebruikt, opdat ze warm blijft;) en wel haalt hij simartoelan- en alngithout om tot brandhout te dienen; jong hout neemt hij daarvoor, droog hout mag hij niet aanwenden voor de verwarming van zijn vrouw. Als de jonggeborene p. 207 twee nachten oud is, laat de vader den wichelaar komen, en neemt één haan (1), die door zijn grootte in aanmerking komt, om als wichelhaan te dienen, zoomede één, die (wat) grooter is; de klein(st)e wordt ,sampoer pandidion” genoemd, en dient den wichelaar tot het lezen van de voorteekenen; daaruit maakt hij op, of aan de jonggeborene een lang leven beschoren is, of niet; de groot(st)e haan noemt men de ,bangoen-bangoen”. Voorts noodigt hij (de vader) ook de vroedvrouw uit tot een etentje te zijnen huize, waarbij 
hij dié stukken van de haan, die ,een naam hebben” (d.w.z. de beste stukken) en naar hun ieders bediening hun toekomen (aan den wichelaar en de vroedvrouw) toebedeelt; aan de vroedvrouw daarnevens een betelpruim in schuitsgewijs gevormd betelblad; en aan den wichelaar één poot, zoomede een pijp van bamboe gevuld me een mengsel van de bast van de tolongbistik en tabak, zooals den wichelaar toekomt. Nadat zij gegeten hebben, wordt door hen nog het een en ander gezegd; waarna wichelaar en vroedvrouw afscheid nemen. Indien er ,vrouw's-verwanten” (2) zijn, dan behooren deze de kraamvrouw eten te komen brengen en iets te offeren voor de levensziel van de jonggeborene (3), tevens medebrengend een kleed om er het kind in te dragen; en dan geeft de vader aan zijn vrouw'sverwanten een maaltje vleesch; en zegt hij hun een Spaansche mat toe als „piso" (4) (hier: tegengeschenk); waarna de vrouw's-verwanten huiswaarts keeren. Als er ,dochter's-verwanten” zijn, en deze eten komen brengen voor de kraamvrouw, tevens iets of ferende voor de levensziel van het kind, en een Spaanschen dollar brengen als „piso" (hier: als geschenk ter verkrijging van zekere rechten) voor hùn ,vrouw's-verwanten”, (als zij dàt doen) dan kan, als er later eens bij den vrouw's-verwant een meisje geboren wordt, dit niet (meer) uitgehuwd worden aan derden, zonder dat die ,dochter'sverwanten" geraadpleegd zijn; eerst als de vrouw'sverwant voor het geval komt te staan, dat het meisje niet uit te huwen is, mag hij haar elders uithuwen. Wanneer hij die dochter zou uithuwen, zonder vooraf met zijn ,,dochter'sverwanten” overlegd te hebben, dan heet hij trouwbreuk (5) gepleegd te hebben, en komt hij in vijandschap met zijn dochter'sverwanten. Ziedaar de regelen, waaraan hij, bij ons, zich houde, wien een kind geboren wordt.

\section{2e HOOFDSTUK (7e „Bindoe”).}

Hetgeen te doen staat als men een kind voor de eerste maal na de geboorte buiten het dorp brengt (6).

Men laat den wichelaar een (gunstigen) dag bepalen, op dien gunstigen dag nu brengen de ouders van het kind het voor het eerst p. 208 naar buiten. Men weekt een kop rijst en stampt het tot meel; dit wordt in een nieuwe rijstzak gedaan; deze (rijstzak) stopt men voorts in een vierkanten rotanbuidel om over den schouder te dragen (op 
den rug of op zij); vervolgens gelast men iemand, uit bamboe een mes te snijden, dat als kenteeken moet dienen voor het voor 't eerst buiten het dorp gebrachte kind, zoodat voorbijgangers weten dat het (kind) van mannelijken kunne is; als het een meisje is, dat voor het eerst buiten het dorp gebracht wordt, neemt men een lepel als kenteeken. Voorts vraagt de heer des huizes aan den wichelaar, waar volgens deze de (kwade) geesten op den loer liggen. Als zich kwade geesten bevinden op de badplaats, dan keert men halverwege terug; bevinden de geesten zich op den weg, dan keert men reeds bij de dorpspoort op zijn schreden terug. Als men met het kind bij de dorpspoort gekomen is, moet men driemaal een handvol van het (meegebrachte) meel op een blad leggen, benevens een betelpruim, en een bloemensmuk van drie twijgen, (om de kwade geesten gunstig te stemmen); op elken zijweg legge men wat meel neer; wanneer men halverwege (de badplaats) gekomen is, legge men (wat) meel in het midden van den weg; en als men tenslotte tot aan de badplaats gekomen is, dan legge men wat meel aan den bovenstroomschen kant van de badplaats, tezamen met het kenteeken. Als men van (het ,naar buiten brengen naar) de badplaats" in het dorp teruggekeerd is, geeft men van het in de rijstzak overgebleven meel eerst wat aan het kind ,met den schoonen naam” (7), en dan pas aan alle kinderen van het dorp die naar het dorpsplein gekomen zijn; eerst nadat aan elk hunner meel is toebedeeld, kunnen zij, die aan den eersten uittocht uit het dorp hebben medegedaan, het huis weer binnengaan. Dan hoopt men wat rijst op een bord, legt er twee stuks gekookte visch op, met citroenzuur en curcuma toebereid (de lengte van die vischjes moet een handspan zijn;) (8) en die offert men dan voor (het heil van) het kind (aan de geesten van voorouders, van overleden hoofden, e.a.). Daarna eerst gaat men (zelf) tot den maaltijd over. Dit zijn de regelen waaraan hij zich houden moet, die zijn kind voor het eerst na de geboorte uit het dorp brengt.

\section{3e HOOFDSTUK (8e „Bindoe”).}

p. 209 Regels die gelden voor hem, die aan een kind een nam wil geven.

Indien de vader (9) het zich veroorloven kan, dan doet hij dat op grootsche wijze en geeft hij bij de naamgeving aan zijn zoon of dochter een vleeschmaal. Als het vleesch gaar is, noodigt hij den datoe uit met een ,nog onbedorven” (10) kind. Voorts doet hij een

Dl. 103. 
soloep (maat) rijst in een nieuwe rijstzak, van een zekere lange breedbladige rietsoort gevlochten; voegt daar een betelpruim bij, gevormd als de snuit van een rat, en drie pennen van een stekelvarken waarmede hị de rijst(zak) vaststeekt; vervolgens haalt hij een groote potscherf (als wierookvat) (11), vouwt een „oelos ragidoep” (een bijzonder fijne kain) op, en legt dat voor den wichelaar neer; het „nog onbedorven” kind zet zich neer aan de rechterzijde van den wichelaar. $\mathrm{Nu}$ noemt de vader den naam van zijn kind, en dan treedt de wichelaar op; hij neemt (met 3 vingers) een greepje van de rijst, legt dat in de hand van het kind, en telt de korrels. Wanneer deze (juist) op een even (12) getal uitkomen, dan (is dit een gunstig teeken en) wordt aan het kind de naam gegeven, die door den vader was opgegeven; ,,even” (= gunstig) zijn de rijstkorrels, indien het aantal van die rijstkorrels, daartoe vier bij vier op één hoopje gelegd, op even uitvalt; als „even” (= gunstig) door hun (aantal) hoopjes beschouwt men het als er (juist) drie, of vier, of vijf, of zeven, of negen hoopjes uitkomen. Nadat hij de rijstkorrels geraadpleegd heeft ( $e n$ bevonden heeft aan de eischen te voldoen), strooit de wichelaar sle rjistkonels over her hoord' van het kind, alsmede over het hoofd van de moeder en het hoofd van den vader. Hierna gaan ze gezamenlijk eten, het heele dorp, allen die mee willen doen. Na dezen maaltijd neemt de vader het woord en verzoekt hij wichelaar en vroedvrouw hun zegen uit te spreken. Zoo is het protocol bij de naamgeving.

\section{4e HOOFDSTUK (9e „Bindoe”).}

Hetgeen te doen staat. aan hem, die het kwaad wil afweren bij het voor de eerste keer afknippen van het (hoofd)haar

\section{van $\mathrm{zij} n$ kind.}

Indien de vader de kosten daarvan bestrijden kan, behoort hij een varken te slachten; zou hij zich dat niet kunnen veroorloven, dan kan hij volstaan met een kip en visch. „Iemand uit de familie van „zijn vrouw's-verwanten, die het ,padao-gial” moet doen en daarom "voor het kind als 't ware een peet is", wordt uitgenoodigd om het

p. 210 haar van het kind te knippen; er wordt een mat naar het dorpsplein gebracht en daar uitgespreid; waarna de vader zich gereed maakt, zijn kind naar het plein brengt, daar gaat zitten, en zijn kind 
op den schoot neemt. En nu gaat de vrouw's-verwant aan het werk, hij voorziet zich van twee kapmessen, en snijdt uit bamboe een wichelstokje, dat hij (zoo glad) afẃerkt als een ,glad-strijkertje" voor vlechtriet. De wichelaar neemt nu het bamboestokje in de hand, houdt het in de richting van het Oosten, en bidt: „Vereerd wichel„stokje, wij zitten met het gezicht naar het Oosten gekeerd, om het „haar te knippen van dit kindje; welnu, laat het gezond blijven! ga „met den hollen kant naar beneden liggen, o, wichelstokje! en mocht „het niet gaan in die richting, gaat $\mathrm{u}$ dan maar met den bollen kant „naar beneden liggen, o, wichelstokje!" aldus de wichelaar; voorts slaat hij er zeven maal mee op zijn wijsvinger, laat het stokje los, en kijkt goed toe: indien het stokje op den buik ligt, dan heet dat „poeloe” (d.i. met den hollen kant naar beneden = gunstig). Vader en kind gaan nu met het gezicht naar het Oosten zitten, en nu wordt het haar van het kind geknipt. Voorts deelt men visch uit, die door het kind wordt doorgegeven, en geeft men daarvan aan alle kinderen van het dorp, die naar het dorpsplein kwamen, aan elk hunner wordt van die visch uitgedeeld. Nadat het haar geknipt is, brengt men het (kind) (weer) in huis, en gaat men aan den maaltijd, waarbij men het dorpshoofd alsmede de aanzienlijken en de ouden van het dorp uitnoodigt. $\mathrm{Na}$ den maaltijd wordt er nog gesproken; waarna een iegelijk zijns weegs gaat. De eerste drie ochtenden moet het haar van het kind dan nog telkens weggeschoren worden. Zoo zijn de voorschriften voor het eerste haarsnijden van een kind.

\section{5e HOOFDSTUK:}

Hetgeen geldt voor hem, die een geboortefeest geeft voor zoon of dochter.

Wanneer de vader ,het doen kan”, dan moet hij het op grootsche wijze doen en moet hij een feest-rijstmaal geven, en daarbij de gondang (de Bataksche gamelan) laten bespelen. Is de vader arm, dan p. 211 doet hij het op kleiner schaal. Men kookt vleesch en rijst; en als de rijst en het vleesch gaar zijn, legt men een handvol rijst op een motoeng-blad, en daarbij alle kleinere gedeelten van het slachtbeest (ooren, oogen, neus, enz.) (13), giet palmwijn in een horen, snijdt gember in kleine stukjes, (legt die ook) op een motoengblad. En 
dan maakt de wichelaar zich òp (om de noodige) aanwijzingen te geven: Als de geesten bij de deur zitten te loeren, dan wordt het eten voor de geesten boven aan de trap neergelegd (14); indien de geesten zich in een hoekje bevinden, dan offere men het eten bij de paal in dat hoekje, en bindt men dáár de stukjes slachtvleesch aan, welke men op het motoengblad gedaan had; eerst als men met dit etengeven (aan de geesten) gereed is, mogen de menschen (zelf) gaan eten. Na den maaltijd wordt er nog wat nagepraat, waarop zij die niet tot de voorname gasten behooren, hun lofrede houden, voorzoover zij daartoe kundig zijn. Zoodra een drietal hieraan voldaan heeft, betuigen allen hun bijval. En dan schenkt de gastheer een drinkschotel palmwijn, en geeft hij ieder (hunner) zijn vleeschaandeel. Zoo zijn de regels ten opzichte van hen, die lofreden uitspreken. Nadat deze lieden hun lofrede hebben uitgesproken, gaan zij allen huiswaarts. Wanneer iemand's ,vrouw's-verwanten” en zijn „dochter's-verwanten”. gekomen zijn, dan laat hij hen pas den volgenden ochtend, als het dag is, naar huis terugkeeren; en biedt hij zijn ,,vrouw's-” en zijn ,dochter's-verwanten” een maaltje vleesch aan; verder geeft hij aan zijn vrouw's-verwanten een Spaanschen dollar bij wijze van vergoeding, van het geldgeschenk (15) (dat door dezen moet worden betaald) wanneer zijn vrouw'sverwanten een vrouw koopen, dienende dit dan als bijdrage daaraan. Aan zijn dochter'sverwanten moet hij een kleed schenken. Mochten zijn dochter'sverwanten dit niet willen aannemen, doch vragen om een ,kleed, , dat niet vergaat”, d.w.z.: een huwbare dochter (een vrouw) dan kunnen zij die koopen, indien hun vrouw'sverwant ermede accoord gaat een dochter aan zijn dochter'sverwanten af te staan; in dat geval hebben de dochter'sverwanten een goudgewicht te geven ter waarde van $4 \mathrm{H}$. (vier Spaansche dollars) als handgeld op afbetaling, opdat geen ander het (aldus op afbetaling gekochte) meisje trouwen kan. Dit zijn de bepalingen die gelden voor hem die het geboortefeest viert van zijn kind.

\section{6e HOOFDSTUK.}

De regelen die gelden voor hem, die zich een vrouw koopt.

p. 212 Wanneer het een dochter geldt van iemand, die in ,geen de „,minste bloedverwantschapsbetrekking staat, iem. die niet alleen zelf ,,van een andere marga is, maar wiens moeder ook van een andere 
„marga is”, (16) dan zendt hij, die een vrouw zoekt (de kooper) eerst iemand naar het andere dorp uit, om een keuze te doen. Wanneer daar volgens zeggen van den ,keus-doener”, iets voor hem „te koop” is, dan gaan ze naar het dorp van dengeen die over het meisje te beschikken heeft, met zich medebrengend een varken ter waarde van zes hoepang; ,,vleeschmaal voor den vader (of voogd) „,van het (begeerde) meisje” heet dat, en daarmede is dan de grondslag gelegd voor de verwantschap met de familie van de (aanstaande) vrouw; aan bruidschat wordt bij die gelegenheid bijwijze van voorschot op het den vader (of plaatsvervanger) toekomende, twee „binsang” (17) (goudgewicht ter waarde van 8 realen) gegeven, en er wordt afgesproken, over hoeveel nachten de ,kooper” komen kan om de zaak definitief af te doen (waarbij men voor den parboroe eten medebrengt als teeken dat de zaak doorgaat). Wanneer het afgesproken tijdstip daar is, gaan zij er nogmaals heen, medebrengende een varken van 3 realen waarde, dat men dan den parboroe (2) als vleeschmaal anbiedt; verder draagt men hem de helft van den bruidschat af; en treft een overeenkomst, wanneer de afgezant van den ,,bruigom” komen kan, om den vader van de bruid te vragen, op welken dag de bruid gehaald mag worden. Op den door hen afgesproken datum zendt dan de vader van den ,bruigom” hem, die het meisje uitzocht, om te vragen, wanneer de bruid gehaald kan worden; de poranak (2) laat voor deze gelegenheid een kip slachten, en als deze en de rijst (die erbij hoort) gaar zijn, dan doet hij die in een zak (van biezen of dierenhuid) die hij aan zijn afgezant meegeeft; aan deze geeft hij wijders geld mede; (t.w.:) één hoepang, (17) als aandeel van den bruigom in de kosten die de parboroe te maken heeft voor het door een wichelaar doen kiezen van een gunstigen dag, en acht oeang (17) voor de raadpleging van den tooverkalender (18). En daarmede gaat dan de datumaanvrager heen. Als deze in het dorp van den parboroe aangekomen is, bezorgt hij de door hem medegebrachte kip ten huize van den parboroe; die de kip dan nuttigt, waarop hij den datum-aanvrager uitnoodigt, om te komen eten. Na dezen maaltijd gaan ze slapen. Als het weer dag geworden is, laat de parboroe een kip slachten voor den datum-aanvrager; en als het voor laatstgenoemde bestemde eten gereed is, dan laat hij hem roepen, zoomede den wichelaar van het dorp; en zetten zij zich aan den maaltijd. Na afloop hiervan, gaan zij tot de besprekingen over; en draagt de datum-aanvrager het (medegebrachte) geld af, (zeggende) : „Welnu, parboroe; hier hebt 
u dan ,,de hoepang voor het kiezen van den gunstigen dag', en hier ,de acht oeang voor het raadplegen van den tooverkalender”. „Kiest „, $\mathrm{n}$ nu maar den gunstigen dag, (opdat we weten) over hoeveel nachten ,wij namens den bruigom komen kunnen, om $\mathrm{u}$ te vragen, op welken ,,dag de bruid gehaald kan worden!” Aldus de afgezant. De parboroe neemt de gelden in ontvangst, en geeft (daarvan) den wichelaar vier p. 213 oeang als honorarium voor het raadplegen van den tooverkalender; deze bestudeert nu zijn kalender, en deelt daarop den soehoet (hier: zijn principaal, (19) den parboroe) mede, over hoeveel nachten het de gunstige dag zijn zal. Waarop de parboroe den datum-aanvrager een touw geeft met knoopen er in (aangevende het aantal dagen). Daarna bespreken ze nog het een en ander met elkaar, en dan besluit de parboroe met den datum-aanvrager (als volgt) toe te spreken: ,.Luister, m'n waarde, gij, onderhandelaar! wil het door $U$ (met mij) ,,afgesprokene onthouden!' Aldus de parboroe. Als zij uitgepraat zijn, keert de afgezant c.s. naar zijn dorp terug. Daar aangekomen, geeft hij de zak (waarin hij het eten voor den parboroe had meegebracht) aan zijn principaal terug. En als dan het eten gaar is, dan noodigt de vader van den bruigom den datum-aanvrager te eten. Na het eten geeft laatstgenoemde den poranak het touw-met-knoopen af. En nadat zij dan nog het een en ander besproken hebben, gaan ze naar huis. Als de afgesproken datum dáar is, maken zij zich (voor de reis) gereed en nemen een kip om te dienen als bijspijs bij de rijst, die men in een korf doet; wanneer men het beest (dat tot vleeschmaal voor de verwanten van de toekomstige vrouw dienen moet) in zijn eigen dorp slacht, dan doet men een gedeelte daarvan in een grooten bamboekoker, een ander gedeelte wordt aan een stok over den schouder gedragen; het vet van het borststuk gebruikende om er den bamboekoker mee af te dekken. En nu gaan zij op weg: vóórop de moeder van den bruigom, achter zijn moeder zij, die de korf (op 't hoofd) draagt; achter de korfdraagster de bruigom. De parboroe brengt intusschen voor zijn dochter in de middenruimte (van het huis) (bij den wand) ,schuins aan den wand gespannen touwen aan, „waarover zij haar slaapmatje en kleeren kan hangen”" (= richt voor haar een eigen slaapplaats in). (20) Als de bruigom in het dorp aangekomen is, gelast de parboroe zijn dochter te gaan naar het huis van zijn ,dochter's-verwanten". De bruigom begeeft zich nu naar het huis van den parboroe, vergezeld door zijn moeder en de korfdraagster, en gaat daar zitten terzijde van de schuins aan den wand gespannen touwen (hooger genoemd); hangt er zijn schouderkleed 
overheen, en hangt daartusschen de hoofddoek op, die hij aan den vader der bruid wil schenken. (21). Voorts wordt den bruigom een maaltijd voorgezet, waarna hij zich naar buiten kan begeven. Daarop p. 214 gaan zij, wien dit door den parboroe wordt opgedragen, aan den slag, om (de rijst en het vleesch door den bruigom voor hem meegebracht) te koken. Als de rijst en het vleesch gaar zijn, dan zetten zich eerst de parboroe c.s. aan den maaltijd; waarna zij zich naar buiten begeven, en de inwoners van het dorp, alsook den bruidschat-betaler uitnoodigen. Als de genoodigden er allen zijn, zetten zij zich aan den maaltijd, waarna men tot de besprekingen overgaat, en de onderhandelingen plaats vinden. $\mathrm{Nu}$ komen de jongelieden van het dor? de ,,doegoel 2" vragen, met een knuppel (22) kloppende op de trap van het huis; hun moet dan worden gegeven het schouderstuk van hat slachtvleesch, (22) zoomede eenig geld. (23) Zoodra de jongelui dit ontvangen hebben scheiden zij (met kloppen) uit, en mogen zij de besprekers niet meer door lawaai storen. Nadat partijen verder onderhandeld hebben, wordt eerst een ,huwelijkspand” (24) gegeven (ten teeken dat men niet terug zal krabbelen, maar de zaak in ernst voleinden wil); waarna men zich buiten gaat vertreden. Voorts doet men rijst op een bord, legt er twee stuks gekookte visch bij (die met citroenzuur en curcuma toebereid is), en nu lat de parboroe zijn dochter roepen; en dan komt degeen ,die haar naar boven zal brengen" (haar geleidster), met de bruid; vóórop de geleidster, daarachter de bruid. In 't huis aangekomen, gaat zij zitten aan de zijde van haar moeder; terwijl men den bruigom dichterbij doet komen, zoodat hij komt te zitten aan de zijde van zijn bruid; voorts geeft men hem een vingerkommetje, brengt het eten op, en zet dat vóór den bruigom neer; terwijl de ,panghombari” (,,een kind dat bij een pas getrouwd ,paar moet slapen zoolang 't verboden is, dat zij het huwelijk lichamelijk vieren", v. d. T.) aan het voeteneind (25) (van bruigom en bruid) gaat zitten; en dan staat de ,pangabis" op, (d.i. hij die de zegen uitspreekt over een getrouwd paar, door hun een kleed boven het hoofd te houden, en een gebed te doen), vraagt (eerst) aan den vader van den bruigom zijn honorarium, en spreekt dan den zegen uit; wel, en als de zegen uitgesproken is, dan wasschen bruigom en bruid, alsook hun ,panghombari” zich de handen, en nemen zij elk driemaal een greepje van de huwelijksrijst; (26) waarop iemand op last van haar moeder (de moeder van de bruid) het eten wegneent; en een ieder het huis verlaat. $\mathrm{Nu}$ makt men in orde een vierkante, met matten omhangen ruimte voor slaapgelegenheid, en begeven zich 
daarin de bruid en de bruigom, zoomede de ,panghombari”; waarna men rijst op een bord doet met een speciale soort visch, ,indahan „loengloengan” (27) geheeten, welk gerecht zij dan in de mat-omhangen slaapruimte nuttigen; voorts gelast de moeder van de bruid de compagnonne rijst voor zijn (28) ('s bruigom's) moeder neer te zetten. Nadat haar schoonzoon en haar dochter gegeten hebben biedt zij p. 215 hun aan twaalf klaargemaakte betelpruimpjes, (die ze legt) op de onderlaag van een nieuwe rijstzak; na het gebruik van den betel leggen zij zich te ruste; met de panghombari tusschen hen in. Zoodra de hanen kraaien, ( $=$ héél vroeg in den ochtend) gaat de bruigom naar buiten, en ruimt zijn echtgenoote de slaapsteê op. Als het volkomen dag geworden is, haalt de parboroe het vleesch dat hij aan den betaler-van-den-bruidschat (29) op moet disschen; en noodigt hij, zoodra het gaar is, den bruidschatbetaler en de inwoners van het dorp, (die n.l. als getuigen moeten dienen bij de afwikkeling van den bruidschat) te eten, waarna zij (dan weer) tot besprekingen overgaan. $\mathrm{Nu}$ wordt de (rest van de) bruidschat afgegeven. Vooreerst vordert nu de parboroe als principaal de ,ina ni mas", en informeert hij naar de ,tandoek ni mas”; de ,ina ni mas” is het grootste (deel) van den bruidschat ( $=$ de eigenlijke bruidschat, n.l. dat wat den parboroe toekomt); onder ,tandoek ni mas" (de wezenlijke waarde van den bruidschat) verstaat men dit: wat zes dollar waard is, wordt (bij het verrekenen van de bruidschat), op één binsang (= vier dollar) gesteld, wat twee binsang ( = acht dollar) waard is, krijgt dan een waarde van zes realen; dat is de ratio bij het bepalen van de ,wezenlijke waarde" van den bruidschat. Hierna wordt afgedragen hetgeen toekomt den oudsten mannelijken bloedverwant van den vader van de bruid (30) : twee binsang (= acht realen) met als negende (bestanddeel) een zijdwapen; maar als een zóó groot aandeel door die ooms van vaderskant gevorderd mocht worden, dan kan hij (de bruidschatbetaler) daartegen opponeeren (31); wanneer zij echter zes realen als hun toekomend opeischen met als zevende (bestanddeel) een zijdwapen dan behoeft daarover nog niet getwist te worden.

Voorts wordt als aandeel van den jongeren broer van den vader één binsang gegeven; indien deze twee binsang zou vorderen, zou men daarover kunnen twisten; wanneer het echter bij één binsang blijft, dan legt hij (de betaler van den bruidschat) er zich zondermeer bij neer. De portie van dezen (jongeren broer) bedraagt evenveel als die van den ouderen broer. Verder wordt als honorarium van den procureur afgedragen twee realen; wanneer hem een volle binsang 
(= vier realen) toebedeeld wordt, dan moet hij zijn ,dochter” (32) en den schoonzoon in zijn huis uitnoodigen.

Dan nog wordt betaald aan het (dorps) Hoofd twee realen.

Vervolgens een reaal toekomende aan de mannen van bruidsmoeder's zusters (33): wanneer hun aandeel tot twee realen verhoogd wordt, dan moeten zij huisraad schenken aan de bruid, en haar in hun huis nooden. Voorts wordt betaald twee binsang (= acht realen) benevens als negende (bestanddeel) een zijdwapen aan den oom (van de bruid) van moeders zijde; als hem zóóveel toevalt, dan behoort hij hen tot een etentje in zijn huis uit te noodigen; als hij zes realen toegewezen krijgt met als zevende (bestanddeel van zijn portie) één zijdewapen, dan kan hij tevreden zijn.

Dan wordt nog betaald een halve reaal als loon voor hem die het p. 216 woord gedaan heeft. Voorts nog één reaal aan de opeenvolgende speechers, t.w. vrienden van den vader van de bruid.

Verder wordt nog betaald een halve reaal aan de dorpsgenooten (van de bruid) ter onderlinge verdeeling; en twee en een halve oeang aan de ,panghombari”; en drie oeang aan haar die de bruid ,bovengebracht" heeft. Als hij al het door hem verschuldigde betaald heeft, vordert de bruidschatbetaler van den parboroe het kleed op, waarop de verschillende deelen van de bruidschat werden neergelegd; en dit wordt hem gegeven; daarna vordert hij het ,kleed dat dient on er „,de korf mee te bedekken”, zoomede een ,kleed ter erkenning van „bruigom”, en een ,kleed als bewijs van de voltrekking van het „huwelijk” (34). Nadat de parboroe (hem) die kains gegeven heeft, legt hij (de bruidschatbetaler) het kleed, waarop de bruidschat neergelegd werd, opgevouwen neer, neemt wat ,baion" (nog al stijf riet met driekantige stengel), en hakt dat in stukjes, die hij dan als rekenstaafjes gebruikt, om er de realen mede te tellen, waarin hij voorts de (gezamenlijke) ,bruidschat” verrekent (opsomt), die staafjes legt hij daartoe (telkens) op voornoemd kleed neer. Nadat hij op die wijze de (waarde van de) bruidschat uitgeteld heeft, telt hij de kains, 'eze waardeerende op één reaal per stuk. Als de verrekening beëindigd is, worden de besprekingen weer opgevat; en daarna doet men der menigte kond, hoeveel de bruidschat bedraagt, opdat men het niet vergete, zulks met het oog op het geval dat de jonge vrouw mocht (komen te) sterven zonder een zoon na te laten; daarom moet hij de waarde van den bruidschat compleet gespecificeerd bekend maken; eveneens moet aan de menigte worden medegedeeld het aantal kains die de parboroe gegeven heeft, opdat evenmin in ver- 
getelheid raakt het aantal kains die ontvangen werden. Is de zaak beëindigd, dan gaat de bruidschatbetaler (de vader van den bruigom) naar huis terug, de bruigom blijft. Zoodra de vader van den bruigom in zijn dorp terug is, bereidt hij het door hem naar huis medegebrachte vleesch; doet, als hij hiermede gereed is, wat rijst op een bord, legt daar het vleesch bij, spreidt een klein matje uit op de „offer-plank" (35) en legt daar (het bord met) het vleesch en de rijst op als offerspijs; daar tevens een waschkommetje bij neerzettende, zoomede eenige palmwijn. Als alles op de offerplank staat, dan biedt hij het in zooveel woorden aan zijn afgestorven voorouders, en aan de geesten (36) van zijn vader en van zijn moeder aan, geen hunner uitgezonderd, alle ,hoogere geesten” (37) roept hij daarbij aan. $\mathrm{Na}$ deze toespraak wacht hij een betelpruimenslang, waarna hij het (een en ander) weer van de offerplank afneemt (38). Nu legt hij zeven

p. 217 soorten betelpruim op een nieuwe onderlegger van een rijstzak, en plaatst deze boven op de offerplank. Dan eten hij en de zijnen de offerspijze op, waarna zij ook de betelpruimen weer wegnemen en die eveneens zelf gebruiken. En als dan de gunstige dag is aangebroken, dan komt zijn zoon ,langs het spoor” naar huis terug, vergezeld door de schoondochter. Inmiddels heeft de parboroe gezorgd voor een kip als bijspijs bij de rijst door zijn dochter naar het huis van haar schoonouders mede te brengen. Soms ook geeft, als hij ,het doen „kan”, de parboroe haar een kain mee, om die als ,geschenk waar,mede men iemand tegemoet komt", aan haar schoonmoeder te schenken. Zoodra zij in het dorp van haar schoonouders gekomen zijn, begeven zij zich naar het huis (van haar schoonouders), vóórop de man. In het huis aangekomen, geeft zij daar de rijst, die zij medebracht, af, en bereidt zij (eenige) betelpruimen, geheel voorzien van hetgeen er bij behoort (kalk, gambir, tabak); waarna zij aan haar schoonmoeder de door haar medegebrachte kain aanbiedt, zoomede (een) van de door haar toebereide betelpruimen; waarvan ze ook elk van haar (nieuwe) familieleden bedient. Dan gaan ze andermaal langs het spoor terug, (nù) naar zìn schoonouders, maar nu moeten zij een varken meebrengen als bijspijs tot de rijst. Eerst daarna komen zijn moeder en zijn echtgenoote voorgoed terug. Zoo zijn de bepalingen ten opzichte van het huwelijk.

Mocht het geval zich voordoen, dat het meisje den jongeman ,achternageloopen" is, (39) dan worden dadelijk de definitieve besprekingen gehouden, (40) waarna het huwelijk tegelijkertijd plaats vindt. Mocht nu later de vader van de bruid of een broer van haar 
zich een vrouw willen koopen, dan is de schoonzoon verplicht nog een stuk slachtvleesch voor zijn rekening te nemen (41). Zoo luiden de regels voor het geval dat een meisje van huis wegloopt.

Wanneer hij tot vrouw neemt een dochter van een oom van moederszijde (een dochter van moeder's broeder) (42) en een grooter stuk slachtvleesch gegeven moet worden, dan is dat ,voor het ,ophangen van de kralen” en ,het noemen van den naam”; na het bezorgen van het vleesch worden dan de besprekingen gevoerd, en worden de namen genoemd van het meisje en van den jongeman die haar trouwen zal.

Ziedaar aard en wijze waarop men zich een vrouw koopt.

7e HOOFDSTUK (10e „Bindoe”).

Regelen ten aanzien van het kort-beitelen (43) der tanden.

Den dag vóórafgaande aan dien, waarop de tanden kortgebeiteld zullen worden, moet men ze met zwartsel van badja-hout (44) p. 218 behandelen. Op den dag zelf vangt het huisgezin aan met rijst en bijspijs te koken. Als een en ander gaar is, noodigt men uit den deskundige (in het kort-beitelen) en den vijler; wanneer een meisje het afbeitelen moet ondergaan, dan doet een zoon van vader's zuster het vijl-werk; wanneer een zoon ,,afgebeiteld” wordt, dan treedt een

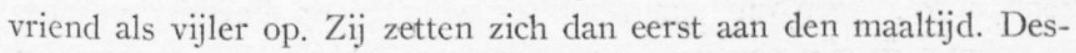
kundige en patiënt mogen zich echter niet verzadigd eten; indien zij te zeer verzadigd zouden zijn, zouden ze maar te meer vrees hebben. $\mathrm{Na}$ den maaltijd gebruiken ze een betelpruim. Als ze hiermee klaar zijn, brengt de persoon aan wien het door den heer des huizes opgedragen wordt, een groote mat naar de rijstschuur (45), zoomede een klein ligmatje en een hoofd-kussen; verder brengt hij een groote mand rijst-bolsters; en haalt hij lanting-bladeren (welke sterk stinkende bladeren n.1. gebruikt worden om er het bloed der afgebeitelde tanden mede af te vegen). Als alle benoodigdheden in de rijstschuur compleet zijn, gaat de patiënt erheen, met den deskundige, den vader, de aanverwanten, en den vijler, die den vijl met zich 
brengt, en een kommetje water, waarin hij één greepje droge rijstkorrels doet; het ligmatje wordt nu uitgespreid, de patiënt legt zich hierop neer; en dan zet zich de deskundige aan het hoofdeinde van den liggende(n patiënt) en geeft hem het stukje hout, dat als mondsperder dienen moet. De patiënt bijt dan daarin, zijn tanden zetten zich daarin vast. Nu treden de vrouwen aan, zij omringen den patiënt, spreiden een kain uit, en leggen die om zijn schouders, heelemaal er omheen. En dan vraagt de deskundige: „Zegt u eens, heer vader! ,wat zullen we doen met de splinters van de tanden van uw kind? „zal ik de splinters van de tanden van uw kind ,,werpen”? (46) opdat ,we het te weten komen, indien ze eventueel een gunstig omen zullen ,aanwijzen? wil het mij zeggen!” Aldus de deskundige. (Waarop de vader antwoordt:) „Ja, beste vriend! „Werpt” U de splinters van „de tanden van mijn kind maar!” Dus ,werpt” hij ze. Zoodra de eerste (47) splinter ,geworpen” wordt, houdt hij die splinter oplettend in het oog: indien de splinter terechtkomt op de knie van den patiënt, of op zijn hiel, dan wel op zijn elleboog, dan wordt dat voor een kwaad omen gehouden; wanneer de splinter bij zijn kuit terechtkomt, of voorbij zijn voeten of op een dijbeen, dan heet zulks ,wild” (overdreven); indien hij terechtkomt op zijn maag, of in de p. 219 leverstreek, dan is dat gunstig; als de splinter op zijn borst valt, dan heet dat ,de borst wordt opengekrabt" (wijst op een droeve gebeurtenis); wanneer hij in den hals valt, is dat gunstig, men noemt dat ,een collier omhangen”; wanneer de splinter op zijn lippen valt, dan wijst dat op ,opslokken" (48); wanneer de splinter op den tong valt, of in den keel, dan is dat een slecht teeken en zegt men, dat ,,een ,kolk hem naar beneden zuigt”; als de splinter in zijn neus terechtkomt, spreekt men van ,gauwdief" en wijst dat op dieverij; wanneer de splinter in zijn oog valt, dan is dat een slecht teeken, en spreekt men van ,,weeklager”; valt de splinter op zijn gezicht, dan heet dat ,het gezicht wordt opengekrabt”, en dat is (allemaal) leelijk! Wanneer de splinter in de hand van den wichelaar terecht komt, dan is dat mooi! Maar dan moet de vader hem inlossen. De inlossingssom bedraagt $1 / 2$ dollar. Valt de splinter in den schoot van zijn moeder, dan is dat ook prachtig; en ook als hij in den schoot van een vrouws(aan)verwant valt, is dat gunstig, maar dan moet hij hem inlossen; de inlossing geschiedt (in dit geval) met een stuk vleesch en een dollar ter vervanging van een zijdewapen. Valt hij in den schoot van een dochtersverwant, dan is dat mooi, maar dan moet hij hem inlos- 
sen: hetgeen gedaan moet worden met een kain en een stuk vleesch, hetgeen de inlos-prijs daarvan is. Nadat (het voorspellen middels) de (eerste) splinter afgehandeld is, wordt de oelos weggeruimd, en tot het kortbeitelen van alle (in aanmerking komende) tanden overgegaan. Hiertoe haalt men het van tevoren gebrande badjahout, (dat als zwartsel dienen moet) van huis, zoomede citroen-zuur, zout, curcuma en kalk; en dan omringt men (den patiënt) opnieuw, en spreidt opnieuw een kleed om hem heen; besmeert hem (de tanden) vervolgens eerst met curcuma, en droge kalk; daarna met citroenzuur en zout, waarvan hij steeds (wat)inslikt; en dan wordt het zwartsel er op gesmeerd; waarbij de deskundige er op letten moet, dat het niet langs de tanden afvloeit, want dat zou niet deugen; als het zwartsel vettig is, zoodat het blijft kleven, is het goed. Nadat het zwartsel er op gesmeerd is, gaat de deskundige naar binnen, slacht een haan (49), en observeert de bijzondere teekens die als omina dienen, waarna hij den hals van de haan bereidt en aan den „,kortgebeitelde" te eten geeft. Eerst nadat deze hem opgegeten heeft, mag hij zich buiten het dorp begeven; zoolang hij hem niet opgegeten

p. 220 heeft, mag hij het dorp niet uit. Voorts gaat men aan den slag om rijst te koken, mitsgaders bijspijs en de (voornoemde) haan. Als hij het zich veroorloven kan, behoort de heer des huizes (ook nog) een varken te slachten. Mocht hij dat niet kunnen doen, dan kan hij volstaan met voor de (andere) lieden visch als bijspijs te geven. Als alles gaar is, noodigt iemand op last van den heer des huizes de ingezetenen van het dorp uit, en gaan ze, zoodra die er zijn, gezamenlijk eten. Van den haan, die bij deze gelegenheid voor waarzeggen gediend heeft, wordt de helft aan den deskundige, de andere helft aan den heer des huizes toebedeeld. Na den maaltijd wordt de betel rondgediend, en gaat men tot gesprek over. Dadelijk na afloop van dezen (ceremonieelen) maaltijd kan men den deskundige vragen stellen: Wanneer het geval ,gunstig" is, dan vraagt men om de „geruststelling”, en geeft de wichelaar zijn geruststellende verklaring; hiervoor betaalt men dan een dollar. Mocht het niet gunstig zijn uitgevallen, dan vraagt men een afweermiddel (50); de prijs hiervan bedraagt, als de voorteekenen er onheilspellend uitzagen, een halve dollar; indien de omina niet onheilspellend waren, een hoepang (de helft er van, I/4 reaal). Als ,inlossing” van het hoofdkussen draagt men een parmasan (51) padi af.

Dit zijn dan de regels die gelden bij het kortbeitelen van de tanden. 


\section{Se HOOFDSTUK (11e „Bindoe”).}

Regelen betrekking hebbende op het zaaien op droge akkers.

Wanneer het seizoen is aangebroken voor het zaaien op droge akkers, op den daarvoor bestemden tijd, dan komen de dorpsgenooten eerst den avond tevoren bij elkaar (52); den ochtend volgende op deze samenkomst verzamelen alle ingezetenen zich, elk met zich medebrengend een hakmes, en maken zij den weg naar de bron (53) alsook de bron zelve in orde. Als zij hiermede klaar zijn, keeren zij naar huis terug, en gaat een ieder eten, waarna elk gezinshoofd zijn deel bijeen brengt (van de bij het Hoofd in te leveren offer- en zaairijst en van de rijst die voor het gezamentlijke eten gebruikt zal worden), (t.w.) één soloep per gezin; welke rijstmaat niet mag worden afgestreken, maar afgeleverd moet worden ,,met een kop er op”. wil het aanvaard worden; het aandeel (bijdrage) van de notabelen is twee soloep. Deze rijst wordt gebracht naar het huis van het dorpshoofd; als ze daar ontvangen is, gelast het dorpshoofd een vrouwelijke bediende, van die gezamenlijk opgebrachte rijst twee maten te weeken om te dienen tot of ferspijs en meel; terwijl hij aan andere bedienden opdraagt bladeren te zoeken, anderen weer groente, en

p. 221 nog weer anderen pootstokken. De te weeken gelegde rijst wordt voorts gestampt, en daarna bereid tot een offerkoek, en één bord meel; dan gaan ze koken, en wel worden vrouwelijke bedienden belast met het koken van de rijst, terwijl het koken van de bijspijzen geschiedt door een gedeelte van het mannelijk personeel, waarvan een ander gedeelte het varken bereidt; als al hetgeen (bij het gemeenschappelijke maal) genuttigd zal worden gaar is, maken zij zich gereed (om te gaan), allen die daar lust in hebben, en begeven zij zich naar de bron. Men laat twee ,nog onbedorven” jongens zich in vrouwenkleeren steken, waarvan dan één het meel op 't hoofd draagt, de ander de offerspijs; anderen weer laat men een groote (zit-)mat en een kleine (lig-)mat dragen, één draagt den horen met palmwijn, en het zout en de gember, die dienen tot offerande (54), alsook kippeneieren. En zoo begeeft men zich naar de bron. Als zij aan de bron zijn aangekomen, spreiden zij de groote en de kleine mat uit; en leggen daarop neer de offerkoek en het meel, en de offerande. en den horen met palmwijn, en het houten bakje met gember. De wichelaar van het dorp noodigt nu de geesten (55) uit, de hun voorgezette offerande te komen gebruiken. Nadat hij deze uitnoodiging 
gedaan heeft, steekt hij op de plaats waar het water opspuit, een stuk hout in den grond, ,,kenteeken” genoemd; indien nu de ,hoogere„geest” (56) zoo welwillend is, de hem gebrachte offerande te aanvaarden, dan wast het water, en wel zóó hoog, dat het door den wichelaar aangebrachte ,kenteeken” geheel onder water komt; is hij echter niet van goeden wille, dan loopt (de hoeveelheid van) het water terug, en valt het door hem aangebrachte teeken om. Als ze met het ,kenteeken” klaar zijn, keeren ze huiswaarts. In het dorpteruggekeerd, verzamelen de dorpsgenooten zich ten huize van het Hoofd; en nu zet men op de ,offerplank" de offerspijze en het meel neer, alles wat men van de bron mede teruggebracht heeft; en legt men het varkensvleesch op een houten bord klaar; voorts doet men rijst op een bord; en legt daar verder kleine stukjes vleesch bij; vervolgens maakt men een schoteltje lever, een schoteltje geroosp. 222 terd vleesch (57), en een schotel fijn gehakt rundvleesch (58); welk vleesch, met de rijst, op de offerplank neergezet wordt. Als alles op de offerplank neergezet is, wordt het met de noodige woorden aangeborlen aan de heilige hoogere geesten en de geesten der voorvaderen, waarna allen aan den maaltijd gaan. Na het maal neemt men de geofferde vleeschspijzen weer weg; en geeft daarvan aan elk gezin een deel, zoo ook van de offerkoek, en van het meel. En dan gaat een bode van het Hoofd er op uit om de zaaiers (59) op te roepen. Nadat hij ze opgeroepen heeft, telt hij de opgekomenen: als er totaal zes zaaiers (59) zijn, dan kookt men zes soehat (51) (rijst); en als er zeven zaaiers (59) zijn, worden er zeven soehat gekookt. Zoodra ze geteld zijn, gaat mannelijk personeel de bijspijzen koken, en het vrouwelijk personeel de rijst. Als alles gaar is, gaan de koksvan-de-bijspijzen eten, zoo ook de rijstkooksters. Nadat deze (bedienden) gegeten hebben, zetten de huisgenooten zich aan den maaltijd. Een deel van de rijst wordt voorts in rijstzakken gedaan, waarop het Hoofd aan de kooksters bevel geeft die (rijstzakken) bij de ingezetenen van het dorp te bezorgen, (en wel) bij elk gezin één rijstzak. Als (deze rijst-zakken) bezorgd zijn, worden ze stevig gebonden. Zoodra het weer dag is, gaat men naar den akker, en op het veld aangekomen, legt men de rijst en de bijspijzen daar neer. Nu deelt het Hoofd zaai-goed uit aan hen die dit in de pootgaten moeten laten neervallen; de pootgaten-makers scherpen hun pootstokken, de aanvegers maken hun vegers (60) in orde. en dan gaan ze aan het werk. Als ze de helft (van den akker) klaar hebben, scheiden ze even uit, en gaan ze schaften, op één hoopje de vrouwen, op een andere 
verzamelplaats de mannen. Nu tijgen de uitdeelers van de bijspijzen aan het werk, en deelen de visch uit; groenten (61) worden uitgedeeld door telkens een handvol daarvan op het eten te leggen; men

p. 223 telt de volwassenen, en zooveel volwassenen als er zijn, zoovele porties maakt men. Zijn de porties ingedeeld, dan deelt men ze onder de schaftenden uit. Als ieder zijn deel heeft, worden de als genoodigden medegebrachte lieden geteld, waarna aan hen hun portie uitgereikt wordt. Nadat elk van de (voor den arbeid) opgeroepenen en van de genoodigden zijn deel gekregen heeft, wordt aan het Hoofd zijn portie toebedeeld. Hierna gaan de bijspijzen-uitdeelers eten. En als dan de menigte gegeten heeft, zet het Hoofd betel klaar op onderlegsels, (compleet) met pinang, gambir, kalk en tabak, en geeft hij één (onderlegsel) aan (het groepje) mannen, één aan (het groepje) vrouwen; en deze verdeelen het dan, zoodat elk zijn deel krijgt. Voorts baden zij zich nog eerst; na het bad gaan ze dan weer voort met zaaien. Als zij den akker af-gezaaid hebben, gaan ze weer eten; het Hoofd vraagt nu de rijstzakken op van de genoodigden, en vult die alle met rijst. Als de eters klaar zijn, vragen zij, hoeveel zaai-goed het Hoofd gegeven heeft; hetgeen deze dan naar waarheid mededeelt. Hierop kondigt het Hoofd het einde aan: „Welaan! onze taak is ,beëindigd, waarde lieden! (gij mannen! en gij vrouwen!). Kom, „laten we allen huiswaartskeeren!" (aldus het Hoofd). Hierop wordt door de voor den arbeid opgeroepenen instemmend geantwoord, waarna zij allen den akker verlaten. Wanneer het Hoofd aldus gesproken heeft, dan kan hij, mocht den menschen iets overkomen, er geen moeielijkheden meer door krijgen; mocht het Hoofd echter nièt ,het einde hebben aangekondigd”, dan moet hij, als iemand ziek van den akker thuis zou komen, den wichelaar opdracht geven (op zijn kosten) voor de genezing te zorgen; en moet, mocht dàn iemand dood terugkeeren van het veld, het Hoofd zorgen voor zijn doodskleed en zijn doodkist.

Dat nu zijn de regelen met betrekking tot het zaaien op droge akkers.

\section{9e HOOFDSTUK (12e „Bindoe”).}

Waar zij zich aan te houden hebben, die een oorlogsverklaring uitbrengen (62) als

begin der vijandelijkheden.

Men draagt zijn wichelaar op, een gunstigen dag te kiezen. Zoodra nu de goede dag is aangebroken, trekken de dorpsgenooten er op 
p. 224 uit, om tolong (een soort bamboe), tabartabar (63), kleine twijgen van den arènpalm, en „bomban” (64) te zoeken, en maremare (65), en vezel van een arenpalm die door den bliksem getroffen is (66). Als zij die materialen verzameld hebben, brengen zij die naar het dorp, waar op alle meegebrachte stukken bamboe door den wichelaar de naam van den vijand geschreven wordt, terwijl men de maremare in lange linten splijt. Wanneer het een individueelen strijd geldt, dan voegt men daar nog bij een gescheurde (67) kinnebak en een versleten (67) rijststamper; wanneer de ,oorlog” echter gevoerd wordt tusschen dorpsgemeenschappen onderling, dan kan men niet volstaan met een versleten rijststamper, doch moet men dien tot een menschenfiguur bewerken, (en wel in de gedaante van een vóórvechter) waartoe men opdracht geeft aan een deskundige in het vervaardigen van uit hout gesneden beelden (68). Als het beeld klaar is, bindt men op den kop van het beeld den kinnebak vast. Als dit gereed is, draagt het Hoofd aan zijn vrouw of dochter op, één soloep rijst te weeken, die na het weeken gestampt wordt. Daarvan makt men voorts één offerkoek, en een bord meel. Als de offerkoek gaar is, bindt men de maremare aan de bamboes vast; spreidt een groote zitmat op het dorpsplein uit, haalt van huis de offerkoek en het meel, en de offergave, brengt dat naar het dorpsplein; en legt het vervolgens vóór den wichelaar neer; deze staat nu op, neemt de offerkoek in de hand, en wel in zijn linkerhand, terwijl hij in de rechterhand houdt de offerrijst die men op een schotel gelegd had; en nu biedt hij het een en ander aan de godheid der vruchtbaarheid (69), aan de heilige hoogere geesten (56), aan de waterstroomgeest (69), en aan de drie goden (70) aan. Nadat hij die allen aangeroepen heeft, legt hij (de voor hen bestemde offerspijzen) neer, het meel wordt vervolgens door hem aangeboden aan de geesten der voorvaderen van het Hoofd, aan den geest van den overleden leermeester van den wichelaar, en aan den heiligen (71) geest van zijn nog levenden leermeester. Na afloop hiervan worden de offerkoek, het meel, en de offerrijst binnenshuis gebracht. Vervolgens gelast men iemand op de groote trom te slaan, en dan gaat men op weg, vóóraan het Hoofd; p. 225 de (beschreven) bamboes worden meegenomen, en wel door ieder der strijders één. Hij die in het midden loopt, schiet nu éénmaal zijn geweer af, hetgeen „bodil panindi” (72) heet. De wichelaar draagt den versleten rijststamper, geheel achteraan loopende. Wanneer zij één kwartier hard-loopens van het dorp zijn, rammen zij de bamboes stevig in (den grond), den rijststamper aan de buitenzijde; waarna

DI. 103 . 
het Hoofd zijn gebeden zegt. Daarop geven zij elk twee schoten af, voordat ze naar hun dorp terugkeeren; onderweg naar het dorp schieten zij dan nog drie keer. Na terugkomst in het dorp verzamelen zij zich op het dorpsplein. De echtgenoote van het Hoofd onthaalt nu alle krijgers, den wichelaar en haar echtvriend op fijn gesneden gekookt vleesch (met gestampte kemiri en andere ingrediënten bereid) (73). Hierna vangt men een jong haantje, dat geschikt is om als wichelhaan te dienen en slacht het; de wichelaar hangt dan het haantje (aan de pooten) op, daaruit maakt hij op, of zij zullen overwinnen (74); nadat hij een en ander nauwkeurig geschouwd heeft, wordt het haantje geroosterd, volgens de regelen in stukken gesneden, en inwendig geschouwd (75), waarna het haantje gekookt wordt. Als het gaar is, wordt er in het huis van het Hoofd om wat gekookte rijst gevraagd, waarvoor een klein bord gebruikt wordt, en dan brengt degeen die het halen ging het naar het dorpsplein en daar wordt het vleesch van het haantje op die rijst gelegd, waarna de wichelaar het als offer aan de animae van hen, dorpsgenooten opdraagt. Nadat hij dit gedaan heeft, worden het vleesch en de rijst verdeeld, aan elk gezin van het dorp wordt een deel toebedeeld. Daarop gaat ieder huiswaarts. Ziedaar, waaraan men gehouden is bij het uitbrengen van een oorlogsverklaring als begin van vijandelijkheden.

\section{0e HOOFDSTUK (13e „Bindoe”).}

Hetgeen geldt ten opzichte van hem, die aan zijn dorpelingen voor een expeditie een ,voorbereidingsmaal” geeft,

$$
\begin{gathered}
\text { (n.1.) de aanvoerder aan } \\
\text { zijn menschen. }
\end{gathered}
$$

Het slachtvleesch voor zoo'n maal moet zijn van $11 / 2$ dollar, de rijst één balamboeng (76). Hij slacht een varken; en laat het vleesch p. 226 koken. Als dit gaar is, verzamelt hij alle ingezetenen van het dorp, (d.w.z) alle mannen. Hij gelast nu zijn vrouw of dochter gezegde parmasan rijst te koken, vraagt van die gekookte rijst een schotel, en legt kleine stukjes van het varkensvleesch bij die rijst; en dan draagt 
de wichelaar het als offer op aan den ,,aardgeest" (godheid der vruchtbaarheid), aan de heilige hoogere geesten, aan de ,waterstroomgeest", aan de schikgodin voor kraamvrouwen en zuigelingen (77), aan ,de dertig dagen” (78), aan de drie goden en aan de geesten der voorzaten van het dorp. Nadat dit opdragen (van de offers) aan de geesten heeft plaats gehad, worden het vleesch en de rijst verdeeld, en als allen hun deel ontvangen hebben, brengt een ieder het naar zijn eigen huis; en offeren (dáár) de dorpsgenooten ieder voor zijn eigen levensgeest. Nadat zij voorts, elk in eigen huis, gegeten hebben, noodigt de leider hen, en wel allen die tegen den vijand zullen optrekken, bij zich te eten. Dan zetten zij zich aan den maaltijd, waarna zij tot de besprekingen overgaan. Nadat deze beëindigd zijn, gaat een ieder weer heen. Zoo gaat het toe bij het geven van een voorbereidingsmaal. Als de leider dit maal gegeven heeft, moeten de mannen zich (voor de expeditie) voorbereiden. Hij, die geen kruit heeft en kogels, die koope dat; wie geen geweer heeft, leene er een; wanneer de mannen niet voor het noodige zorgen, dan kunnen, mocht iemand komen te sneuvelen, zijn nagelaten betrekkingen het Hoofd niet voor „,smartegeld” (79) aanspreken; en mocht iemand dan slechts ,,verschrikt" zijn door den vijand, dan behoeft het Hoofd ook geen offer te brengen voor de animae van den verschrikte.

Dit zijn dan de regelen met betrekking tot oorlogsvoering.

\section{1e HOOFDSTUK (14e „Bindoe”).}

Waar hij zich aan te houden heeft, die een ,belooning" uitdeelt voor het versterken

van de palissadeering (amheining),

(n.l.) het dorpshoofd aan de dorpsing ezetenen.

Naargelang van de belangrijkheid van het onderhoud is de belooning van het werk aan die palissadeering; naarmate dáárvan ook wordt er rijst verstrekt, wordende een en ander onder de ingezetenen verdeeld. Die rijst nu wordt in het huis van het dorpshoofd gekookt. Zoodra ze gaar is, noodigt hij alle dorpsingezetenen uit, en wel een iegelijk die er aan mee wil doen. Dan zet men zich aan den maaltijd; na afloop waarvan de zaak besproken wordt; waarop een ieder zich 
verwijdert. Deze gedragslijn geldt voor hem, die het versterken van de wallen ,,beloont”. Als het Hoofd aldus gedaan heeft, dan moeten (de ingezetenen) de palissadeering, waar deze niet hecht genoeg is, verstevigen; en de bamboedoeriversperringen, als deze niet meer voldoen, weer op peil brengen; indien iemand zijn (deel van de) palissadeering (wallen) niet verstevigd heeft, dan zal, mocht er een vijand of een tijger binnenkomen, en mocht er dan iemands varken weggehaald of iemands kind door den vijand gedood worden, men hem, die voor (het betrokken deel van) de omwalling verantwoordelijk is, daarvoor kunnen aanspreken. Zoo zijn de regelen te dien opzichte.

\section{2e HOOFDSTUK (15e „Bindoe”).}

Hetgeen te doen staat aan hem die aan zijn dorpsgenooten bekend makt, dat hij een geschil wil uitvechten.

Wanneer het hierbij gaat om een schulden-verrekening, moet hij die de actie voert (procedeert) voorzien in vleesch ter waarde van $1 / 2$ binsang (80), en een ampang (81) rijst (voor het geven van een maaltijd) aan de dorpsgenooten; gaat het om de aanmaning tot betaling van een schuldvordering (het vorderen van een inschuld), dan moet de aankondiger van het twistgeding vleesch geven van $1 \frac{1}{2}$ dollar, en een parmasan rijst. Indien hij hieraan voldaan heeft, stelt zich het geheele dorp gezamentlijk partij; ook wanneer een bemiddelaar zou optreden, leggen zij dan voor zijn maaltijd collectief botje bij botje bij; kortom: wat er ook noodig zij voor het twistgeding, dat dragen zij collectief; wanneer iemand niet betalen kan, wordt zijn schuld opgeschreven; het dorpshoofd springt dan voorloopig bij. Als dan het geding beslecht is, dan moet hij die schuld in termijnen betalen. De strijd is beslecht, wanneer de een(e partij) de (haar) door de andere partij te betalen schadeloosstelling (,,boete”) aanvaardt; dat wat geacht wordt den schuldenaar toe te komen, wordt met zijn schuld verrekend. Wanneer de partijen een zaak beslechten door betaling en aanvaarding van een schadeloosstelling (,,boete”), dan moet die schadeloosstelling eerder betaald worden dan de verschuldigde collectieve bijdrage. Zoo luidt het recht ten aanzien van hem, die aan de dorpsgenooten bekend maakt een geschil te willen uitvechten. 


\section{3e HOOFDSTUK (16e „Bindoe”).}

228 Hetgeen hem te doen staat die (in oorlogsdagen vóór een expeditie) een wichelaar

ontbiedt, zoomede een woordvoerder

(dis put-leider); een boodschapper (oproeper), en een uitvoerder van bevelen (82).

De lastgever moet slachten een varken van 1 dollar; als dit gaar is, noodigt hij den wichelaar, den dispuut-leider, den bevelen-uitvoerder en den boodschapper uit; en dan zetten zij zich aan den maaltijd; waarna tot de besprekingen overgegaan wordt; als deze beëindigd zijn, schenkt de lastgever aan den wichelaar een witte hoofddoek en een witte wichelaars-kain, en geeft hij (den wichelaar) voorts nog een dollar ,,betel-geld”; is het een wichelaar van het (eigen) dorp, dan zegt de lastgever hem (bovendien) 4 dollar toe (als honorarium), geldt het een wichelaar die (van elders) gehaald is, dan belooft hij hem acht dollar. Als dit plaats gehad heeft, geeft de wichelaar aan zijn helpers instructies. Het werk van den ,,woordvoerder” (83) is (het volgende) : indien er besprekingen (moeten) worden gehouden, waarbij een dispuut-leider noodig is, dan is hij de man daarvoor, dat is dan zijn functie. Het werk van.den ,,bevelenuitvoerder” is : indien er menschen in het dorp komen, of een bemiddelaar; of voor deze iets in het dorp gedaan moet worden, bijv. een kip gehaald moet worden, of een varken, of een hond, dan doet hij dat; moet er collectief op te brengen rijst worden opgevraagd, dan doet hij dat; dàt nu is hetgeen de bevelenuitvoerder moet doen. De taak van den „boodschapper” is : wanneer men vergaderen wil; hetzij om te beraadslagen over een te ondernemen expeditie of voor welk doeleinde ook, dan moet hìj de menschen oproepen om ter vergadering te komen, dat is hetgeen de boodschapper doen moet.

\section{4e HOOFDSTUK (17e „Bindoe”).}

Hetgeen moet worden in acht genomen door hen die een offer-en wichelhut (84) voor den wichelaar willen oprichten.

$\mathrm{Z}_{\mathrm{ij}}$ komen dan eerst eens (ter vergadering) bijeen, de dorpsgenooten; en daags daarop maken zij (met de tenuitvoerlegging van het 
plan) een aanvang (t.w., in de eerste plaats, het door den wichelaar doen uitwichelen van den gunstigen dag voor het beginnen met de eigenlijke werkzaamheden). Wanneer nu de gunstige dag dáár is, gaan ze erop uit, om hout en maremare te verzamelen; en zetten zij een offerwichelhut op; en die maken zij dan op één en denzelfden

p. 229 dag af, zij mogen daar nooit twee dagen over doen. Is de hut gereed, dan brengt men er rondom een begroening aan; plaatst daarop de groote trom in die hut, zoomede pauken en bekkens (85), hangt voorts een gevlochten bord (voor offerdoeleinden) terzijde van de daksparren op; een kleine gevlochten offerschotel boven den poot van de groote pauk; en een groot offerschaaltje, dat kunstig gevlochten is (86), terzijde van de offerplank van de hut. Vervolgens neemt men voor de inwijding van de offerhut een haan, die dan eerst (door den wichelaar) ,gehangen" wordt, om door hem op omina te worden geschouwd. Daarna geeft het Hoofd bevel om (den haan, zoomede wat rijst) te koken, en meel te stampen, terwijl men ook nog eenige met curcuma vermengde rijst kookt. Wanneer dat alles gaar is, brengt men al die ingrediënten in de offerhut, legt den haan op de rijst; doet daar de pooten van den haan, een handvol gekookte (gewone) rijst, en een weinig visch bij, zoomede een touw van buffelhuid; verder doet men op de kleine offerschotel offerspijs, niet door de geesten te omvatten, en nu worden er nog toebereid: een hoopje offerspijs met curcuma toebereid, en een hoopje niet met curcuma toebereid, elk daarvan voorzien van platte meelkoekjes (zoo groot als een Spaansche mat), en van (een ander soort) lekkernij uit meel (klonten meel met zout), zoomede in banaanblad gekookte meelkoekjes, en kogelvormige meelkluitjes (87), en (pinkdikke, tusschen de palmen der handen gerolde) meelstaafjes, en kleine staafvormige meelrollen, waarbij gevoegd worden : kleine nangka's, keladi, pisang, en suikerriet; en in tweeën gesneden, met kalk bestreken, visch; en dat (alles) leggen ze dan op de beide offerschotels; voorts doen zij erbij een roode krans, en een witte krans, en varens, en palmbloesem; vervolgens leggen zij één hoopje offerspijs op de offerplank van de hut; en zetten zij ook wat, met curcuma toebereidde (88), rijst op die plank neer; tenslotte bereidt men nog een zuiveringsmiddel (89), dat, als het gereed is, (ook) op de offerplank neergezet wordt. En nu vraagt men aan de echtgenoote van het Hoofd den grooteren tabaksbuidel, het kleine tabaksdoosje, en (een kalkdoosje) van messing, bereidt betelpruimen, met gambir, pinang (areca-noot), tabak, en kalk, en die leggen ze dan (mede) op de 
p. 230 of ferplank. Daarna wordt een rijstwan met figuren beteekend om er mede te wichelen; waarop de wichelaar-priester overgaat tot het opdragen van de offers aan de Godheid der vruchtbaarheid, aan de heilige geesten der voorvaderen, aan de Waterstroomgeest, aan de Kraamvrouwen-schikgodin, aan de demonen van de dertig dagen en die van de twaalf maanden, zoomede aan De Drie Goden, en aan de geesten van zijn overleden leeraren, en aan den heiligen geest van zijn nog in leven zijnden leeraar. Nadat hij zich van het aanbieden der offeranden gekweten heeft, gaat hij eten; waarna hij den boodschapper opdraagt, de muzikanten te roepen. Als deze gekomen zijn, wordt de gondang (90) bespeeld. Dan komt de wichelaar (weer) in actie, neemt een oelos radigoep op, gaat staan, en spreidt dien oelos, die men ,balok-balok” (91) noemt, naar links en rechts uit, opdat de animae van hen, dorpsgenooten, niet door de sopo aangelokt worden (92) en, (het lichaam van de menschen verlatende), daarheen zullen gaan. En nu roept hij den naam af van het Hoofd van zijn vijanden (hem aldus toeroepende) : „Kom hier, gij anima (93) van „Radja Dinges! en ga dansen op de klanken van deze gordang sipa,moetoeng! (94) dáár is Uw eten, (door mij) afgedekt, daar (vindt ,ge) een handvol rijst, en visch, en kippepooten! daar vindt ge het ,touw van dierenhuid om $U$ mede te binden! laat uw vrouw, en uw „kinderen, en uw huis, en uw rijstschuur, en uw dorp in den steek!" aldus de wichelaar. Vervolgens roept hij de namen van zijn vijanden beurtelings op, voorzoover hij die kent. Nadat hij de animae zijner vijanden opgeroepen heeft, houden de bespelers van de gondang met spelen op, en gaat een ieder slapen. Zoodra het dag is, slacht het Hoofd een varken van een dollar, en noodt hij, als dit gaar is, den wichelaar en alle voorname lieden, het heele dorp, te eten. Zij gaan dan eten; en als het maal afgeloopen is, tot het zakelijke over. De wichelaar spreekt zich nu (als volgt) uit: „Hoort u eens, mijne „Heeren! laten wij-van-dit-dorp onze kinderen instrueeren nooit of ,te nimmer naar de offerhut te gaan; mochten ze er toch heengaan, ,,dan zullen ze schuldig gerekend worden; hun boete bedraagt dan ,een haan en een kip, een soehat rijst, en eẹn vaâm witte kain; dat , zijn zij dan verschuldigd. Mocht een buitenstaander (niet-dorps,genoot) naar de offerhut gaan, dan moet hij worden opgevat, en ,nadat hij geboeid is, in het blok gesloten worden; en mocht een ,van de zijnen genoegdoening aan willen bieden, dan wordt hem ,medegedeeld, wat hij schuldig is : hij is dan als boete verschuldigd ,een varken van een dollar en 6 soloep rijst, die hij onder het spelen 
,,van de gondang moet afdragen; dat is dan, wat hij als boete op,brengen moet. Wat ons (zelf) nog aangaat, laten we geen ruzie „,maken met onze echtgenooten of met wie dan ook! Hij die ruzie „,mocht maken, is een kip ,,schuldig”, en een soehat rijst; dat is dan ,zijn boete. Als iemand zich het hoofdhaar en de huid wascht op de ,plaats, waar de regendruppels van het dak vallen, of grond uit,graaft, of iemand anders vervloekt, hem „naar den vijand" ver,wenscht; dan zal, als het een jong iemand betreft, hij moeten geven ,rijst met curcuma bereid, en een kippenei; betreft het een volwas,,sene, dan is hij een (zeer) oude (bijna wêerlooze) haan en 2 soloep ,rijst schuldig. Hij die op het dorpsplein iets aan 't sleepen is, zich ,,iets over het hoofd doet (95), of op het dorpsplein de haren los laat ,hangen, is verschuldigd een bord meel, een hoopje offerspijs, een „,soloep gepelde offerrijst, en twee kippeneieren, daar wordt hij mee ,,beboet. Als iemand zich zoover mocht laten gaan, dat hij zijn vrouw „met de hand slaat of (versch) bloed doet druipen, dan krijgt hij een ,groote boete: zijn boete bedraagt dan een groot varken en een „parmasan rijst, hij moet de groote trom opstellen (95a), de pauken ,op het dorpsplein ophangen (96b), en voor of feranden zorgen. Hij, ,die een ander knevelt, zonder vooraf „,de ouden” (97) er in gekend ,te hebben, wordt beboet met een varken van een dollar en een ,djoeal rijst; er moet een zuiveringsmiddel gemaakt, en de geknevelde ,,daarmede ,gezuiverd" worden, en hij moet hem een vleeschmaal ,,voorzetten; maar ook als dit plaats gehad heeft, moet hij toch nog, ,hoeveel zijn schuld ook bedraagt, die schuld in haar geheel voldoen,

p. 232 „en mag hij die niet in termijnen betalen”, aldus de wichelaar. Dan neemt het Hoofd het woord, en doet aan de dorpsingezetenen kond: „Dat gelde dan voor ons, mijne heeren! gij hebt de woorden van ,onzen leermeester gehoord!" Nadat zij uitgesproken zijn, gaat een ieder zijns weegs, en begeeft de wichelaar zich naar de offerhut; gedurende zeven nachten wordt dan voortdurend op de gondang geslagen in de offerhut, en worden voortdurend de animae (98) van den vijand opgeroepen. Ziehier dan, waar hì aan gebonden is, die een offer- en wichelhut bouwt. 


\section{5e HOOFDSTUK (18e ,Bindoe”).}

Regelen betreffende het inwijden van een offer- en wichelhut voor den wichelaar.

Men slacht een roode en witte kip (99) om door den wichelaar geofferd te worden; men neemt een haan, geschikt om er mede te wichelen, en om door den wichelaar op de omina ,geschouwd" te worden; en men slacht een varken om dat den wichelaar, den ,dorpsouden" en den helper van den wichelaar als maal voor te zetten. Voorts haalt men een bamboestaak, bindt daar een roode kain aan als vlag, en steekt die (staak) vóór de offerhut in den grond. Vervolgens komen alle ingezetenen van het dorp goudstukken (= geld) aanbrengen, en vullen er een schotel mede. De echtgenoote van het Hoofd krijgt nu opdracht rijst te weeken, om er meel van te maken, welke rijst terdege gestampt wordt, en waaruit dan bereid worden een homp offerkoek, en een bord meel, drie ronde meelkluitjes, drie meelstaafjes, drie staafvormige meelrollen, drie meelklonten, twee platte meelkoekjes, en twee in pisangblad gekookte meelkoekjes. Als deze gaar zijn, legt men ze op een bord, en zet men een en ander beneden neer; waar de helper van den wichelaar het in ontvangst komt nemen, en naar de offerhut brengt. Vervolgens wordt de gondang in de offerhut bespeeld; en voert de wichelaar dansen uit, wat hij (éérst) doet met de offerkoek; nadat hij daarmee gedanst heeft, legt hij die neer, en danst hij vervolgens met het meel ; waarna de wichep. 233 laar met dansen ophoudt, en ook de gondangspelers stoppen. Dan gaan de dorpsgenooten aan den maaltijd, na afloop waarvan een ieder huiswaarts keert. Zoo is de gang van zaken als men een ,,sopo” voor den wichelaar inwijdt.

\section{6e HOOFDSTUK (19e „Bindoe”).}

De gebruiken, geldende voor hen, die een aanval beramen.

Vooraf vergaderen de dorpsgenooten, hetgeen des ochtends plaats heeft, waarbij de wichelaar de strijders ondervraagt, hoeveel hunner bereid zijn te gaan; nadat hij hen ondervraagd heeft, draagt hij den bereidwilligen op hun ,droom af te wachten” (100). Den volgenden ochtend ondervraagt hij de strijders dan (terzake van hun droom), en deelt elk hunner hem mede wat hij gedroomd heeft; allen, wier 
droomen gunstig waren, komen in aanmerking; met hen, wier droomen niet gunstig waren, wordt ten eenenmale geen rekening gehouden. Nadat de ondervraging is beëindigd, wordt overgegaan tot wichelen ,met d'een of d'andere wicheltoestel" (101) en het raadplegen van de hangende haan.

Zoodra nu de hangende haan en het wicheltoestel gunstige omina hebben uitgewezen, gelast de wichelaar den expeditie-leider te zorgen voor ,het maal, bij het vertrek op een expeditie genuttigd”; deze slacht dan een varken, dat in de sopo bereid wordt; en gelast zijn echtgenoote in het woonhuis rijst te koken. Als het vleesch gaar is, alsook de rijst, schept men deze met een lepel in een rijstzak, en brengt ze naar de sopo; de krijgslieden gaan nu in de sopo er rond omheen zitten, allen bijeen gezeten, en nu stopt de leider zijn krijgslieden het varkensvleesch in den mond; nadat hij hen allen (met stukjes varkensvleesch) ,gevoerd" (102) heeft, zetten zij zich aan den maaltijd, en als zij daarmede klaar zijn, dalen zij uit de sopo af naar het dorpsplein; en gaan zij elk bij zich thuis ,het voedsei „halen dat men op een expeditie meeneemt” (103); waarna zij zich weer op het dorpsplein verzamelen. De wichelaar besprenkelt de krijgslieden nu met een zuiveringsmiddel (wijdingsmiddel); waarop zij (krijgs)kreten (104) aanheffen, en voorts vertrekken. Buiten de poort gekomen lossen zij één schot los kruit, waarna zij naar het veld van den vijand optrekken. Daar brengen zij den nacht door. Nadat zij verder bij daglicht hun aanvalsplan beraamd hebben, begeven zij zich wat dichterbij de poort van den vijand, en kijken daar uit naar een plaats, waar zij zich in hinderlaag kunnen leggen; zien zij een gunstige plek, dan leggen zij zich daar in hinderlaag; zien zij echter geen gunstige plek, dan zoeken zij deze elders. Als dan de vijand naar

p. 234 buiten komt, vuren ze er hevig op en wordt er van beide kanten geschoten. Wanneer zij iemand gedood hebben, trekken beide partijen zich terug (105), en heffen zij (de expeditieleden) voortdurend vreugdekreten aan, totdat zij in hun dorp teruggekeerd zijn. (Ook) wanneer beide partijen er heelhuids afkomen, trekken de wederzijdsche schutters zich terug, en schieten zij elk op den terugweg naar hun dorp hun geweer éénmaal af. Zij doen dit nòg ééns, als zij in het dorp zijn aangekomen. (Daar) strooit de echtgenoote van den expeditieleider ongekookte rijst over de hoofden der strijders; waarna zij elk in hun eigen huis gaan eten; (dit) indien zij niemand gedood hebben. Mochten zij echter wèl iemand (van den vijand) gedood hebben, dan worden reeds, terwijl zij zich nog in de uiterste 
verschansing bevinden, de bekkens opgehangen en de groote trom op het dorpsplein neergezet, en dan worden reeds van een varken de pooten gebonden voor het maal, ,waar de expeditieleider, na voot, deel in den strijd behaald te hebben, zijn strijders op onthaalt". Zoodra de deelnemers aan de expeditie in het dorp zijn aangekomen, voeren zij vanwege dien behouden terugkeer allen dansen uit; ook de wichelaar en de expeditieleider, en voorts alle inwoners van het dorp, allen die dat doen willen. $\mathrm{Na}$ beëindiging hiervan stoppen de muzikanten; wordt het varken geslacht en gekookt en wordt ook de rijst op het vuur gezet. Als het vleesch en de rijst gaar zijn, gaan zij allen aan den maaltijd; waarna nog een en ander ,gezegd" wordt; en daarna gaat een ieder zijns weegs.

Zoo zijn de gebruiken bij het zenden van een expeditie naar 's vijand's veste.

\section{7e HOOFDSTUK (20e „Bindoe”).}

Ziehier de gebruiken, wanneer iemand een feest viert naar aanleiding van het

feit, dat hij in den krijg iemand gedood heeft.

Wanneer hij het zich permitteeren kan, dan geeft hij dat feest zoo snel mogelijk; moet hij het (geld daarvoor) echter nog ,bijeenzoeken", dan gaat er wat langer tijd mee heen; zoodra hij het (benoodigde geld) bijeen heeft, houdt hij de dorpsingezetenen ,vast” (106) (met de woorden) : „Gij allen, vrienden, wij dorpsgenooten! ,dat (voorloopig) niemand naar zijn rijstveld ga, of waarheen ook ,maar; gaat nu voorloopig nergens heen! we zijn van plan feest te ,,vieren naar aanleiding van het feit, dat we iemand in den krijg „gedood hebben, al zouden we slechts kuikens voor dat feest slachten! ,laten we dus in dit dorp bijeen zijn!" zoo spreekt de feestgever, „Wel! dat is goed, ,,feestgever”!' aldus de ,menigte”. En dan tijgen ze aan het werk, halen hout van de saroemarnaek om er een slachtpaal van te maken, halen voorts sanggarriet, en bladeren van den bortapalm, den waringin en den andoedoerpalm. Als zij dat alles bijeengezocht hebben, brengen ze het naar het dorp, heien de paal p. 235 op het dorpsplein in, en binden de slachtpaal-krans om den top daarvan; voorts draagt de feestgever zijn echtgenoote op, rijst te weeken 
om er een offerkoek van te maken; zoodra de rijst geweekt is, wordt ze gestampt, en wordt er een offerkoek van gemaakt, die, als ze gaar is, op een bord gelegd, en naar het dorpsplein gebracht wordt. En nu worden de pauken opgehangen, en de groote ,trom” op het dorpsplein neergezet; en voert de feestgever dansen uit, en mede het Dorpshoofd, als de feestgever tot de notabelen behoort of huisgenoot is; alsdan voert ook de echtgenoote des feestgevers een dans uit; nadat zij hun dansen beëindigd hebben, voeren de krijgslieden hun dansen uit, allemaal, omringend het feestvarken aan den slachtpaal; en eerst als alle dorpsinwoners die zich daartoe genegen gevoelen, hun dansen uitgevoerd hebben, houden ze er voorloopig mee op; en brengen zij de bekkens en de pauken naar het huis van den feestgever. Vervolgens doodt men het varken, kookt het binnenshuis, en zet tevens rijst te koken; en zoodra dan het vleesch, de rijst, alsook de groenten gaar zijn, legt men dat alles op onderleggers; en verdeelt de vleeschuitdeeler het vleesch; hij verdeelt de hompjes vleesch in drie porties; één (portie) geeft hij aan den feestgever; één aan de menigte, het dorpshoofd en de notabelen; één wordt toegewezen aan de expeditieleden, en deze hebben daar geheel en gezamentlijk de beschikking over; (daarentegen) gaan alle stukken vleesch, die den gasten naar hun rang worden toegewezen, (voorloopig) naar den feestgever. Een door deze daarmede belast persoon doet dan de uitnoodigingen, en wel noodigt hij alle ingezetenen van het dorp uit; als al deze uitgenoodigden in het huis van den feestgever zijn aangekomen, gaan ze (eerst) eten, waarna de feestgever de diverse toewijzingen verdeelt, en de stukken vleesch, die naar ieders rang en stand hem toekomen, onder de gasten laat ronddienen; het onderkaak-stuk en het bovenborststuk geeft hij aan het Hoofd; het bovenkaakstuk deelt hij toe aan de notabelen; eenige andere mooie stukken geeft hij aan zijn makkers. Nadat deze voorname stukken rondgedeeld zijn, gaat men aan den maaltijd, en vervolgens tot betelpruimen over, en dan wordt er nog wat gesproken; waarna een ieder zijns weegs gaat.

Zoo gaat het toe, als iemand een feest geeft naar aanleiding van het feit, dat hij in den krijg een vijand gedood heeft. 


\section{8e HOOFDSTUK (21e „Bindoe”).}

Waaraan hij gehouden is, die een hooge rijstschur bouwt dan wel een groot woonhuis.

Wanneer hij een dorpsvakman daarvoor neemt, bedraagt diens honorarium twee dollar, mocht echter een vakman van elders gehaald p. 236 worden, dan bedraagt diens honorarium vier dollar. En wanneer zij dan naar het bosch zullen gaan om hout te kappen, moet de opdrachtgever zorgen voor (slacht-)vleesch, om dit den ,architect” voor te zetten. Ze gaan dan naar het bosch, en kappen er het hout; en daar werken ze de diverse houtwerken geheel af ; en brengen deze voorts naar het dorp. Wanneer er niet veel lieden in het dorp zijn, dan roept de bouwer lieden op uit andere dorpen. Wanneer de door hem opgeroepen lieden aangekomen zijn, slacht hij een varken, dat hij aan die opgeroepenen als maal voor moet zetten; daarna gaan zij, de dorpelingen, allemaal, mèt de opgeroepenen, op weg, en brengen de houtwerken naar het dorp. Als zij ze afgeleverd hebben, slacht de bouwer een varken van twee dollar om het den houthalers als maal voor te zetten. Daarna slacht hij (nog) drie nachten (lang), nadat de houtwerken in het dorp gebracht zijn, een groot varken, een feest gevende voor (ter wijding van) die houtwerken. Als de gunstige dag daar is, laat de ,architect' de echtgenoote van den bouwheer rijst weeken om er offerspijs van te bereiden, die, als ze toebereid is, op een schotel gelegd, en naar beneden gebracht wordt. Men spreidt een mat uit op de plaats waar het huis staan moet; en legt het meel en de offerkoek daarop neer; en nu wordt de offerande opgedragen aan de Godheid der vruchtbaarheid, aan de heilige geesten der voorvaderen, aan de Waterstroomgeest, aan de Kraamvrouwen-schikgodin en aan De Drie Goden. Nadat men dit gedaan heeft, ,spijzigt” men de houtwerken; na afloop geeft men (de offerspijzen) over aan den bouwheer; en krijgen allen die zich geweerd hebben, er hun deel van. Hierna worden de stijlen (staanders) van het huis opgezet; en de verschillende deelen van het bouwsel daaraan gehecht, totdat het op-den-dakstoel-na-gereed (107) is. Nu wordt er een varken geslacht voor bijspijs van de lieden (die het huis in elkaar zetten) ; en gaan deze, als een en ander gaar is, aan den maaltijd. Dadelijk na den maaltijd maken zij het huis af tot-aan-den-nok (107); zij voltooien het dakgeraamte, met de daksparren, en de daklatten (en al). Dan is het avond en scheiden zij voorloopig met werken uit, en gaan zij p. 237 eten. Den volgenden ochtend wordt de dakbedekking gelegd. Nu 
moet de bouwheer een varken slachten voor een maaltijd voor hen, die de dakbedekking aanbrengen. Het huis wordt nu geheel afgebouwd en de stookplaats aangebracht, terwijl elke hoek van de stookplaats voorzien wordt van sangge-sangge (108) en bangoen-bangoen (109). Vervolgens laat men (den wichelaar) een gunstigen dag bepalen, en als deze aangebroken is, slacht de bouwheer een groot varken, treedt zijn huis binnen en noodigt de dorpsingezetenen in dat huis te eten; na het maal wordt er gesproken; (n.1.) spreken de genoodigden hun loftuitingen uit, voorzoover zij daartoe vaardig zijn. Wanneer de bouwheer het zich veroorloven kan, wijdt hij zijn huis officieel in, daarbij geschenken gevende aan de dorpsgenooten vanwege de hulp, die ze verleend hebben bij het bouwen; en noodigt hị de heele gemeenschap (groep van bijbehoorende dorpen) uit, om het feest mede te vieren, en laat hij den gondang spelen, zeven dagen en zeven nachten; des daags wordt de gondang bespeeld op het balcon van het huis, en worden de dansen op het dorpsplein uitgevoerd; des nachts vinden de dansen en het gondangen binnenshuis plaats. Als de zeven nachten om zijn, scheidt men met het gondangen uit, en nu slacht de bouwheer een buffel, voor een afscheidsmaal, dat hij aan zijn Hoofd aanbiedt, zoomede aan zijn verwanten van dochterszijde, en aan zijn verwanten van vrouws-zijde. Als het vleesch gaar is, gaat men aan den maaltijd; waarna de bouwheer aan het ten gastmale genoode Hoofd een kalebas palmwijn aanbiedt, hetgeen hij ook aanbiedt aan zijn dochtersverwanten en aan zijn vrouwsverwanten. Als ze dan met eten klaar zijn worden de etensborden weggehaald, reikt de bouwheer aan zijn genoodigden de (sirih-)zak aan en bedienen zij zich allen van een betelpruim, waarna de sirih-zak geretourneerd wordt. Nu spreekt de bouwheer hen allen toe; nadat hij de vele andere gasten toegesproken heeft, eindigt hij tenslotte met een toespraak (110) aan de ,,vrouws-” en ,,dochters-verwanten”. De verwanten van vrouwskant schenken hem dan elk één dollar als ,tegenprestatie”; aan elk der vertegenwoordigers van zijn dochtersverwanten schenkt hij(zelf) een oelos (schouderkleed), terwijl zijn ,,dochtersverwanten" elk een dollar aan hun ,vrouws-verwanten” (dus: aan hem) (als tegengeschenk) afgeven (111). Daarna gaat een ieder naar zijn dorp terug. Ziedaar de regelen geldende ten opzichte van hem, die cen huis of rijstschuur bouwt, wanneer hij met aardsche goederen bedeeld is; bij een arm iemand heeft een en ander nièt op deze wijze plaats. 
19e HOOFDSTUK (22e „Bindoe”).

p. 238 Waaraan hij gebonden is, die op het veld offert opdat de veldvruchten gedijen.

De dorpsgenooten komen dan eerst eens bijeen; wel, en als ze dan verzameld zijn, dan spreekt het Hoofd hun als volgt toe: „Laten ,wij, allen van dit dorp, gaan visschen (resp.: visch zien te krijgen) „om visch-in-zuur (resp. zure-visch) (112) te maken!” ,Uitstekend!” aldus de onderhoorigen en notabelen. Daarop gaan de dorpsgenooten alle voor visch zorgen, om er, elk voor zich, de diverse soorten vischin-zuur van te bereiden. Als de gunstige dag dáár is, maken zij zich op, en gaan zij buiten het dorp de benoodigde ingrediënten halen; men kapt bamboe, meet een stuk daarvan af ter lengte van een mensch, laat daar de twijgen en bladeren aan zitten; haalt voorts zand, en vezel van den aren-palm, omwikkelt het zand met die aren-vezel, en hangt dat met arenvezel omwikkelde zand aan de bamboe op. De echtgenoote van het Dorpshoofd krijgt voorts order om rijst te weeken voor meel; ook wordt er rijst gekookt; de geweekte rijst wordt gestampt en bereid tot twee brokken offerspijs, één klein en één groot brok, zoomede een bord ,geluksmeel” (113), waar een kippenei aan toegevoegd wordt; daarna wordt de offerspijs gekookt; men schept de gekookte rijst in een rijstzak; en haalt curcuma en motoengbladeren; de helft van de rijst wordt nu van curcuma voorzien, in de andere helft wordt géén curcuma gedaan; voorts wordt het in motoeng-bladeren gewikkeld; men makt twee ,peperhuisjes" (puntzakjes), twee ,ketoepat's”, twee ,lěmpěrs”, in 2 rijen gesteld. Zoodra men alle offeringrediënten klaargemaakt heeft, gaan de dorpsgenooten allen de beste kleeren aandoen, waarover ze beschikken; voorts halen zij de muziekbekkens uit het huis van het Dorpshoofd

p. 239 en brengen die naar het dorpsplein; en zij brengen uit de sopo de groote trom en de pauken naar het dorpsplein, en halen er ook blaasinstrumenten bij; dan beredderen ze nog weer de rijst, en de offerspijzen, en het meel; en vangen een paar kippen op, één witte, één roode (130), waarna zij midden op het dorpsplein de gondang bespelen (ter begeleiding van) den wichelaar, die voortdurend met de twee kippen dansen uitvoert. $\mathrm{Na}$ afloop hiervan begeven zij zich op weg naar de badplaats (bron), terwijl zij voortdurend de ,gondang dalan" (114) spelen. Als zij op de badplaats aangekomen zijn, steken zij de bamboestaak in den grond en leggen de offeringrediënten naast die bamboestaak klaar. Nu gaat de wichelaar zitten, legt 
het door hem gemaakte toovermiddel om de geesten op een afstand te houden (afweermiddel) aan zijn linkerzijde neer, en de ,tooverdrank" rechts van zich, terwijl men steeds voortgaat met gondangen; vervolgens roept de wichelaar de geesten aan: alle ,hoogere-geesten” roept hij aan, waarvan hij den naam kent; en hij roept aan: de Schikgodin voor kraamvrouwen en zuigelingen, en de Aardgeest (God v. d. vruchtbaarheid), en De Drie Goden; (hèn) allen, die deze in schuddende beweging zijnde wereld beheerschen, roept hij uitnoodigend aan; nadat hij hen aangeroepen heeft, voert de wichelaar dansen uit; en nadat hij drie malen voor hen gedanst heeft, danst hij met de offerspijzen; daarna gaat hij op zangerigen toon spreken, en roept hij zijn leermeesters, voorgangers in het leiden van de veldoffers, op: „Komt u toch hier, heilige geest van mijn leermeester „Datoe Ranggo ni Adji (115), en mijn leermeester Datoe Sorsor di „Bale (116), en Datoe Rindang di Baho (117)! Gij, mijne leermees„sters, zijt met het offeren-op-het-veld vóórgegaan! Komt mij zoo „,snel mogelijk te hulp, en gaat hier (vóór mij) staan, om mij te „,beleeren en raad te geven! Hier hebt ge de volledige offerspijzen, „geluks-meel”, een kippenei, zoomede prachtige (versierde) rijst, en „op diverse wijzen bereide visch-in-zuur; hier ook hebt ge rijst, ,„gepakt in puntzakjes, als ketoepats en als lěmpěrs, alsook palmwijn

p. 240 ,in een horen, gesneden gember, een rood en een wit hoen, en een ,fraaie uit palmvezel gemaakte haan (118) als offer aan u, mijn „leermeesters; dat alles wordt u eerbiedig als huldegift aangeboden, ,waarbij we te kennen geven, dat we dezen rijkelijk bloeienden „,banjaanboom (119) eeren, want hij komt snel op, wordt snel groot, ,bot snel uit, krijgt snel twijgen en takken, en draagt snel vruchten, ,inheemsch als hij is hier op Sumatra (120), hij ook is de verzamel,plaats van de vogelsoort ,pidong ramboe”," (121) aldus de wichelaar. Dan houdt hij met dansen op. Nu voeren de dorpsgenooten, allemaal, een dans uit; elk hunner danst met de kip en haan, en de offerkoekjes, en het meel. Als een ieder de (verplichte) dansen uitgevoerd heeft, stoppen zij er mede. De beide hoenders worden nu geslacht; volgens de regels geroosterd en vervolgens opengesneden, waarop zij (door den wichelaar) op de bijzondere teekens geschouwd worden; hierna worden ze goed gekookt; en zoodra ze gaar zijn, op een bord gelegd, en (door den wichelaar) aan de door hem aangeroepenen opgedragen. Na de toespraak gaat men aan den maaltijd, waarbij de visch en het hoendervleesch verorberd worden; als ze hiermede klaar zijn, wordt er nog het een en ander ge,,zegd"; waarop zij naar het 
dorp terugkeeren, onderweg voortdurend den marsch-gondang spelende. In het dorp teruggekomen, brengen zij de bekkens en de pauken naar het huis van het Dorpshoofd. Dan gaan de vrouwelijke bedienden aan het werk om rijst te koken, terwijl de mannelijke bedienden de bijspijzen koken; als al het eten gaar is, doet een door het Hoofd daarmede belast persoon de uitnoodigingen, en wel noodigt hij de geheele dorpsbevolking uit. Als de genoodigden gekomen zijn, zet men zich aan den maaltijd, na afloop waarvan daarmede belaste p. 241 mannelijke (bedienden) het eten opruimen, en de echtgenoote van het Hoofd de (betel-)tasch aan de genoodigden aanreikt; deze bedienen zich allen van een betelpruimpje, en geven de beteltasch weer terug. Vervolgens gaat men opnieuw aan het gondangen, en voeren allen, die er zich toe geroepen gevoelen, dansen uit, de gondangspelers volhardende tot de dag aanbreekt. Dan laat het Hoofd een groot varken halen, en dit op het dorpsplein (aan een paal) vastbinden; en worden alle muziekinstrumenten naar beneden gebracht, naar het dorpsplein, ook wordt de groote trom uit de sopo naar beneden gehaald, en midden op het plein neergezet, en de pauken opgehangen; voorts worden de offerkoeken uit de woning gehaald, alsook de rijstofferande; en nu gaan ze weer over tot het bespelen van de gondang, en voert het Hoofd dansen uit; en wel danst hij (éérst) met de rijst-offerande; als hij deze dans voleindigd heeft, danst hij met de offerkoeken; voorts gaat hij zeven maal om het het varken heen, waarna hij (met dansen) ophoudt. Na hem voeren de aanzienlijken en de onderhoorigen dansen uit; elk van de dansenden danst met de offerande en de offerkoekjes. Houden de mannen (met dansen) op, dan begeven zich de vrouwen ten dans, elk harer dansend met de offerande en de offerkoekjes; tenslotte scheiden ook deze (met dansen) uit, en voert de wichelaar weer dansen uit; nadat hij drie dansen gedaan heeft met de offerande, danst hij met de offerkoekjes. Daarop vraagt hij (hem) den tooverstaf (aan te reiken) en een bepaald kleedingstuk (122), hetwelk hij zich omdoet; den tooverstaf steekt hij nu naast het varken (in den grond) vast; en nu laat hij de muzikanten zeven malen de op de offerspijzen betrekking hebbende melodieën spelen. Nadat alle ,stukjes” afgespeeld zijn, zet hij de offerspijzen (weer) neer; en laat hij de muzikanten de ,gondang hadjembar" spelen, d.i. de gondang ter eere van Boroe Sibaso Bolon (123); en nu danst hij, met den tooverstaf in de hand, om het varken heen. Hierna houdt hij even pauze, waarna p. 242 hij vraagt een gondang ter eere van Datoe Panoesoer (124), aan

D1. 103. 
welken dans hij zich ten zeerste geeft, om dan geheel en al met dansen op te houden. De boel wordt nu opgeruimd, de bekkens binnenshuis gebracht, de pauken en de groote trom in de sopo. Dan wordt het varken bovengenoend geslacht en ten huize van het Hoofd gekookt; ook kookt men rijst. Als alles gaar is, de rijst en het slachtvleesch, dan gaat de bediende van het Hoofd (de menschen) uitnoodigen; en als de genoodigden allen gekomen zijn, gaat men aan den maaltijd. Is de maaltijd beëindigd, dan zet een iegelijk zich aan het betelkauwen, en wordt er nog wat ge,,zegd"; waarna een ieder het huis verlaat; zij hebben zich van hun taak gekweten. Zoo nu luiden de regelen met opzicht tot hen, die op het veld offeren, opdat de veldvruchten gedijen.

\section{0e HOOFDSTUK (23e „Bindoe”).}

De regelen watraan zij gebonden zijn, die een offerstellage oprichten, hetzij wij 1 de wichelaar waarzeggen moet, omdat

iemand ziek is, dan wel inzake een twistgeding.

De belanghebbende doet zijn wichelaar ,zitting” houden. Door wichelarij wordt nu de gunstige dag gekozen. Is die gunstige dag daar, dan noodigt belanghebbende zijn wichelaar uit voor een maaltijd, (waarbij) deze twee helpers oproept; zij gaan eerst aan den maaltijd. Nadat zij gegeten hebben, maken de wichelaar en zijn dienaren zich op, om het offerstellaadje te bouwen. De lastgever doet de (van te voren bereide) offers in een rijstzak, en de wichelaar gelast dan (één van) zijn bedienden deze (rijstzak met) offers in een kleed gewikkeld op den rug te dragen, waarvoor zij een oelos ,ragidoep" (125) gebruiken; en nu gaan zij op weg naar de plaats, waar ,de geest van den oudsten voorvader" verblijf houdt. Daar bouwen sij het stellaadje. De helpers (van den wichelaar) halen jonge boompjes (126) en ontschorsen die; verder gelast hij één hunner te gaan halen: ,mare-mare”, en (een soort) riet, bladeren van den andoedoer, zoomede bladeren van jonge arenpalmen en waringinbladeren. Zoodra deze teruggekomen is, zetten zij het stellaadje op, en nadat dit van een rondhouten vloer voorzien is, bevestigen zij de maremare (aan het stellaadje), en wel doen zij het er rondomheen. 
Zij steken voorts een stammetje aan den achterkant van het stellaadje in den grond, daaraan binden zij de einden van de maremare(slinger) vast; verder bevestigen zij er andoedoerbladeren aan, bladeren van jonge arenpalmen, riet en waringin-bladeren; en wel rondom elken paal van het stellaadje. Als het stellaadje voltooid is, maken zij (van) bamboe zooiets als een (hoender-)korf, om er het tegenmagische middel in te doen; twee stuks maken zij ervan, en die bevestigen zij dan aan de deur van het offerstellaadje, één aan den linker-, één aan den rechterkant; die aan den linkerkant maken ze van aarde, die aan den rechterkant bestaat uit water; (dat) water doen zij in een Caladium-blad (127), en dat hangen zij dan aan de korf. Voorts nemen zij een boomstammetje ter dikte van een arm, en voorzien dat van inkepingen om er een ladder van te maken. Als p. 243 dit gedaan is, bevestigen zij het aan het stellaadje; (maar) ze zetten het op den kop, de punt (bovenkant) naar beneden gericht, de voet (het ondereind) naar boven. Dan draagt de: wichelaar de offerspijzen op aan de Godheid der vruchtbaarheid, aan den Voorvadergeest, aan den Waterstroomgeest, en aan De Drie Goden. Nadat hij dit gedaan heeft, offert (128) hij aan het stellaadje, den geesten aanzeggende, het stellaadje dien éénen nacht te bewaken, opdat er niets aan beschadigd worde. Hierna keeren zij huiswaarts. De opdrachtgever geeft nu last om rijst te weeken; er worden twee soloeps te weeken gezet. Dan worden er drie hoopjes offerspijs bereid, één daarvan zóó groot, dat de geesten het niet omvatten kunnen, en twee nog grootere; daarnevens worden bereid één hoopje kogelvormige meelkluitjes, drie (pinkdikke, tusschen de palmen der hand gerolde) meelstaafjes, drie kleine staafvormige meelrollen, drie in de ,vuist” saamgedrukte rijstballen, drie met zout bereide meelklonten, en drie in banaanblad gekookte meelkoekjes. Als ai deze dingen bereid zijn, worden ze gekookt. Voorts wordt er bereid een bord meel. En verder worden er gemaakt vier betelpruimen waarbij de steel aan het blad gelaten wordt, waarvan twee in een vierkant gevouwen, en twee gevormd als de snuit van een rat. Als het te-koken-gezette gaar is, wordt het op een houten schotel gelegd om in den wind af te koelen (129); daarna doet men al die ingrediënten voor de offerande in een rijstmand, met daarnevens één roode krans, en één witte krans (130), en speciaal bereide.(131) gember, en palmbloesem. Dan kookt men rijst, en zoodra deze gaar is, maakt men twee puntzakjes, twee vierkante zakjes van opgevouwen blad, en twee rechthoekige zakjes van gevouwen blad. Hierna worden de wichelaar en zijn hel- 
pers geroepen om te komen eten, na afloop waarvan zij huns weegs gaan. Als het weer dag is, roept de lastgever de muzikanten en personeel op, en geeft hun een maaltijd tezamen met den wichelaar. Voorts bereiden zij, wien dat door lastgever is opgedragen, zure visch en visch-in-het-zuur, om naar buiten het dorp (naar het of ferstellaadje) mede te nemen; en worden er twee hoenders, één witte, t.w. een (vecht-)haan, en één zwarte, t.w. een kip, opgevangen. Dan nog wordt een jonge maagd (132) in de kleeren gestoken, en wel in een nieuw gewaad, met gouden sieraden en groote kralen; en doet men één bekken en de kleinste trom hooren, zoomede een klarinet en een gescheurd (of gebarsten) bekken; en begeven zij zich op weg. $\mathrm{Na}$ aankomst aan het stellaadje, legt men de offeringrediënten op het stellaadje, laat er één homp offerspijs achter, bij wijze van huldegift (aan de geesten); op de mat legt men die neer, nadat men ze op een schotel gelegd had; nadat de offeranden neergelegd zijn, neemt de wichelaar zijn plaats in, grijpt de beide hoenders beet, en noodigt de geesten uit, zich van het aangebodene te bedienen; de muzikanten gaan intusschen steeds door met den gondang te bespelen, terwijl de p. 244 wichelaar voortgaat met het uitnoodigend oproepen van de geesten. Als hij hiermede klaar is, pauzeert hij, en houden ook de gondangspelers op. $\mathrm{Nu}$ worden de hoenders geslacht, en nadat de haan geschouwd is, worden de (beide) hoenders gekookt, en als ze gaar zijn, op een schotel gelegd. Daarop beginnen de muzikanten weer met het bespelen van de gondang, en draagt de wichelaar de hoenders aan de geesten op; nadat hij dit gedaan heeft, worden ze verdeeld; aan de muzikanten wordt hun portie toebedeeld, ook aan de helpers wordt een portie gegeven, en de ,lastgever" krijgt zijn deel. Nadat zij gegeten hebben, gaan zij naar huis terug, steeds de gondang bespelend, totdat zij in het dorp terug zijn. Daar aangekomen, gaan zij naar het huis (van lastgever), (voortdurend) de gondang bespelend, terwijl de lastgever c.s. dansen uitvoeren. $\mathrm{Na}$ deze dansen laat men de gondangspelers voorloopig pauzeeren, en tijgen de vrouwelijke bedienden aan het werk, om rijst te koken. Dan laat de ,lastgever" een varken halen van een dollar waarde, en laat hij dit door mannen bereiden. Als rijst en slachtvleesch gaar zijn, zendt ,lastgever" (offerfeest-gever) iemand uit, om de menschen uit te noodigen. Als de genoodigden gekomen zijn, gaat men eten, waarna men opnieuw begint te gondangen. $\mathrm{Nu}$ gaan dansen uitvoeren: de helpers van den wichelaar, de muzikanten, de vrouwelijke bedienden, voorts de lastgever-tot-het-offerfeest, en de wichelaar. Nadat deze 
drie dansen uitgevoerd heeft, reikt de "lastgever" den wichelaar de offerspijs aan; en deze draagt ze dan op aan de geesten van zijn overleden leeraren, en aan den geest van zijn nog levenden voorganger; nadat hij met die offerspijzen gedanst heeft, stopt hij. Het gondangen houdt nu op, een iegelijk gaat naar buiten, en de groote trommen worden naar de sopo gebracht. Als het weer dag is, slacht de ,lastgever" een kip voor een maaltijd voor den wichelaar; en zoodra ze gaar is, wordt de wichelaar uitgenoodigd, en gaan zij aan den maaltijd. Na het maal, wordt de $\operatorname{sirih}(z a k)$ aan den wichelaar aangereikt. Daarna spreekt de lastgever zijn wichelaar uiteindelijk toe (zich excuseerende voor het sobere maal, dat hij hem voorzette) (133) en verzoekt hij hem zegenwenschen te willen uitspreken. Nadat de wichelaar het een en ander gezegd heeft, neemt hij afscheid, zijn taak is volbracht.

Zoo luiden de regelen, waaraan hij gebonden is, die een offerstellaadje opricht.

\section{1e HOOFDSTUK (24e „Bindoe”).}

Wat hij doen moet, die offert aan den schutsgeest van de rijst op het veld, opdat

$z$ ij $n$ a rbeid vruchten draagt.

Hij kan dat doen in den zaaitijd, of na het zaaien, danwel na het wieden. Alsdan wordt de wichelaar geroepen, en wordt (door wichelen) de (gunstige) dag gekozen. Daarna zendt de ,lastgever” iemand er op uit, om visch te vangen. Als deze van de vischplaats teruggep. 245 komen is, wordt een gedeelte van de visch bereid tot zure visch, een ander gedeelte tot visch-in-zuur, de ronde visch tot offervisch. En als dan de uitgewichelde dag aangebroken is, dan tijgt de ,lastgever” aan het werk; hij geeft aan vrouwelijk personeel opdracht kransen te maken en motoengbladeren te halen; gelast anderen rijst te weeken; geeft voorts aan mannelijk personeel opdracht een slachtpaal te maken. De vrouwen stampen de geweekte rijst, een deel van haar maakt er meel van, anderen offerkoeken. Zooals de (diverse) soorten (offerspijzen) die de oprichter van een offerstellaadje laat bereiden, zijn ook de soorten offerkoek die hì laat maken, die offert aan den schutsgeest van de rijst. Daags daarop gaat het personeel van ,lastgever” aan het werk om rijst te koken en als deze gaar is zendt lastgever zijn personeel met uitnoodigingen rond en worden alle 
inwoners van het dorp genood. Als de genoodigden gekomen zijn, zetten zij zich aan den maaltijd, waarna men tot besprekingen overgaat. Vervolgens gelast „lastgever” zijn bedienden een varken bij de pooten te binden, (waarna het met de pooten omhoog weggedragen wordt); een groot varken nemen zij daarvoor. En dan maken zij zich op om te gaan, en vertrekken zij naar het rijstveld. Als zij op het veld zijn aangekomen, heien zij er den slachtpaal in, en binden daar het varken aan vast. Voorts leggen zij er alle of feringrediënten neer. $\mathrm{Nu}$ roept de wichelaar de geesten uitnoodigend aan; na dit aanroepen van de geesten wordt het varken gedood en toebereid; (intusschen) is ook de rijst gaar geworden en gaan zij aan den maaltijd. Na dit maal reikt de vrouw van ,lastgever” de betel-zak aan; en voorzien zij zich allen van een betelpruim; na het gebruiken waarvan nog het een en ander ge,,zegd" wordt. Hierna deelt de wichelaar mede, hetgeen naar zijn deskundig inzicht verboden (134) moet worden: „Welnu, heer ,lastgever”! Wil luisteren naar wat ik ,zeg! het verbod dat ik $\mathrm{U}$ voorschrijf is, dat gedurende de zeven „komende nachten niemand het rijstveld betreden mag buiten u, ,lastgever; en mocht iemand dit veld tòch betreden tijdens de komen,de zeven nachten, dan zal hij de schade, die U, mijn lastgever, lijden ,zal, tot het volle bedrag moeten betalen; mocht voorts iemand van ,een ander dorp het verbod overtreden, dan zal hij de schadeloos,stelling (135) aan $U$ onder het spelen van de gondang (hetgeen „,meerdere kosten met zich brengt) moeten aanbieden!”, aldus de wichelaar. Daarna brengt de lastgever het aan de ingezetenen van het dorp over: „Zoo is het dan, heeren! wij, die hier op dit veld staan, ,als er onder ons zijn, wier kinderen niet aanwezig zijn, laten zij ,hen dan vanavond bekend maken met het door den wichelaar uit„gesproken verbodsvoorschrift: „Mijn lastgever! luister naar het ,,verbod dat ik U als deskundige voorschrijf!” zoo zeide hij. Welnu

p. 246 „dan, mijne heeren! gij allen (menigte)! luistert naar het door den „leermeester uitgesproken verbod!” aldus ,lastgever”. Waarop de menigte haar bijval te kennen geeft. Nadat hij uitgesproken is, keeren zij naar het dorp terug, en is de taak volbracht. Zoo luiden de regelen voor hem, die offert aan den schutsgeest van de rijst. 
22e HOOFDSTUK (25e „Bindoe”).

Regelen voor hem, die een beeld als platsvervanger in actie brengt, hetzij ingeval

van ziekte, danwel va nwege een

belangrijke gebeurtenis (136).

Wanneer aan de geesten slechts een uit wilde banaanstam (137) gesneden beeld wordt opgedragen, dan behoeven er geen offerkoekjes van rijst bij gebruikt te worden, doch kan worden volstaan met offerrijst aan te bieden ter betuiging van hulde en eerbied (138). Nadat de ,plaatsvervanger" buiten het dorp gebracht is, behoeft het offer (139) slechts te bestaan uit een kippenei; de ,waggelende” plaatsvervanger heet dat. Mocht echter iemand een onheilspellende droom gehad hebben, of bij het wichelen met de haan ongunstige voorteekenen zich hebben voorgedaan, dan moet men een dikke stam van een tamme banaan halen, en maremarebladeren, zoomede bladeren van een ouden arènpalm (dienende laatstgenoende bladeren) om er een offermandje (140) van te vlechten. Van die banaanstam (141) wordt dan een menschelijke figuur (beeld) (142) vervaardigd; een offermandje wordt gevlochten; en de maremarebladeren (tot lange linten) gespleten; verder laat de bij-de-zaak-belanghebbende jonge andoelpakstammetjes van buiten het dorp halen. En vervolgens geeft hij zijn vrouw opdracht een kop rijst te weeken; en als deze geweekt is en gestampt, dan wordt er één grootere offerkoek van gemaakt, en één koek, die door de geesten niet te omvatten is. Is een en ander gaar, dan wordt de wichelaar geroepen, de ,plaatsvervanger” wordt naar de woning gebracht, zoo ook de maremare, en het offermandje, en de andoelpak-stammetjes. Als alle offeringrediënten in de woning zijn gebracht, dan schrapt de helper van den wichelaar de (afgeblakerde) schilfers (143) van de rijstpot af, en wordt de ,plaatsvervanger" be-ascht; de kleine(re) offerkoek wordt in het gevlochten offer-mandje, de grootere offerkoek op een bord gelegd, gember in dunne plakjes gesneden op een motoeng-blad en wat palmwijn in een horen gegoten. Dan verzoekt de wichelaar den cliënt om een oude versleten mat, wikkelt hier den ,plaatsvervanger” in, bekleedt de borst van den plaatsvervanger met de maremare,,linten”, en legt hem vervolgens de stokken voor het dragen van een lijkbaar (144) op de borst. Hierop vraagt hij den cliënt om de offerrijstkoekjes, stopt deze in een rijstzak en draagt ze aan de geesten op. Nadat hij dit gedaan heeft, ,voedert" hij den plaatsvervanger, knijpt met de 
nagels een weinigje van de sagoesagoe (145) en van de timpa (146) af en stopt (ook) dat den plaatsvervanger in den mond; dan neemt hij met een paar vingers wat gemberplakjes op, die hij den plaatsvervanger (eveneens) in den mond stopt; tenslotte druppelt hij hem p. 247 wat palmwijn uit den horen in (den mond). Als de spijziging is afgeloopen, richt de wichelaar zich op, wikkelt (zich) een witte doek om het hoofd, stampt drie maal op den vloer, fluit daarbij drie malen, zingt den plaatsvervanger toe (147), en sist hem weg (148) : ,oeloebalang" (voorvechter) noemt de wichelaar dezen ,plaatsvervanger”. Nadat deze toegezongen is, bespuwt (149) de belanghebbende hem, waarop de knecht van den wichelaar den plaatsvervanger naar buiten brengt, de wichelaar gaande achter den wegbrenger. Als de plaatsvervanger gedeponeerd is, wordt hij tweemaal toegeroepen (150); en daarop keeren zij naar huis terug. In de woning (van zijn cliënt) teruggekeerd, strooit de wichelaar rijstkorrels over het hoofd van zijn cliënt. Hierna zet de wichelaar zich neer (tot voortzetting van zijn taak); de cliënt haalt een jong haantje, geschikt om als wichelhaan dienst te doen, en geeft die den wichelaar, hem tevens aanbiedende een betelpruim in schuitvormig betelblad gewikkeld, voor dadelijk gebruik gereed. En nu bezweert de wichelaar het haantje tot het uitbrengen van een orakel. Als dit gebeurd is, snijdt hij het haantje open, en roostert het volgens de regels; na het roosteren, legt hij het haantje (in stukken) open, en beschouwt de diverse teekens; na het schouwen rukt hij het de ingewanden uit, waarna het vleesch van het haantje en die ingewanden gekookt worden. Zoodra het vleesch gaar is, en er ook rijst gekookt is, wordt de rijst op een schotel opgehoopt en het vleesch van het haantje daarbij gelegd. Daarna maakt men nog een maal gereed, bestemd voor den wichelaar. Dan verzamelen zich de cliënt cum suis en offert de wichelaar voor de gezamentlijke animae van den cliënt en al de zijnen. Na het offeren gaan zij aan den maaltijd, waaraan zich mede zetten de wichelaar en zijn knecht. Vervolgens geeft cliënt als belooning van den wichelaar aan deze een van de ,beste stukken" van het haantje, (n.1.) één poot; verder geeft hij hem een pijp van bamboe, gevuld met een mengsel van de bast van de tolong-bistik en tabak, en een betelpruim in schuitsgewijs gevormd betelblad. Nadat zij klaar zijn met eten, gaan zij tot den betelpruim over. Na het betelpruimen verzoekt de cliënt (den wichelaar) den zegen (te willen uitspreken), waaraan de wichelaar dan voldoet. Nadat hij (den zegen) uitgesproken heeft, verlaat de wichelaar met zijn knecht het huis, zijnde hun taak vol- 
bracht. Zoo nu luiden de regelen voor hem, die een ,parsili” als plaatsvervanger in actie stelt.

\section{3e HOOFDSTUK (26e „Bindoe”).}

Ziehier de regelè voor hem die een ,sipaimbar" (151) als plaatsvervanger stelt.

Dit kan geschieden voor een kip, die haar eieren opslurpt (152), voor honden die in zijn woning coitus plegen (153); voor slangen, die coitus bedrijven; voor hagedissen, die elkaar omhelzen; voor kreeften, die elkaar omhelzen; voor sprinkhanen; of voor menschen, die coitus bedrijven. Dan vraagt hij den wichelaar den gunstigen dag te willen bepalen; nadat de wichelaar hem dien bekend gemaakt heeft.

p. 248 gaat de cliënt voor visch zorgen, waarvan hij gedeeltelijk zure visch, gedeeltelijk visch-in-zuur maakt. Als dan de door den wichelaar uitgewichelde dag dáár is, noodt hij hem ten eten; de wichelaar roept twee van zijn knechten op; samen gaan zij aan den maaltijd. Na den maaltijd gaan ze tot besprekingen over en vraagt de cliënt, welke ingrediënten hij moet hebben, waarop de wichelaar ze alle opnoemt Dan gaan zijn knechten er op uit, om ze te verzamelen, (de wichelaar) alles opnoemende, wat zijn knechten verzamelen moeten. $\mathrm{Zij}$ verzoeken den cliënt om een leeren zak, gaan het dorp uit, en halen dan tabartabar(154)-bladeren, zeven takken met zeven bladeren van den sĭbalikangin (een boom, welks bladeren met den wind een witten achterkant laten zien), , zeven bladeren van den andoelpak; zeven van de gandaroesaplant (155); zeven van een zeker laag gewas, dat men op de graven pleegt te planten (156); zeven van de palisstruik (157); zeven van een zekere slingerplant; zeven van de babolhas (158), zeven van de langge (159); twee sihoeks (160); twee bladeren van de siling (160); twee van de bira (161); en twee planten zwarte rijst. Wanneer zij dat alles bijeengegaard hebben, brengen zij het naar de woning van cliënt. Dan zegt de wichelaar den cliënt aan, rijst te (laten) weeken. Drie maten rijst worden er geweekt en goed gestampt. Als de rijst gestampt is, wordt de wichelaar geroepen. $\mathrm{Er}$ wordt dan eerst één offerkoek bereid. Daarna vraagt hij aan zijn knechten de bira-bladeren en de twee siling-bladeren en wordt het meel bereid. Als er voor een menschelijk wezen een plaatsvervanger moet worden ge- 
steld, dan maakt hij van het meel een menschelijke figuur; geldt het een hond, dan vormt hij van het meel) een hond; als het een kip geldt, dan makt hij het in den vorm van een kip; als het een slang is, geeft hij er den vorm aan van een slang; gaat het om een hagedis, dan maakt hij er een hagedis van; als het een kreeft geldt. dan vormt hij er een kreeft van; en als het sprinkhanen betreft, geeft hij er de vorm van een sprinkhaan aan. Nadat hij dit werk voltooid heeft, verzoekt hij om een ouden (versleten) rijstwan, en daarin worden dan de bijeengezamelde ingrediënten bijeengedaan. Voorts legt hij de offerspijs op een bord, en de twee soorten van zure visch op een schotel, maar die legt hij elk op een aparte plaats neer. Daarna verzoekt hij cliënt om de offerrijst, en doet die in een rijstzak. Vervolgens laat cliënt een haan opvangen, geschikt om als wichelhaan dienst te doen, geeft deze over aan den wichelaar; en deze roept dan in p. 249 een gebed de geesten aan; na deze aanroeping ,,voert” een bediende van den wichelaar de verzamelde ingrediënten; daarop neemt de wichelaar ze, in een kleed gewikkeld, over den schouder, grijpt het haantje, en bezweert het, een prevelgebed uitsprekende, om een orakel uit te brengen; heeft dit plaats gehad, dan (be)spuwen cliënt en de zijnen (den plaatsvervanger), en als dit gebeurd is, brengen de knechten van den wichelaar den plaatsvervanger voor de dorpspoort, waarna zij in het dorp terugkeeren. Nu wordt het haantje geslacht, en nadat het geslacht en geroosterd is, volgens de regels in stukken gesneden en worden de goede en slechte teekens opgenomen; na dit schouwen wordt het haantje gekookt. Als dan het vleesch en ook de rijst gaar zijn, wordt (de rijst) op een schotel opgehoopt en het haantje daarbij gelegd; ook stapelt men nog een hoopje rijst op, bestemd voor het maal van den wichelaar. Daarop verzamelen cliënt c.s. zich allen en offert de wichelaar het haantje aan hun gezamentlijke animae. Nadat hij geofferd heeft, gaan zij eten, ook de wichelaar en zijn knechten. Voorts geeft cliënt den wichelaar het hem krachtens zijn functie toekomende. Als de maaltijd afgeloopen is, gaat men over tot betelpruimen. Daarna neemt cliënt het woord en verzoekt hij den wichelaar zijn zegen-wenschen uit te spreken. Als dit plaats heeft gehad, vertrekken wichelaar en helpers; zijn taak is volbracht. Zoo luiden de regelen voor hem, die een ,sipaimbar" als plaatsvervanger stelt. 


\section{4e HOOFDSTUK (27e „Bindoe”).}

De regelen geldende voor hen, die een behoedmiddel (162) (willen) maken.

Geldt het een behoedmiddel voor het geheele dorp (163), dan moeten de dorpelingen collectief rijst en kippen bijdragen; voorts moeten zij, van het betrokken dorp, voor visch zorgen. Als de (door den wichelaar uitgewichelde) gunstige dag dáár is, moeten zij hun (bijdrage aan ) rijst brengen naar het huis van het dorpshoofd. Dan koken de vrouwelijke bedienden van het dorpshoofd die rijst, terwijl de mannelijke bedienden de bijspijzen (groenten en vleesch) en de visch koken. Als het eten gaar is, gaan bedienden van het dorpshoofd de menschen uitnoodigen; alle inwoners van het dorp worden genood. Als de genoodigden gekomen zijn, gaat men eten. Nadat de maaltijd is afgeloopen, weeken bedienden van het Hoofd wat rijst; en maken er één offerkoek van; daarop koken zij deze zooals het hoort en als ze gaar is, doen ze die in een rugzak; evenzoo de offerrijst, palmwijn in een horen, en gember, en olie (vet), en zwartsel (164) en garen. Voorts neemt de wichelaar voor het verzamelen van de benoodigde ingrediënten een nog onbedorven knaap, hij laat hem een oelos ,ragidoep” (165) als schouderdoek dragen, een „simarindjam” (166) als saroeng, een sjerp als gordel, een dolk als mes, en een tooverstaf als stok. De wichelaar zelf gebruikt als stok een lans, die met messingbanden versierd is. Dan vertrekken zij tot het bijeengaren van de ingrediënten; sommigen gaan bamboe zoeken, anderen maremare, en weer anderen halen vezel van den aren-palm; het zoeken van sanggesangge (167) en bangoenbangoen (167) wordt opgedragen aan hen die (óók) voor oebi-knollen moeten zorgen. Dadelijk als zij het dorp uit zijn, beijveren zij zich om de ingrediënten te verzamelen. Als zij alle ingrediënten, de zij vinden kunnen, verzameld hebben, begeven zij zich naar den stam van een pisang sitabar (168); daar prikt (de wichelaar) den tooverstaf rechts van hem in den grond, links de met messingbanden versierde lans; voorts zet hij er de offerspijzen neer en den palmwijn, de gember, de offerande en een wierookvat, waarna hij een en ander aan de geesten opdraagt. Nadat hij dit gedaan heeft, bewierookt hij den pisangstam; en wikkelt daar het (medegebrachte) garen om. Daarop steekt hij zijn speer in de bast van de banaan tot twee vingers breedte, dit doet hij in het vierkant, en wipt dan het (vierkantje bast) met de punt van het dolkmes los. Als dit (vierkantje) op de oelos gevallen is, be,,schouwt" hij het: 
als het dadelijk ,,met den hollen kant naar beneden" valt, dan is dat gunstig; mocht het echter met den bollen kant naar beneden (dus ongunstig) neerkomen, dan wipt hij voor een tweede maal; het afgespeerde stukje (bast) legt hij voorts bij de offerrijst. Hierna legt hij de binnenbast van de pisang bloot; meet stukken af van telkens vier vingers breed en ter lengte (hoogte) van den afstand van den top van den middelvinger tot aan het midden van de handpalm, en dan snijdt hij uit die binnenbast twee maal zeven stukjes. Is dit afgeloopen, dan keeren zij naar het dorp terug. Daar aangekomen, brengen zij de door hen medegebrachte ingrediënten naar het huis van het dorpshoofd. $\mathrm{Nu}$ voorziet hij de stukken bamboe (die ze eveneens medegebracht hebben) van letters en teekens, twee stuks per huis, één (om) vóór het huis, één (om) binnenshuis (te worden aangebracht). Verder worden er korven gemaakt in den vorm van een kippenkorf, om, boven op een bamboestaak aangebracht, er het behoedmiddel in te plaatsen. Dan is het avond en noodigt het Hoofd den wichelaar en alle ingrediëntenverzamelaars uit zich aan den maaltijd te zetten. $\mathrm{Na}$ den maaltijd teekent (de wichelaar) op de bijeengegaarde bladsoorteri diverse teekens en figuren (169), zoowel de ,toempak-sala”-figuur (170), als kwadraten (171) en kruisjes (172). Als hij met de teekeningen klaar is, stopt hij ze in een rijstmand. Dan vangt men een haan op, die geschikt is voor het ,hangorakel", en wel een vechthaan, een roode haan, die boven de sneb een plek heeft, waarvan de kleur bij die van het geheele lijf afsteekt.

p. 251 De wichelaar nu wascht van den haan pooten en snavel, en laat hem drinken; waarna hij hem aan den linkerpoot vastbindt; vervolgens spreidt hij een mat uit op het brandhout-stellaadje en legt daar de (rijstmand met de) ingrediënten op; daarna bindt hij den haan vast, terzijde van de rijstmand; bevestigt de lans aan de linker-, den tooverstaf aan de rechterzijde, en legt er vervolgens het dolkmes neer; dan legt hij als offer naast de rijstmand de offerkoek neer, zoomede de offerrijst, en palmwijn in een horen, de in stukjes gesneden gember en twee soorten van visch-in-zuur. Dat biedt hij dan aan in een gebed (173) aan de Godheid der vruchtbaarheid (Aardgeest), aan de heilige Hoogere geesten der voorvaderen, aan de Waterstroomgeest, aan de Kraamvrouwenschikgodin, aan de demonen van de dertig dagen, en die van de twaalf maanden, aan den heiligen geest van zijn nog levenden leermeester, aan de geesten van zijn overleden leeraren en aan De Drie Goden. Is dit offer gedaan, dan „,voedert” hij de ingrediënten, het (dolk)mes, den tooverstaf en de speer. $\mathrm{Na}$ 
dit ,,voederen”, ruimt hij de offerkoek en de offerrijst op. waarna een ieder het huis verlaat en slapen gaat. Als het weer dag is, spreidt men een mat in het midden van het dorpsplein uit, brengt de ingrediënten uit het huis naar beneden, mitsgaders den tooverstaf ; alle utensiliën brengt men naar beneden. Daarop voorziet de wichelaar den rijstwan van teekens en figuren, waarna een wierookvat wordt klaargezet en bewierookt hij eerst de biezen mat (174) (waarop hij straks zijn wichel-verrichtingen zal doen); nadat deze bewierookt is, doet hij hetzelfde met den rijstwan; daarna bewierookt hij. de citroenen, waarmede hij (straks) wichelen zal, zoomede het mes (175) (waarmede hij straks uit de citroenen schijfjes zal snijden). Nadat de bewierooking heeft plaats gehad, spreidt hij de biezenmat uit, legt den rijstwan op die biezenmat, legt voorts de citroenen op den rijstwan, tezamen met het mes (dat hij gebruiken zal); bedekt dan de citroenen met een witte kain; en wijdt voorts die middelen naar behooren door tooverspreuken en gebed; als hij dit gedaan heeft, haalt hij de witte kain weer weg, en verdeelt hij de citroenen; eerst geeft hij er het Dorpshoofd twee: één citroen voor de mannen, één citroen voor de vrouwen; dan geeft hij er twee aan het Hoofd van de inwonende marga (176); daarna worden alle ingezetenen van het dorp er van voorzien, elk gezin twee stuks : één citroen voor de mannen, één voor de vrouwen, vervolgens wordt aan het Hoofd afgegeven de dorpscitroen; en verder geeft hij zijn knechten hùn citroenen, zoomede die voor hem, wichelaar, zelf; ook geeft hij er aan de p. 252 verzamelaars der ingrediënten, terwijl er één citroen in de rijstzak gelaten wordt, bestemd voor het behoedmiddel. En nu staat het Dorpshoofd op, en draagt in een gebed (177) aan de animae van de mannelijke leden (van zijn gezin) hun citroen op, waarna hij die aan den wichelaar overreikt. Deze snijdt er boven den rijstwan schijfjes af (die hij op den rijstwan laat vallen); en deelt, als hij er een orakel uit kan opmaken, dit aan het Dorpshoofd mede. Daarna reikt het (Dorpshoofd den wichelaar) de citroen van de vrouwelijke leden van zijn gezin over. De wichelaar snijdt er schijfjes af; en deelt het daaruit verkregen orakel mede. Voorts geeft een ieder van de dorpsgenooten zijn citroen aan den wichelaar (voor het verrichten van dezelfde waarzeggerij). En tenslotte doet de wichelaar dezelfde verrichting met de dorpscitroen. Vervolgens neemt hij het dolkmes in de hand, legt een (vleesch-)hakbord neer, en houwt schijfjes af van de citroen van het voorbehoedmiddel; daaruit komt hij te weten, of het door hem gemaakte voorbehoedmiddel 
kracht heeft of niet; wanneer steeleinde en kroontje beide met den hollen kant naar beneden liggen (178), dan is dat (een) gunstig (teeken) en heet het ,dat het krachtig is”; mocht voorts het steeleinde op den hollen kant liggen, en het kroontje op den bollen kant, dan is ook dàt gunstig, en heet het ,oentetoeboe” (179); als beide schijfjes op den bollen kant liggen, dan is het voorbehoedmidde? minder krachtig; wanneer het kroontje op den hollen, het steeleinde op den bollen kant ligt, dan ziet het er leelijk uit, „niet harmonieerend" wordt dit genoemd. Nadat het wichelen (met de citroenen) beëindigd is, gaat men over tot het slachten van het haantje. De wichelaar hangt dit voorts volgens de regels op; en als het dood is, ,schouwt" hij de pooten, de darmen, en de vleugels; hierna roostert hij het volgens de regels; is het dan geroosterd en gesecteerd, dan kijkt de wichelaar naar de orakelteekens; na beëindiging waarvan het haantje gekookt wordt. Vervolgens worden de ingrediënten (bovengenoemd) in stukjes" gehakt, waarbij allen een geschreeuw aanheffen (180). Als zij met het hakken gereed zijn, en het haantje gaar is, vraagt een bediende in de woning de (benoodigde) rijst, waaraan het haantje toegevoegd en aan de opgeroepen geesten aangeboden wordt. Daarna wordt een hamer uit de woning gehaald, en nu ,,voedert” (de wichelaar) de bestanddeelen (181) van het voorbehoedmiddel, zoomede den speer, den tooverstaf, het (dolk)mes en den hamer. Daarop spreekt de wichelaar tooverformulieren uit, neemt zijn bediende den hamer op en slaat er voortdurend mede (182), terwijl alle lieden een geschreeuw aanheffen. Nadat de wichelaar de tooverformulieren uitgesproken heeft, houdt men ook met het geschreeuw op, en gaat een iegelijk over tot het maken van zijn p. 253 voorbehoedmiddel-houders (183); den langsten houder steken zij vóór hunne huizen in den grond, den korten houder plaatsen zij binnenshuis; verder hangen zij mare-mare-bladeren in de dorpspoort op, alsook bladeren van de hatoenggal (184) en bladeren van de silindjoeang (185) èn ,afwendkruid” en ,afschrikkruid”. Nadat een ieder in de woning zich nedergezet heeft, noodigt een bediende van het Hoofd (de menschen) ,aan tafel”, en gaan zij allen aan den maaltijd. Als het eten gedaan is, wordt de betelzak aan de genoodigden aangereikt, één aan den wichelaar afzonderlijk. Hierna wordt gesproken en spreekt het Dorpshoofd den wichelaar toe, zich excuseerende voor het eenvoudige maal (133). Na beëindiging van den maaltijd, verzoekt het Hoofd den wichelaar om zegenwenschen uit te spreken. Vervolgens ondervragen de dorpsingezetenen hem elk 
(ten aanzien van het over hen uitgebrachte orakel). En nadat dan de wichelaar hun medegedeeld heeft, wat de citroenen voor elk hunner als orakel uitbrachten, doet hij kond van de verbodsvoorschriften, die men in het belang van (een goede werking van) het voorbehoedmiddel in acht nemen moet: ,gedurende de komende drie nachten „,mag er niet getwist worden; mocht er toch iemand in het tijdsver„loop van deze drie nachten twist maken, dan is hij een haan schuldig „en twee soloeps rijst; wel, daar wordt hij dan mee beboet! Vandaag „mag men geen grond uitgraven! ziedaar de geboden in het belang „,van ons voorbehoedmiddel, voorzoover ons, inwoners van dit dorp, ,,betreft! Wat de menschen buiten ons dorp aangaat, die geen ver,wanten in dit dorp hebben, zij mogen hier niet binnenkomen; mocht ,er toch zoo iemand binnenkomen, zonder naar de verbodsvoorschrif„,ten geinformeerd te hebben, dan krijgt hij voor de hem op te leggen „,boete geen betalingstermijn, maar moeten wij hem met kracht tot ,,betaling manen!” Aldus de wichelaar. Nadat de wichelaar dit uitgesproken heeft, gaat een ieder huiswaarts. In het tijdsverloop van de (gezegde) drie nachten moet de wichelaar het voorbehoedmiddel nog voortdurend bezweren.

Zoo nu luiden de regelen voor hen, die een voorbehoedmiddel voor het dorp laten bereiden; geldt het een voorbehoedmiddel voor een enkel huis, dan hebben slechts de bewoners van dat huis de zorgen en lasten ervan te dragen.

\section{5e HOOFDSTUK (28e „Bindoe”).}

Regelen voor hen, die een ,afweer"-

offerschotel willen maken.

De bewoners van het betrokken dorp moeten beginnen met voor visch te zorgen. Als ze dan die (aan een palmblad-nerf geregen) (186) offerande-visch hebben, vlechten zij ieder voor zich uit palmbladeren een offerschotel en zet elk gezin rijst te weeken. Als zij ieder hun offerschotel gereed hebben, halen zij bamboe, om er een (soort hoender-)korf van te maken. Als het avond is, leggen zij de offerspijzen op de offerschotels. Vervolgens wordt aan jongelingen en knapen opgedragen om buiten het dorp op de loer te gaan liggen, p. 254 waarna zij zelf het dorp uitgaan, een ieder van hen zijn of ferschotel dragende; mèt hen vertrekken twee met een geweer bewapende 
lieden. Als zij buiten het dorp zijn, zetten zij de offerschotels op een rij neer, de bamboestaken (waarop de korven met schotels geplaatst worden) in den grond vaststekende, waarna een ieder zijn offerande ten eigen faveure aan de geesten opdraagt. Als dit gebeurd is, worden de twee geweren afgeschoten. De op de loer liggenden staan nu uit hun schuilplaats op, en nemen den inhoud van de offerschotels weg; dan worden zij (de ,wegnemers”) achtervolgd; en loopen deze hard weg, om hetgeen zij weggenomen hebben in veiligheid te brengen. Vervolgens keeren de achtervolgers naar het dorp terug, achter hen aan de op-de-loer-liggers, het door hen weggenomene opetende, immers mogen zij dat niet naar het dorp medenemen; (eerst) nadat zij het opgegeten hebben, keeren (ook) zij naar het dorp terug. En dan legt zich een ieder te ruste.

Zoo luiden de regelen voor hen, die een ,afweer"offerschotel maken. 


\section{COMMENTAAR BIJ DE VERTALING, voorzoover niet reeds in den tekst verwerkt.}

(1) Bij voorkeur wordt er voor het wichelen een haan, soms echter ook wel een kip gebruikt. Ook tot offerdier neemt men bij voorkeur een haan.

(2) Ter verduidelijking hiervan en van hetgeen in de verdere hoofdstukjes betrekking heeft op de aan-verwantschapsverhoudingen moge onderstaand schema dienen:

Hendrik mg. Aritonang

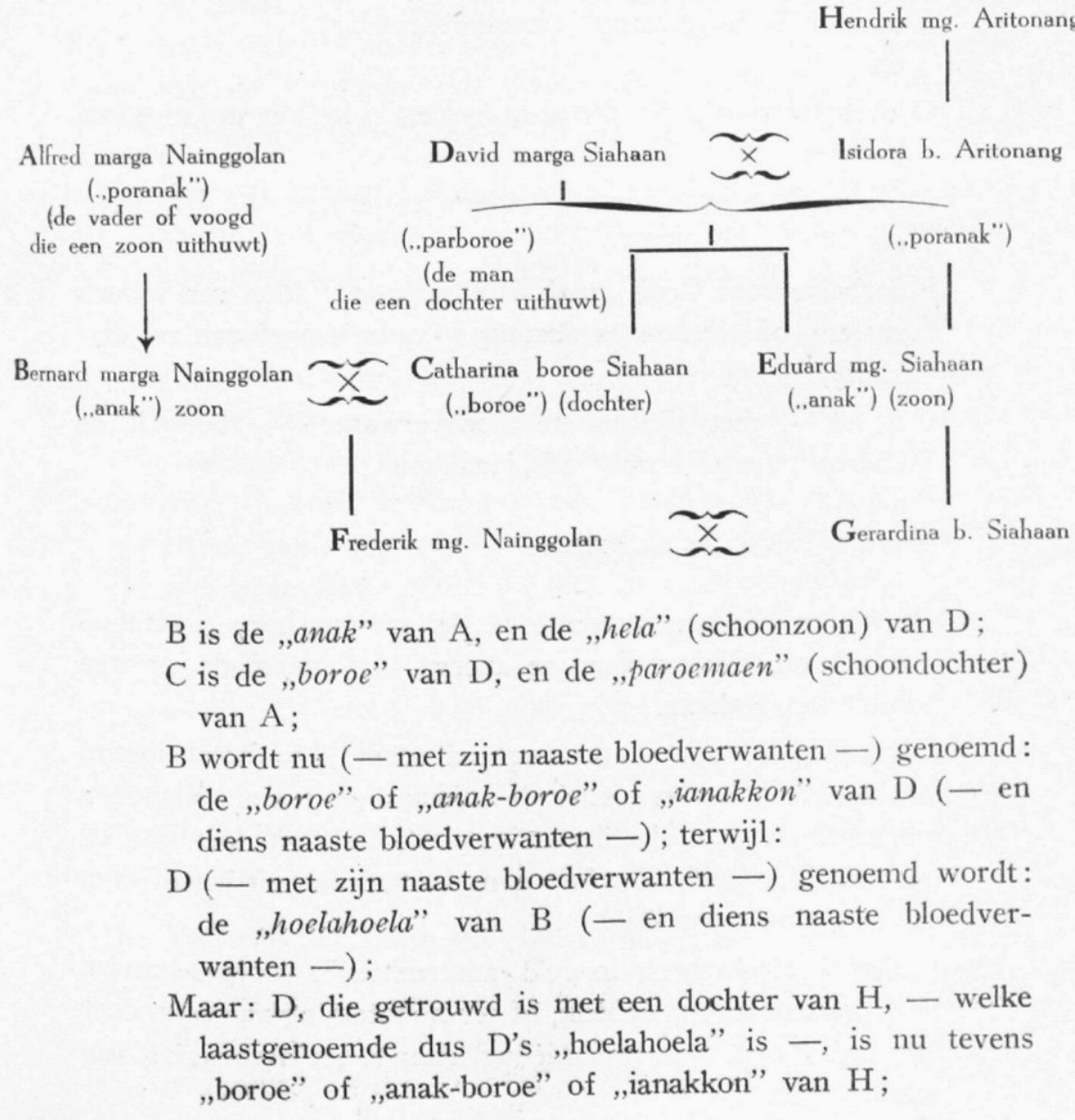

D1. 103. 
D heeft dus aanverwantschap (,partondongan”) naar twee kanten :

1e door zijn vrouw krijgt hij als aanverwanten: de „hoelahoela" (weleens vertaald met ,bruidgever”), in dit stuk te noemen: de ,vrouws-verwanten";

2e door zijn dochter: de ,boroe”, ,anakboroe” of ,ianakkon”, (weleens vertaald met ,bruidnemer”), in dit stuk te noemen: de ,dochters-verwanten”).

Nu kan zich nog door het z.g. ,voorkeur”- of ,cross-cousin”huwelijk, dat ingesteld werd om een eenmaal ontstane partondongan te verstevigen, het geval voordoen, in bovenstaand schema geillustreerd door het huwelijk van $F$ met $G$ :

$\mathrm{E}$ is voor $\mathrm{F}$ de ,toclang” (moedersbroeder),

en

$\mathrm{G}$ derhalve voor $\mathrm{F}$ de ,boroe ni toelang” (dochter van moeder's broeder),

$\mathrm{C}$ is van $\mathrm{G}$ de ,namboroe” (vader's zuster),

en

F derhalve voor G de ,anak ni namboroe” (zoon van vader's zuster), of ,ibebere ni damang” (vader's neef van zusterskant),

$\mathrm{F}$ is nu - met zijn naaste bloedverwanten - voor $\mathrm{E}$ de ,,boroe”, ,anak boroe” of ,,ianakkon”;

en

$\mathrm{E}$ is voor F de ,hoelahoela”.

De marga Siahaan tenslotte is de ,marga boroe” (trouwmarga) van Nainggolan, de marga Aritonang de ,marga boroe" van Siahaan.

(3) (,mangoepaoepa”) of (,mangoepa tondi”) = het beloonen van de tondi, den levensziel, de anima, dien den animistischen mensch, zoo goed als dieren en planten, leven doet, aan de materie leven geeft. Die belooning bestaat dan uit het offeren van een goeden maaltijd.

(4) (,piso") = geschenk in geld, adatrechtelijk voorgeschreven, bij wijze van tegengeschenk, of ter honoreering van bijv: door den radja verleende bemiddeling, danwel ter verkrijging van zekere rechten. 
(5) (,mangalangkoep”) = ,echtbreukplegen”, onder welk begrip de Batak echter niet slechts dat verstaat, wat wij daarmede aanduiden, want door den Batak wordt ook hij ,pangalangkoep" geheeten, die van een meisje werk maakt dat reeds met een ander ,verloofd"is, en waarvoor door dien ander reeds een gedeelte van den ,koopprijs” betaald werd. En zoo heeft „,pangalangkoephon" de beteekenis van: een door den parboroe reeds aan een ander toegezegd meisje aan een derde uithuwen, voordat het door den anderen candidaat voor haar betaalde voorschot op den bruidschat terugbetaald is.

Het ,mangalangkoep” in het hier omschreven geval wordt als een nog ernstiger feit aangemerkt, omdat er reeds een „partondongan" (aanverwantschap) tusschen partijen (,hoelahoela" en ,,ianangkon”) bestond, en met het uithuwen door de hoelahoela van een andere dochter aan derden, het ,,voorkeurrecht" van de ianakkon, d.i. diens recht op een ,cross-cousin”huwelijk, veronachtzaamd is.

(6) Zie voor een parallel met de Minangkabausche adat het Hoofdstukje: „Oepatjara toeroen mandi di Minangkabau” in „Modern Maleisch, Zakelijk Proza” van Dr. C. Hooykaas.

(7) (,Sioeli-goar”) : = het kind ,,met den schoonen naam”: De (Heiden-)Batak mag den naam van zijn vader of andere naaste verwanten niet rechtstreeksch noemen - zulks is „soebang” (= taboe) - omdat hij daardoor de ,tondi” (anima) van den betrokkene zou kunnen blootstellen aan het gevaar van een eventueel kwaadwillende magische kracht. Ook zịn eigen naam geeft hij niet graag rechtstreeksch op; wil men zijn naam weten, dan moet men hem de vraag stellen, hoe het kind heet naar wien hij zich noemt: ,,ise panggoaranmoe?". En wel is het oudste kind, waarnaar de vader en de moeder zich noemen met „Ama ni - ” (de vader van -), en „Nai - - (de moeder van -). Vaak schromen zij ook dien afgeleiden naam te noemen, en moet men zich tot derden wenden, om te weten te komen, hoe iemand heet.

(8) Vgl. van der Tuuk, blz. $136 \mathrm{j}^{\circ}$ blz. 148.

(9) (,soehoet") : in het algemeen degeen die de leiding heeft en de verantwoordelijkheid draagt; het hoofd van het gezin, de aanvoerder in den ,oorlog”, de feestgever, enz. 
(10) („na sohaboeboehan”) : v. d. Tuuk Wdb. ,dat nimmer nog gebruikt is, zoowel van goederen gezegd, als van een maagd, of een jongeling, die nog niet met de andere kunne kennis gemaakt hebben".

(11). (,ngarngar”) $=1$. potscherf; 2. een zekere kamfersoort. Zie hier een van de bij het Batakvolk zoozeer gewilde woordspelingen, die nu eens een gunstigen, soms ook echter een kwaden magischen invloed zouden kunnen uitoefenen. De gedachte n.l., dat het gesproken woord een magischen invloed uitoefent, leeft bij den Batak zeer sterk; gaarne maakt hij daarom gebruik van op elkaar gelijkende woorden, - op meerdere voorbeelden daarvan kan in de hier behandelde onderwerpen gewezen worden -, omdat hij daar hetzij de gewenschte goede uitwerking van verwacht, of een door hem beoogde vernietigende kracht. Aan den anderen kant vermijdt hij soms het gebruik van anders alledaagsche woorden, bijv. op jacht, in den ,oorlog”, of in het oerbosch, waarvan o.a. de „Kamfertaal” een uitvloeisel is. En vooral is het de ,tooverpriester-wichelaar”, die bedreven is in het, ter magische beïnvloeding, uitdenken en gebruik maken van zoowel symbolische handelingen, als karakteristieke woordspelingen.

(12) (,singko”) : ,even zijn van het getal, bij het tellen van rijstkorrels, waaruit men een greep neemt, die men vervolgens twee aan twee telt;... zoo nu het getal even is, dan is dit een gunstig voorteeken, en wat men voorheeft, als b.v. de voorgestelde naam van een kind, wordt doorgezet" (van der Tuuk, Wdb. 170).

(13) Men geeft aan de geesten dus niet het beste weg, hetgeen ook niet noodig is, omdat het hierbij niet om de materie te doen is, doch om ideeële motieven gaat.

(14) eigenlijke beteekenis van ,,marioelangi”: iemand uit de hand iets in den mond stoppen.

(15) „piso”: vgl. noot 4, óók: het geschenk in geld, dat de familieleden van de bruid bij het huwelijk ontvangen.

(16) „boroe ni sipanorbangi”) : v. d. Tuuk, Wdb. blz. 251.

(17) 1 ,riar” (reaal) $=25$,oeang” $=400$ duiten; 1 ,hoepang” $=6$,oeang”; 1 , ,binsang” $=4$ Downloaded from Bri 
(18) De ,porhalaan” (tooverkalender) dient uitsluitend voor het (door den wichelaar) kiezen van den gunstigen dag (,pandjoedjoeronari”).

(19) (,,soehoet”) : vgl. noot 9.

(20) Vgl. de indeeling van de (slaap-)ruimte in een Bataksch huis, door mij beschreven op blz. 17 van „Het Toba-Bataksche Huis". (Meded. Encycl. Bur. Afl. XXIII).

(21) n.l. een zoogenaamde ,,sende sihoelimat" = een fraaie hoofddoek.

(22) Let wel op de woordspeling, beteekenende ,,doegoel 2" zoowel: „,schouderstuk van het slachtvleesch”, als: „knuppel” (vgl. noot 11).

(23) Bij de Bataks heeft een ,,tali” de waarde van 3 ,oeang” = 48 duiten (15 ct.).

(24) ,,een teeken, dat de twistende partijen aan den bemiddelaar overgeven ten bewijze dat zij, zoolang hij de zaak in handen heeft, zich van vijandelijkheden zullen onthouden, bestaande meestal in een wapen” (v. d. Tuuk, blz. 430).

(25) (,telaga”) is de ruimte in het midden van de woning, waarheen de voeten wijzen van de in lengte- en in de breedterichting van het huis te slapen liggende personen. De Bataksche woning toch is niet in werkelijke vertrekken, doch slechts in denkbeeldige slaap- en woonruimten verdeeld, die des nachts hoogstens door matten eenigszins afgeschut zijn: vgl. noot 20 en het op die blz. vermelde omtrent de slaapstede van de bruid.

(26) Let hier weer op de woordspeling! ,hasampoeran” toch beteekent zoowel: ,,vermenging” als ,,echt-vereeniging”; de ,,vermenging" i.c. betrekking hebbende op de rijst met visch (vgl. noten 22 en 11).

(27) Wederom een woordspeling: ,loengloengan” toch beteekent zoowel : ,afkomstig van een loengloeng”, ,een van een kleine opening voorziene, met steenen afgedamde plaats op ondiepe plaatsen eener rivier, om er visch te vangen”, als : ,een mat, die gordijnsgewijze om een slaapstede hangt".

(28) Hier staat in de Bataksche tekst: ,,inantasida”, waarschijnlijk is hier een $n$ uitgevallen, en werd bedoeld ,inantanasida”, een

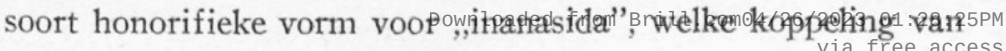


een beleefdheidsvorm in de 1e persoon meerv. aan een pron. poss. van de 3 e persoon niet ongebruikelijk is: zoo staat ,amanta hami” naast het specifiek honorifieke „damang”. (Het Bataksche praefix ,da-” = het Maleische suffix ,-da”). (De door Malaici gemeenlijk gehuldigde opvatting dat het Maleische suffix ,-da" verklaard zou moeten worden als te zijn ontstaan uit „Baginda”, zoomede de daaraan vastgeknoopte exegese dat, waar dit honorifieke suffix zoowel bij den 2 en als bij den 1en en 3en persoon gebezigd wordt, zulks moet worden toegeschreven aan een teloorgaan van de etymologie van genoemd suffix, moet óók in verband met dit Bataksche aequivalent als onjuist worden bestempeld.

Zoowel het Maleische als het Bataksche „da” komt m.g. vaak, n.l. in die gevallen, waar gedacht moet worden aan uitingen van aanhankelijkheid, teederheid, intieme genegenheid, e.d., overeen met ons toevoegsel ,-ke” (moederke, meiske, vrouwke enz.).

(29) (,paroendjoek”) = de ,poranak": de vader van den bruigom, of hij die namens deze optreedt en de bruidschat betaalt.

(30) „poramaan” = „degeen, aan wien men een vader heeft”, d.i. in eerste instantie na den eigen vader diens broer, die namens hem optreedt. En zoo kan insgelijks ,,boroe” óók beteekenen: »dochter « van vader's broer" en andere mannelijke verwanten, van den vader, die namens deze optreden.

(31) eig. $=$ een pompoen bekappen, figuurlijk $=$ een twistgeding voeren. Vgl. v. d. Tuuk, Wdb. blz. 376 ad : ,singkam mabarbar" = een sikkamboom, waarin men gekapt heeft; figuurlijk: een twistgeding, dat voor een vergadering is gebracht, daar de vergaderingen in de open lucht gehouden worden, en de menigte, daarbij tegenwoordig, gewoon is, vermaaikshalve hier en daar in een boom te hakken".

(32) Vgl. aanteekening ad: „paramaan” (noot 30); blijkbaar treedt als procureur één van de ,paramaan”'s op.

(33) (,pariban”) = zuster van iemand's vrouw, alsook haar man. (,toelang”) $=$ broeder van iemand's moeder.

(34) (,Oelos sampetoea”) : v. d. Tuuk, Wdb. : ,benaming van een oelos, die de bruigom zijn schoonvader bij de voltrekking van zijn huwelijk geeft" (dus andersom). 
(35) „pan(g)oembari” is de aan weerskanten van de woonruimte in de lengterichting van het huis tegen de stijlen aangebrachte lange plank, welke middels (tusschen lengtestoof en stijltop vastgeklemde) houten haken (oengal 2) zijn opgehangen. Zie „Het Toba-Bataksche Huis”, blz. 18.

(36) Onder ,,begoe” verstaat de Batak de ,tondi ni na mate” : geest van den afgestorvene; vgl. van der Tuuk ad ,djolma”: „sitonga di begoe, sitonga di djolma" = ,tenhalve bij de menschen, tenhalve bij de geesten zijn, is : half dood zijn.

(37) ,parsoemangotan” = „parsimangotan” = de gezamentlijke soemangot (of simangot). Zoo worden genoemd de geesten van gestorven voorname verwanten, die onder dezen titel een hoogeren rang bekleeden dan de „begoe”, de geesten van de groote meerderheid van gewone verwanten.

(38) Vgl. noot 13.

(39) De uitdrukkingen: ,boroe manaek”: als het meisje bij den jongeman ,bovenkomt”, en : ,,boroe maitoeroen” : als het meisje uit het huis van haar vader ,,afdaalt" (= wegloopt), staan in beteekenis gelijk aan de uitdrukking ",boroe mahiompo", waarnaar Van der Tuuk in zijn woordenboek ad "manaek" verwijst. Een meer uitvoerige verhandeling over het mahiempe-geval geeft „Patik dohot oehoem ni halak Batak”, dat, voorzoover het huwelijksrecht betreft, door mij vertaald werd, en opgenomen is in Kol. Tijdschrift, Jaarg. 1921, nos. 1-3.

(40) Voor ,hata saoet” geeft Van der Tuuk: „benaming van hetgeen iemand den vader van het meisje dat hij koopen wil, te eten geeft, als teeken dat de zaak doorgaat".

(41) $\mathrm{Bij}$ het betalen van den bruidschat moet de vader van den bruigom n.l. een stuk vleesch meebrengen.

(42) Wanneer hij dus een crosscousin-huwelijk pleegt. (Zie noot 2).

(43) Ethnologisch wil het mij wel van belang voorkomen, in verband hiermede op te merken, dat er steeds abusievelijk geschreven en gesproken wordt van het ,gebruik van het afvijlen der tanden" zonder meer. Bij de Bataks althans is, zooals ook uit het in dit hoofdstukje beschrevene blijkt, het afvijlen niet de hóófdzaak, maar slechts een finishing touch bij het afbeitelen; vgl. Van der Tuuk (wdb.) : „lontik” I: 
,een ijzeren werktuig, waarmede men de tanden kort beitelt”; en dienovereenkomstig: „,mangalontik” I : „kort beitelen der tanden.

(44) (,badja”) : na het afbeitelen en gladvijlen van de tanden worden deze met een zalfje van roet uit badja-hout besmeerd, hetgeen dienen moet, eensdeels om den pijn aan de min of meer blootgekomen tandzenuwen te verzachten, anderdeels om tandontstekingen te voorkomen.

(45) Het onderste, geheel open, gedeelte van de rijstschuur wordt n.l. gaarne voor dergelijke werkzaamheden gebruikt, aangezien ze met het oog op de duisternis niet binnenshuis, en o.a. met het oog op de vrij rondloopende honden, varkens etc. niet op het dorpsplein kunnen worden verricht.

(46) Hier in de beteekenis als van het ,werpen" van dobbelsteenen; v. d. Tuuk (Wdb.) geeft dan ook voor ,,boeang” (blz. 410) $=$,de tanden zóó vijlen (lees: afbeitelen), dat de splinters er afspatten, uit het vallen der splinters de toekomst willende voorspellen".

(47) De voorspelling wordt gedaan op de splinters van den eersten tand, die kortgebeiteld wordt.

(48) (,mordaoep”) : volgens v. d. Tuuk (blz. 284) : „naam van een rots, die naar de overlevering vroeger menschen opgeslokt zou hebben".

(49) Zooals al eerder opgemerkt is (zie noot 1), neemt men voor de waarzegging liefst een haan, omdat het mannelijke exemplaar meer ,tondi" heeft, dan het vrouwelijke. En als de datoe dit voor zijn doel gewenscht vindt, bepaalt hij zelfs zijn voorkeur op een jong haantje, omdat bij een jong haantje de meeste kans bestaat, dat er geen ziekelijke afwijkingen e.d. zich voordoen, die een ongunstig omen zouden opleveren.

Zie ook v. d. Tuuk, ad „manoek” (blz. 418).

(50) ,porsili”. V. d. Tuuk: = ,een beeld als plaatsvervanger van iemands lichaam, zooals gebruikelijk is bij het afwenden van een kwaal, die door een geest is verwekt".

Op dat beeld wordt dan de ziektekwaal of ev. andere gebreken van den patiënt door magische middelen overgebracht, waarna het beeld zoo spoedig mogelijk weggebracht wordt naar de 
plaats waar de booze geesten worden vermoed zich op te houden.

(51) („Pormasan”) : een gevlochten zak voor het bergen van rijst, als inhoudsmaat gelijkstaande met 12 ,,soloep”: 1 ,,soloep” = 4 ,,bale” of ,tangkar” (= de Mal. takar), welke laatstgenoemde maat ongeveer met een klein melkblikje gelijk staat; 4 soloep $=1$,,soehat".

Het woord ,pormasan" voor rijstzak moet de afleiding van het grondwoord „mas” ontleend hebben aan de ,gouden” kleur van rijpe padi.

(52) Dat hier niet gerept wordt van de noodzakelijke vóórwerkzaamheid van den wichelaar: het bepalen van ,den gunstigen dag" moet aan bekorting worden toegeschreven; deze steeds noodzakelijke vóórwerkzaamheid werd imers in de hieraan voorafgaande hoofdstukken reeds genoegzaam vermeld, en werd hier mitsdien als iets vanzelfsprekends kortheidshalve weggelaten. Voor het bepalen van den gunstigen dag wordt ò gebruik gemaakt van de ,porhalaan": zie noot 18; danweI van ,,mormanoek di ampang”, zie blz. 390 van Tijdschr. BB 1915 , in mijn artikeltje over de Permalimsekten.

(53) i.c. ,bron”, óók: „,badplaats”, bestaande meestal slechts uit een bamboe-(water)leiding of als zoodanig dienende uitgeholde aren-stammen.

(54) V. d. Tuuk: ,een offerande bestaande meestal in één soloep gepelde rijst, één kippenei, één boengaboenga, één gedraaid betelblaadje, badja, olie, en drie geknipte betelbladen met hun toebehooren".

(55) Namelijk die van de voorvaderen, wier zegen voor het welslagen van den oogst op de van hen geërfde akkers ingeroepen wordt.

(56) Met „sombaon” (= de te aanbidden persoon) wordt aangeduid de oudste van de soemangot ni ompoe, d.i. van de geesten der voorvaderen (zie noot 37 ).

(57) V. d. Tuuk (blz. 326) : ,tegen het vuur aan gaar-gemaakt vleesch, dat fijn gehakt, en met Spaansche peper, zout en limoensap genuttigd wordt". 
(58) V. d. Tuuk (blz. 290) = ,,salintoktok” (blz. 153) : fijn gehakt rundvleesch, met bloed, Spaansche peper, limoensap en zout genuttigd".

(59) eig.: de lieden, die de poot-gaten maken; hier moet deze term echter, evenals in den aanvang van deze beschrijving, als een algemeene benaming worden opgevat voor allen, die aan de eerste bewerking van den drogen akker deelnemen, derhalve omvatten deze ,pangordang” zoowel : de pootgatenmakers, als de werkelijke zaaiers en de lieden, die, na het gaten-maken en zaaien, de pootgaten weer dichten door aanvegen van aarde en mest, ev. als zoodanig dienstdoend vuil-afval.

(60) V. d. Tuuk (blz. 194) : ,bezem, waarmede men op een hauma de vuilnis over het gezaaide veegt, om te beletten, dat er de vogels bijkomen".

(61) In tegenstelling van vorengenoemde ingkajoe dengke; vg!. v. d. Tuuk, blz. 117 :, ingkajoe godang = groente, in tegenoverstelling van ingkajoe, daar dit ook visch of vleesch beteekenen kan".

(62) V. d. Tuuk, blz. 15: = „sampak aek” (blz. 146); eigenlijke beteekenis $=$,met water werpen", euphemistische uitdr. voor : „oorlogsverklaring, bestaande in een getal tegelijk geloste schoten, die men in de nabijheid van den vijand laat hooren".

(63) (,tawar”) $=$,plant met witte bloesem en roode bloemknoppen", (v. d. Tuuk 237).

(64) V. d. Tuuk, blz. 388 (1e) : ,zeker boompje; de geelgroene ronde als een maizkorrel groote vruchten zweeten, als zij rijp zijn, van binnen steeds vocht uit"; (2e) naam van een hijzonder groote tolong-soort".

(65) (,maremare”): v. d. Tuuk, blz. 420: ,zekere moerasplant (varen), wier witte bladen bij feestelijke gelegenheden ter begroening dienen”. Mij is als ,maremare” slechts bekend de versiering gemaakt van jonge bladeren van den aren-palm, die daartoe opengevouwen en vlakgestreken worden (van het jonge blad zitten de beide helften op elkaar gekleefd).

(66) Ziehier een voorbeeld van het toeschrijven van magische kracht aan het gebezigde voorwerp. In het aanval- en afweermiddel gebruikt de Batak gaarne allerlei zaken, die ,door den 
bliksem getroffen" zijn, zich de vernietigende kracht van den bliksem overgebracht denkend op dat voorwerp. Dergelijke voorwerpen heeten dan ook ,,morbegoe" te zijn, in tegenstelling met voedingsmiddelen en geneesmiddelen, die men ,,mortondi" noemt.

(67) Ook voorwerpen, die op eenigerlei wijze gemaltraiteerd zijn, vertrapt, stukgehakt, doorboord, verroest, gesmolten of versleten, danwel afkomstig zijn van onder noodlottige omstandigheden gestorven menschen of dieren, zijn den tooverpriester welkom; waarbij de idee voorzit, dat de vijand of de geesten, tegen wie het toover- of afweermiddel aangewend wordt, eveneens vertrapt, stukgehakt, etc. zal worden.

(68) In de Borasnipati, de hagedis, die de Batak in drie soorten onderscheidt, n.1. boraspati-ni-tano $=$ veldhagedis, horaspatini-hoeta $=\operatorname{dorps}(\mathrm{wal})$ hagedis, en boraspati-ni-roema $=$ huishagedis, denkt de Batak zich belichaamd de Godheid der vruchtbaarheid; men vindt dan ook in vele streken, o.m. in Oeloean-Toba, (vgl. Het Toba-Bataksche Huis, blz. 14) op huizen en rijstschuren een hagedis gebeeldhouwd, náást, of in de plaats van, de overigens meer gebruikte figuur van de vrouwenborsten, tot het ,,afroepen” van rijke oogsten en kinderzegen.

(69) Een andere natuurgod is Boroe Saniangnaga, die in de gestalte van een slang in rivieren zoude huizen, en als heerscheres van den stroom gedacht wordt zoowel een goeden, als een kwaden invloed op het lot der menschen te kunnen uitoefenen.

(70) Onder de Debata na Toloe moeten verstaan worden de drie goden: Batara Goeroe, Soripada en Mangalaboelan, de Bataksche Trimoerti; hiernaast noemt de Bataksche mythologie nog den Debata Moela Djadi (den „Schepper”), en Debata ni Asiasi (God van het medelijden); van laatstgenoemden heeft de Batak echter uiteraard niets te vreezen, ergo behoeven aan hen geen offers gebracht te worden.

(71) „badia”, eig. : ,tondi na badia” = de heilige geest. Een leeraartooverpriester als i.c. heeft immers evenals aanzienlijke Hoofden, dappere aanvoerders, rijk met kinderen gezegende lieden, en zoomeer, een sterker en rijker ,tondi” dan de massa. Deze aangeboren of verworven superioriteit wordt ook met ,sahala" aangeduid: vgl. noot 1 op blz. 360 Tijdschr. Binn. Best. 1914 
in mijn artikeltje: „De Toba-Bataksche Grondrechtsbegrippen” en (noot 2) op blz. 188 van Tijdschr. B.B. 1916 in mijn artikeltje over „De Permalimsekten van Oeloean, Toba en Habinsaran".

(72) Zie v. d. Tuuk, blz. 258 ad ,,manindi”.

(73) (,disanti”) : Vgl. v. d. Tuuk, blz. 142.

(74) De ,hangende haan” wordt, nadat hem de keel is doorgesneden, eerst uitwendig geschouwd: of de snavel vol danwel leeg is; of de oogen open zijn, danwel met bloed gevuld; of de veeren glad liggen of rechtopstaan, enz.

(75) Ook de inwendige schouw is van belang voor het vernemen van gunstige of ongunstige omina: kleeft er bijv. bloed aan de lever, dan zullen er dooden vallen; en wel bij de eigen partij, als de lever links bebloed is; bij den vijand, als het bloed aan den rechterkant is. En zoo meer.

(76) V. d. Tuuk (blz. 377) = pormasan: vgl. noot 51.

(77) „Boroe na mora” : (de rijke vrouw) is de Geest die het gemunt zou hebben op kraamvrouwen en zuigelingen; zij wordt gedacht te huizen in kloven en ravijnen.

(78) Behalve de natuurgeesten kent de Batak ook de astrologische geesten, aan wie de tijdindeeling te danken is; hier gaat het om de verdeeling in maanden (manen), elders om de verdeeling in telkens 7 dagen, ontleend aan de 7 planeten, die ook aan onze dagen de namen gegeven hebben( zon, maan, Mars, Mercurius, Jupiter, Venus en Saturnus). Vgl. ook: Legge, blz. 40 : „, . . de beschermgeest van dit jaar; den geest die de tiende maand bestuurt, en degenen die elken dag bewaken...." (,De Godsdiensten van China, beschrijving van het Confucianisme en van het Taoisme", vert. d. C. Beets).

(79) V. d. Tuuk, blz. 14: ,geldbedrag aan de verwanten eens gesneuvelden, door den aanlegger van de expeditie te betalen".

(80) V. d. Tuuk, blz. 375: parbaribaan $=1 / 2$ binsang $=2$ dollar.

(81) ampang = een groote mand, parmasan $=$ een gevlochten rijstzak (12 soloep) : vgl. noot 51 .

(82) De hier genoemde drie functies worden straks breeder omschreven. Voor „partahi moesoe” geeft v. d. Tuuk, blz. 219: 
,.iemand die de mindere werkzaamheden die een expeditie voorafgaan, moet doen: als bijv. het vangen van de kip waaruit de datoe den toekomstigen uitslag moet afleiden".

(83) V. d. Tuuk, blz. 329: ,pande-pande” (of : ,pande hata”) = een persoon die in het midden van de twistvoerende sprekers zit, om het einde van ieders redevoering, en het antwoord daarop aan te kondigen; zoo een persoon stelt men, om het tegen elkander schreeuwen van de disputanten te vermijden".

(84) Zie v. d. Tuuk, blz. 328: ,pantang = een verbod, dat men nakomen moet, om iets te doen gelukken, als bijv. het niet eten van zekere spijzen, om een geneesmiddel van kracht te doen zijn; pantangan = een sopo in oorlogstijd, waar de datoe zit te wigchelen, en vele dingen niet mogen plaats hebben (van daar den naam)"; (verschillende pantang worden in dit hoofdstuk genoemd).

(85) „Gordang” is de groote trommel. Tot het volle orkest behooren nog 5 ,tataganing”, en als kleinste der trommels de „odap”, verder 5 gongs (,ogoeng”), die op elkaar afgestemd zijn, één waarvan „hesekhesek”, heserheser”, „hasarhasar”) een barst hebben moet, en dan nog de klarinet (,saroene”).

(86) „poea” is eigenlijk (zie v. d. Tuuk, blz. 357) : ,de door zijn kunstig nest bekende vogel, die bij ons onder den Mal. naam „,tămpoewa” bekend staat (fringilla planceus)”.

(87) V. d. Tuuk, blz. 355: ,poeroerpoeroer: meelkluitjes van de grootte van een geweerkogel, als ingrediënt van offeranden". Hier komt de symboliek met haar magische kracht (vgl. noot 22) weer tot uiting, immers: poeroer $=$ hard gemaakte kleikluiten die met de sijor (slinger) tegen de rijstdiefjes worden geslingerd; vgl. ook het door V.d. Tuuk ad verbum „poeroer” aangehaalde spreekwoord: ,'t is beter dat de kleikluiten de rijsthalmen neerslaan, dan dat de rijstdiefjes de rijst opeten" ". Vgl. mede de hierboven gebezigde uitdrukking: „offerspijs niet door de geesten te omvatten", waarmede bedoeld wordt, dat de geesten wel het essentieele van de offerande, den geur mogen genieten, doch niet de geheele substantie mogen meenemen"; vgl. noot 13 .

(88) V. d. Tuuk, blz. 52: ,indahan nioebatan" = indahan na hinoenihan". 
(89) V. d. Tuuk, blz. 54 : ,mangoeras” = iets zuiveren, heiligen, als bv. een wigchelarij om ze krachtig te maken" (Pangoerason is derhalve te vergelijken met wijwater).

(90) De Bataksche ,gamelan”, bestaande uit de instrumenten in noot 85 opgesomd.

(91) (,balokbalok”) : eig. = ,grensscheiding”, i.c. (zie v. d. Tuuk, blz. 377) : ,een kleed, dat de wigchelaar op de pattangan (phonetisch geschreven) - vóór de andjap 2 (= ragaraga = gevlochten borden voor of ferdoeleinden) uitgespreid houdt, om de geesten die den vijand toegedaan zijn, er van af te houden".

(92) De „tondi” (anima, levensziel) wordt geacht het menschelijke lichaam, ook anders dan door den dood, te kunnen verlaten.

(93) ,partondion” = ,tondi”; zooals ,parsimangotan” (zie noot $37)=$,simangot”. (De ,par....-an”- of ,par....-on”"constructie dient om uit te drukken de collectiviteit, het geheel, het totaal; i.c. vgl. ons: ,met uw geheele ziel”).

(94) Zie.v. d. Tuuk, blz. 352, verwijzende naar ,sialtong” op blz. 24 : ,benaming van de grootste der 9 pauken, die, alleen geslagen, teeken van alarm is".

(95) V. d. Tuuk, blz. 267: ,zich het hoofd bedekken, zooals de weduwe zeven dagen lang na den dood van haar man doet, brengende zij gedurende dat tijdsverloop iederen morgen spijzen naar zijn graf".

(96) a. (,halang”) : schuins ergens op doen rusten: v. d. Tuuk, blz. 76: „zooals men de pauken doet, wanneer men ze bespeelt; de ,halangan gordang” = ,de breede met bloemwerk beschilderde plank, die de bonggar 2 van buiten afsluit, en waarop men de pauken pleegt tegen aan te doen leunen” (vgl. „Het „Toba-Bataksche Huis”).

b. (,rambing ogoeng”) v. d. Tuuk, blz. 439: ,rambing” = rek, waaraan men bij een orkest de ogungs ophangt, bestaande meestal uit twee in den grond gestokene stokken, waarover een rijststamper wordt geplaatst".

(97) (,,sintoea”) (de ouden): ,iemand, die bij een vergadering meetelt doordat zijn jaren vergevorderd zijn", (v. d. Tuuk, blz. 279).

(98) Om hem voorts te vernietigen. 
(99) „,manoek lahi bini” = een roode en witte kip: v. d. Tuuk, blz. 397 , ad „bini”.

(100) (,marmangmang”) v. d. Tuuk, blz. 415 : ,een droom afwachten om zich daarnaar bij hetgeen men doen zal, te regelen". De Batak legt daartoe bij het slapen zijn hoofd neer op een houten, met rood en wit snijwerk versierd ,kussen”, dat in het midden voorzien is van een vakje, waarin toovermiddelen gedaan worden.

(101) (,martondoeng”) : zie v. d. Tuuk, blz. 244; vgl. ook: „,tondoeng parepare”, pag. 210 H.schr. (4e hoofdstuk); en ,partondoengan", pag. $230 \mathrm{H}$.schr. (14e hoofdstuk).

(102) Door welke handeling het Hoofd aan zijn krijgslieden van zijn „sahala” (zie noot 71 ) mededeelt, aan hen als het ware den ,z.egen" geeft.

(103) Wederom een woordspeling: „palias” gebezigd als de naam van het voedsel, dat men op een expeditie meeneemt (v. d. Tuuk, blz. 333) en: palias! = het zij ver!; .,palias, so ra hona!" = ver zij (de kogel), moge hij niet geraakt worden!"

(104) d.w.z. kreten als: „palias so ra hona!" in de vorige noot genoemd; of : „Horas ma hita!” - „Dat het ons wèl ga!” e.d. meer, gericht op het welslagen der expeditie.

(105) Een Bataksche veldslag werd als gewonnen beschouwd, zoodra aan den kant van den vijand er ook maar één man gesneuveld was.

(106) (,,dihoeroeng”) : v. d. Tuuk, blz. 101: = ,iem. in huis opgesloten houden, iem. waarschuwen om de plaats niet te verlaten, omdat hij bv. deelnemen moet aan een op handen zijnd feest".

(107) Vgl. ook mijn beschrijving (van) „Het Toba-Bataksche Huis”.

(108) (,sanggesangge”) ; v. d. Tuuk, blz. 140: 1. zekere citroengeurige grassoort; 2 . de jonge spruiten, die naast de suikerrietstokken staan.

Sanggesangge, door, v. d. Tuuk ad 1. bedoeld is het bekende sereh-gras.

(109) (.,bangoenbangoen”); v. d. Tuuk, blz. 365: zekere zroenie (die als geneesmiddel te eten gegeven wordt aan een vrouw, die pas uit het kraambed is opgestaan).

(110) (,piso"). Vgl. noot 133. 
(111) Reconstructie: De hoelahoela (c.s.) van den bouwheer (dat zijn dus zijn schoonvader c.s.) geven elk aan den bouwheer $1 \$$; de bouwheer geeft aan elk van zijn ,ianakkon” (dat is: aan zijn schoonzoon c.s.) een oelos; en de laatsten geven elk aan hùn ,hoela 2" (d.i. aan den bouwheer) 1 \$ als tegengeschenk.

(112) (,,anang”) : iets zuur maken met verzuurde palmwijn (toeak) of citroen.

(,polong”) ; (v. d. Tuuk) : = zuurdeesem, bestaande in gekookte rijst met visch, en een weinig zout, die men in een bamboekoker laat verzuren.

(113) (geluksmeel) een bepaalde meelspijs; an het in deze combinatie gebruikte woord: ,goergoer" moet de beteekenis gegeven worden van: ,toenemen”, n.l. van geluk en rijkdom, het geheel dus een symbolische benaming (vgl. noot 11).

(114) (,gondang dalan”) : Men zou dit de ,marsch-gondang” kunnen noemen; daarnaast heeft men dan de ,welkomst-gondang”, de ,afscheids-gondang”, ,verzoenings-gondang”, en nog vele andere. Vgl. de ,genderang perang”, de ,genderang kembali" en de ,genderang kesoekaan" in Hikajat Amir Hamzah, Niemann I, blzz. 200, 195, 168.

(115) (Datoe Rangga ni Adji”) : v. d. Tuuk (blz. 432) geeft voor „,rangga” : ,naam van een geest, die droogte verwekt, en tengevolge daarvan hongersnood”. „Adji” = toovermiddel.

(116) (Datoe sorsor di Bale”). Voor ,sorsor” geeft v. d. Tuuk (blz. 163) : ,bij ongeluk geschieden; zonder dat men verwacht, geschieden; het ongeluk hebben iets te doen, bij ongeluk iets doen".

„bale” = het Mal. „balai” (v. d. Tuuk, blz. 379) $=$ het Bat. ",sopo", (rijstschuur) tevens vergaderplaats.

(117) („Datoe Rindang di Baho”) : „Rindang”: v. d. Tuuk, blz. 450 : een parasietplant.

„Baho” = het Mal. „bako 2”: een rhizophoor (mangrove). Rindang di Baho dus = „Rhizophoren-Parasiet”.

(118) „(mombang na djagar”) : een uit idjoek (vezel van den arenpalm) gemaakte, met zand opgevulde haan, die in het huis hier op de offerplaats - aan een bamboestaak opgehangen wordt. 
(119) De ,hariara” (banjaanboom), een soort ficus, is voor de Bataks, wat de waringin is voor de Javanen: de boom bij uitstek voor beschaduwing van heilige plaatsen, pleinen, markten, enz.

(120) („Poelo Morsa”) : v. d. Tuuk (blz. 424) : Morsa = „Sumatra $=$ het eiland der stervelingen".

(121) (,pidong ramboe”) : volgens v. d. Tuuk (blz. 439) (III) is ,ramboe" de naam van een Attingano-soort.

(122) (,hobahoba”) : v. d. Tuuk, blz. 84: ,een kleedingstuk, dat men zich zóó omdoet, dat de strooken zich midden op de borst kruisen”.

(123) V. d. Tuuk, blz. 367: ,,iem. die door een geest bezocht, en daarom (bij kwalen enz.) geraadpleegd wordt".

(124) („Datoe Panoesoer”) : v. d. Tuuk, blz. 185: (,Een volleerde datoe, die zelfs door datu's geraadpleegd wordt”) = ,die bekwaam is in het in practijk brengen van de wigchelarij".

(125) (,oelos ragidoep”) : de „radja” onder de oelos.

(126) „anak nihajoe”: malaiisme (kajoe) instede van „haoe”.

(127) (,,boeloeng langge”): „Een soort van Caladium, wier bol oneetbaar is, en wier bladen gebezigd worden om er uit te drinken of te eten" (v. d. Tuuk, biz. 465).

(128) V. d. Tuuk (blz. 142) ,,santi” =,eene offerande, bestaande meestal in één soloep gepelde rijst, enz....” en ,mananti” $=$ aan iets gepelde rijst offeren als aan een te vallen boom tegen wiens stam men eenige rijstkorrels knipt".

(129) Weer een woordspeling: vergelijk de uitdrukking: „papoerpoer sapata” = een vervloeking ,doen uitvliegen”, een symbolische handeling, waarbij iemand, die denkt dat hij onder een vervloeking staat, als tegenactie met behulp van den wichelaar, zijn vloek op een zwaluw legt en deze daarmede wegvliegen laat.

(130) Het gebruik van een roode en een witte krans ontmoetten wij reeds eerder, zie blz. 408, verder komt in deze beschrijvingen voor: een roode en witte kip: zie blz. 417,418 en noot 99 , en : wit en rood houtsnijwerk: ziet noot 100 . Bekend is ook de van roode en witte strengen katoen gevlochten hoofddoek van de porbaringin; en de rood en witte kleeding, de witte offerkip en 
de roode offergeit van de Parsiakbagisekte: zie blz. 192 van Tijdschr. Binn. Best. 1915 in mijn artikeltje over de Permalimsekten. Voor de combinatie van deze beide kleuren zie ook Legge : „Confucianisme en Taoisme”, blz. 66: „... met stieren .... een hagelwitte .... die grooten Tsjaoe is toegedacht; een roode dien men wijden zal aan heel ons vroeger vorstental".

(131) (,pege saoer”) : Vgl. ,,dengke saoer”: noot 112 en v. d. Tuuk, blz. $136 \mathrm{j}^{\circ} 148$.

(132) „na morbadjoe”: zij, die (nog) een baadje dragen, om haar boezem te bedekken; en dat zijn dan: 1e. de ongehuwde meisjes, 2e. de gehuwde vrouwen, zoolang ze nog geen zuigelingen hebben.

(133) Vgl. v. d. Tuuk, blz. 135 : ,,hata saoet” $\mathrm{j}^{\circ}$ „,manaoethon”, ,de complimenten die een gastheer aan de gasten maakt, zeggende dat het maal niet veel te beduiden had, en dat zij zulks voor lief moeten nemen".

(134) (,Roboe”) : gebods- en verbodsvoorschriften.

(135) (,,manoela”) $=$,,als bewijs van schuld een slagtbeest aan zijn tegenpartij in een geding betalen; panoela $=$ het bedrag van vleesch, of wel een maal, dat de verliezende partij nog boven de boete (dangdang) aan de overwinnende te betalen heeft; welk maal de beide partijen met de regtsprekenden gewoon zijn te deelen". (V. d. Tuuk, blz. 275). - En bij gelegenheid hiervan moet de verliezende partij dan óók de gondang laten spelen, waarbij dan weer speciale dansen van boetedoening en verzoening uitgevoerd worden; (zooals vertaler zelf meermalen nog meemaakte in de jaren 1914 -1917).

(136) Het schijnt, dat de man van Nai Pospos, (of van elders?) die dit Hoofdstukje aan den Batakschen (?) opschriftsteller heeft voorgedragen, zelf terzake van het hier behandelde onderwerp slecht op de hoogte geweest is. Vooral blijkt dit uit het foutieve gebruik van het woordje ,saem” in de combinatie ,saem sitasita", welke woorden n.l. een tegenovergestelde beteekenis hebben; een ,saem” wordt n.l. aangewend in gevallen van ziekte of in andere noodlottige gevallen, tot afweer (dus repressief), terwijl van een ,sitasita” gebruik gemaakt wordt, wanneer er nog niets ernstigs aan de hand is, ter voorkoming van een noodlottige wending (dus preventief). 
Ook van der Tuuk geeft voor saem (blz. 136) : ,een middel tegen den invloed van een ongunstig omen, of een kwalenverwekkenden geest"; terwijl hij voor sita (blz. 172) geeft: ,,(Sanscr. tjitta) : blijdschap zonder reden; naam aan een feest gegeven, dat zonder eenige reden wordt gevierd".

(137) „Oensim” = de wilde banaan, de vruchten waarvan niet gegeten worden, en is economisch dus niet van belang, al wordt in sommige cultuur-arme streken bij gebrek aan beter materiaal het blad wel gebruikt bijwijze van sigaretten-papier.

(138) (,parsantabianna”): Dit woord werd eerder vertaald met: ,huldegift”. (Zie blz. 422). In casu moet aan dit woord de beteekenis worden toegekend van het Malẹisch ,per$\operatorname{sembah}(\mathrm{an}) "=$ een eerbiedig aangeboden geschenk (mempersembahkan $=$ een mededeeling of geschenk van een sembah vergezeld doen gaan, iets eerbiedig mededeelen of schenken), een huldegift, waarvoor in het Bataksch ook „somba” gebezigd wordt.

(139) (,oepaoepa”): Eigenlijk = ,belooning”. (Vgl. noot 3).

(140) (,Mombang”) : v. d. Tuuk, blz. 424:, ,in den vorm van een schotel gevlochten bladen, doende men de uiteinden franjegewijs van den rand afhangen, dienende om er offeranden enz. op te leggen". Deze schotel wordt, met de offerspijzen er in, boven op een bamboestaak geplaatst, die daartoe aan den top gespleten en uitgebogen wordt.

(141) (,pisang”) : Malaiissme: de wilde banaan noemt men in het Bataksch ,oensim” (zie noot 137), de tamme banaan: ,gaol”.

(142) die dan als plaatsvervanger optreden moet.

(143) (,,tè”) = Mal. ,tahi”.

(144) Tot dit doel moesten dus de jonge andoelpak-stammetjes dienen, eerder genoemd.

(145) (,sagoesagoe”) : een soort van rijstkoekje.

(146) (,timpa”) : eveneens een soort van rijstkoekje: v. d. Tuuk, blz. 259: „(twee) als een Spaansche mat groote platte meelkoekjes als onder de offeranden gebezigd worden".

(147) Met ,ende” wordt hier bedoeld het „vers”, waarmede de „plaatsvervanger" het buis uitgezet wordt. 
(148) Corrupte tekst; in verband met het in de vorige noot en noot 50 medegedeelde moet hier bedoeld zijn het wegjagen van de geesten ; „morsisiksisik” = een onomatopee, overeenkomende met ons ,sissen”.

(149) Een symbolische handeling.

(150) Met de boodschap n.l. dat hij maar naar de kwade geesten zich begeven moet.

(151) ,sipaimbar”: een uit aarde vervaardigd beeld, dat men in geval van ziekte, enz. als plaatsvervanger stelt; dus in aard en wezen gelijk aan de in het vorige hoofdstuk behandelde porsili; de paimbar wordt echter, zooals uit het ondervolgende zal blijken, ook voor andere dan menschelijke wezens aangewend.

(152) Wat een abnormaal iets, derhalve een slecht teeken is.

(153) Lapsus voor marsahe, vgl. het volgende.

(154) (,tabartabar”) : een struik, met de bladeren waarvan men de geesten uit het dorp verdrijft, door met die bladeren tegen de wanden van het huis te slaan (vgl. Warneck).

(155) (,,sisangkil”) : van der Tuuk (blz. 139): ,die zeer vaak als ingrediënt in behoedmiddelen gebezigd wordt".

(156) (,sipilit”) : een laag gewas, dat op graven groeit; V. d. Tuuk (blz. 349) : papilithon = ,een andere richting doen nemen" (magische kracht van het woord?).

(157) (,,sipalis”) : wellicht óók om de symboliek van het woord? Immers: mamalis oedan $=$ den regen door tooverij verjagen. (V. d. Tuuk, blz. 333, geeft geen naam op).

(158) (,,Sibabolhas”) : soort van plant en symbolieke beteekenis onbekend.

(159) (,langge”) : soort van Caladium, wier bol oneetbaar is, en wier bladeren gebezigd worden om er uit te drinken, of te eten.

(160) (,,sihoek”; ,siling”) : beide een soort moerasplant.

(161) (,,bira”) : ,zekere Caladiumsoort met reusachtig groote bladen, en een bol die genuttigd wordt” (v. d. Tuuk blz. 399).

(162) (,pagar”) : v. d. Tuuk (blz. 321): ,een behoedmiddel”; „,porpagaran” $=$,een houten beeld, dat men midden op de 
halangan gordang plaatst, in tijd van oorlog zet men het een bord (waarin een behoedmiddel) op het hoofd, terwijl men het tevens een mes in de regter-, en een lans in de linkerhand te houden geeft".

De ,pagar" is een ander soort afweer- en voorbehoedmiddei dan de porsili, saem, sitasita en sipaimbar. De ,pagar” wordt niet in een ,plaatsvervanger" er op uitgestuurd, maar krijgt een plaats in of voor het huis van dengeen, die zich er door wil beschermen tegen allerhand kwade invloeden, waartegen alle andere middelen falen.

(163) bijv. ter bestrijding van epidemieën.

(164) zwartsel, om er de figuren mee te teekenen.

(165) („oelos ragidoep”) : Deze oelos geldt als het beste en mooiste, althans het voornaamste weefsel.

(166) (,simarindjam”): Deze oelos is er een, waarvan de zoom (, ,sisi”) uit een andere streek ,geleend" is (indjam = leenen). (V. d. Tuuk geeft in zijn Bijvoegsel op blz. 508 voor ,marindjam” slechts de beteekenis op van: „valsch haar”).

(167) (,handjar”) : v. d. Tuuk, blz. $69=$,de als hoepels om de steel der lanzen geslagene messing-banden.

(168) V. d. Tuuk, blz. 229, verwijst naar ,tawar” (blz. 237); pisang sitabar moet men mogelijk naar analogie verklaren van het door van der Tuuk vermelde ,tano tabar" = ,grond, waarop men volgens de omina in den strijd niets te vreezen heeft".

(169) (,,radja”): (v. d. Tuuk, blz. 434) :,,een streep of lijn, als die welke op de amuletten voorkomen”; mangaradja = ,figuren of streepen teekenen op iets, als b.v. de figuren die betrekking hebben op iets, als bijv. de figuren die betrekking hebben op de wigchelkunst".

(170) (,toempaksala”). Van der Tuuk (blz. 273) : ,,zekere figuur in de wigchelkunst gebruikelijk".

(171) (,matoga”): een vierkant, waarin een scheefliggend kleiner vierkant, de ,bindoematogoe”. Waarschijnlijk een symbolische benaming: toga $2=$ iets, waarop men zich verlaat; manogai: iemand geruststellen, zekerheid schenken (v. d. Tuuk, blz. 239). 
(172) (,pinąrpoejoean”) : V. d. Tuuk verwijst op blz. 354 (onder „poejoe”) voor de hier gebezigde term naar „pinorsihora” (blz. 168); sihora: naam van het klinkerteeken $\mathrm{x}$; pinorsihora $=$ in de gedaante zijn van gemeld letterteeken; de gedaante van een kruis hebben".

(173) (,diparsomahon”) : Van der Tuuk geeft onder „,soma” III: ,morsoma $=$ mortangiang $;$ morsomahon $($ diporsomahon $)=$ manangiangkon"; vgl. noot 138 .

(174) (T.r.: lagelogin), ,loging”: v. d. Tuuk, blz. 475 : zekere lange breedbladige rietsoort, die tot allerlei vlechtwerk dient.

(175) (,Tongontongon”) : „Kamfer-taal” voor ,,raoet” (mes) : v. d. Tuuk, blz. 240.

(176) (,namora”) : Dit woord wordt gebezigd om aan te duiden: de echtgenoote (van het Hoofd), voorts ook om aan te duiden , de notabelen" ( mora $=$ rijk); in verband waarmede deze term te vergelijken is met het Maleische ,orang kaja”; en tenslotte (zie ook v. d. Tuuk, blz. 424) : = ,de bewoners van een hoeta, die van een andere marga zijn als die waartoe de radja behoort; het opperhoofd van die bewoners".

(177) (,sahadathon”): van het Arabisch(-Maleisch): sjahadat.

(178) Vgl. v. d. Tuuk, blz. 230, onder ,tampoek” : „panampoehi = het wigchelen met een citroen, waarvan men de tampoek en de porboengaan afsnijdt, terwijl het vallen van het afgesnedene op een, van een de acht cardinaalpunten van het compas voorstellende figuur voorziene, rijstwan verschillende omina aangeeft”; ,tampoek” vertaalt v. d. Tuuk met: ,het kroontje of den knop waaraan de vrucht aan den tak zit”, ,parboengaan” met: ,'t tegenovergestelde van ,tampoek”, de kant namentlijk van een vrucht, die de tegenovergestelde is van die waar 't kroontje zit".

(179) (,oente toeboe”): Hiermede wordt bedoeld, dat de citroen een omen heeft uitgebracht, dat op vruchtbaarheid wijst, (toeboe $=$ groei, ontstaan, geboren worden), resp. op succes.

(180) V. d. Tuuk, blz. 190: ,soeroeng” = ,uitroeping waarmede men een pangoeloebalang aanzet, zijn vernielende kracht den vijand te laten gevoelen". - In dit verband zal ook gemelde handeling van het in stukjes snijden als symbolische handeling gezien moeten worden. 
(181) V. d. Tuuk, blz. 354: ,poepoek ni pagar” = ,de inhoud of wel de ingrediënten, waaruit een amulet of pagar bestaat”.

(182) Zie noot 181: Ook hier weer een symbolische handeling.

(183) Deze houder bestaat uit een bamboepaal, die aan het boveneind gespleten en korf-vormig afgewerkt wordt, om er het voorbehoedmiddel in te plaatsen.

(184) (,hatoenggal”) : een struik met roode bladeren.

(185) (,,silindjoeang”) : struik met mooie roode blaadjes.

(186) Zie v. d. Tuuk, blz. 191. 